\title{
How well targeted are soda taxes?
}

\author{
Pierre Dubois, Rachel Griffith and Martin O'Connell*
}

March, 2020

\begin{abstract}
Soda taxes aim to reduce excessive sugar consumption. Policymakers highlight the young, particularly from poor backgrounds, and high sugar consumers as groups whose behavior they would most like to influence. There are also concerns about the policy being regressive. We assess who are most impacted by soda taxes. We estimate demand using micro longitudinal data covering on-the-go purchases, and exploit the panel dimension to estimate individual specific preferences. We relate these preferences and counterfactual predictions to individual characteristics and show that soda taxes are relatively effective at targeting the sugar intake of the young, are less successful at targeting the intake of those with high total dietary sugar, and are unlikely to be strongly regressive especially if consumers benefit from averted internalities.
\end{abstract}

Keywords: preference heterogeneity, discrete choice demand, pass-through, soda tax

JEL classification: D12, H31, I18

Acknowledgments: The authors gratefully acknowledge financial support from the European Research Council (ERC) under ERC-2015-AdG-694822, the Economic and Social Research Council (ESRC) under the Centre for the Microeconomic Analysis of Public Policy (CPP), grant number RES-544-28-0001, the Open Research Area (ORA) grant number ES/I012222/1, ANR-10ORAR-009-01 and ES/N011562/1, ANR-17-EURE-0010 (Investissements d'Avenir program) and the British Academy under pf160093. Data supplied by TNS UK Limited. The use of TNS UK Ltd. data in this work does not imply the endorsement of TNS UK Ltd. in relation to the interpretation or analysis of the data. All errors and omissions remained the responsibility of the authors.

*Correspondence: Dubois: Toulouse School of Economics, pierre.dubois@tse-fr.eu; Griffith: Institute for Fiscal Studies and University of Manchester, rgriffith@ifs.org.uk; O'Connell: Institute for Fiscal Studies, martin_o@ifs.org.uk 


\section{Introduction}

Sugar consumption is far in excess of medically recommended levels in much of the developed world. Excess sugar consumption is linked with a range of diet-related diseases, including diabetes, cancers and heart disease, and is thought to be particularly detrimental to children (WHO (2015)). Soft drinks products are a leading contributor to dietary sugar (see CDC (2016)). Taxes on these products (soda taxes) have been proposed as a way to reduce sugar consumption for individuals whose consumption generates costs that are borne by others (externalities) or for whom any future costs of consumption are large and partially ignored at the point of consumption (internalities). A growing number of jurisdictions have adopted soda taxes. ${ }^{1}$ Soft drinks are a particularly large contributor to dietary sugar among the young, those with high overall dietary sugar, and youth from low income households, ${ }^{2}$ and policymakers have identified these groups as the ones whose behavior they would most like to change. The impact of soda taxes, and whether ultimately they are successful in improving welfare, will depend crucially on how demand responses vary across individuals from these targeted groups.

Our contribution in this paper is to assess whether soda taxes are effective at lowering the sugar consumption of individuals that policy has targeted (i.e. the young, high sugar consumers and the poor). We focus on the important but understudied on-the-go segment of the market. We use novel data on UK individuals to estimate a model of consumer choice, uncover individual specific preferences, and simulate the impacts of a soda tax. We show that the tax does a good job at targeting young consumers and those from low income households, but not individuals from households with high total dietary sugar. The economic burden of the tax is moderately higher for individuals from lower income households; however, we also find that they reduce sugar consumption by more, so this leaves open the possibility that these offset the economic burden. Relative to the existing literature we make two main advances.

First, we study purchase decisions made by individuals for immediate consumption on-the-go. Studying the on-the-go segment is important for a number of reasons. Firstly, consumption on-the-go is common - close to half of sugar from soft drinks is obtained outside the home. Yet there is little evidence on choice behavior on-the-go, with the bulk of the literature focusing on purchases made in super-

\footnotetext{
${ }^{1}$ As of December 201943 countries and 8 US cities had soda taxes in clear (GFRP (2019)).

${ }^{2}$ See, for example, Han and Powell (2013), Cavadini et al. (2000), CDC (2016) and Public Health England (2015), and Appendix A.1 where we provide evidence of this based on dietary intake data from the UK and the US.
} 
markets and brought into the home for future consumption. Secondly, observing individual on-the-go purchases provides an excellent opportunity for identification of individual preferences; in contrast to information on household level at-home purchases, purchases and consumption are closely aligned and individual preference estimates can be obtained without the need to place strong restrictions on the intrahousehold preference structure (see, for example, Adams et al. (2014)) Thirdly, the on-the-go data contain information on teenagers and young adults, who are explicit targets of the soda taxes, but who are typically not identified as a distinct group in data based on household purchases.

Second, we model consumer preferences as individual level parameters that we estimate, rather than modeling them using the standard random coefficient approach (where they are treated as random effects drawn from a known distribution). This is important because it allows us to better assess how well targeted a tax is and whether it is regressive. In particular, it means we avoid placing restrictions on (or ruling out) correlation between consumer level preferences and attributes (including purchase behavior for other goods). As a result we are able to directly relate individual level preferences and predictions of the impact of the tax to consumer attributes, and can therefore assess precisely which individuals respond to the tax and on whom the economic burden of the tax falls most heavily.

We find that preferences vary with demographics in ways that would be difficult to capture by specifying a priori a random coefficient distribution. For instance, our estimates show a non-monotonic relationship between age and sugar preferences; on average those aged 13-21 have stronger preferences than those aged 22-30, who in turn have stronger sugar preferences than older individuals, but among older individuals sugar preferences are increasing in age. In contrast sugar preferences exhibit a monotonically increasing relationship with deciles of the distribution of total dietary sugar. However, unlike the young, those with higher overall levels of dietary sugar also tend to be relatively price insensitive.

Our results suggest that taxes of the form and size that have been implemented in the UK and many US locations lead to reductions of around $21 \%$ on average in the amount of sugar consumers get from soft drinks on-the-go. Consumers switch to alternative sources of sugar (both drinks and snacks), but this effect is relatively modest. The tax is relatively well targeted at lowering the sugar consumption of young people (including those from low-income households). In particular, those aged 13-21 have the most steeply sloped demands, reducing sugar in response to the tax by around $40 \%$ more than those aged over 40 . The tax is less effective at targeting the on-the-go sugar intake of people with a consistently high level 
of dietary sugar in their overall diets. Despite the individuals being more likely to purchase soft drinks and to obtain relatively large amounts of sugar from them, their sugar intake from drinks responds less strongly than those with more moderate levels of sugar in their diets. This is because they tend to have strong preferences for sugar and to be less price responsive.

Compensating variation, a measure of the direct costs the tax places on the consumer through higher prices, is relatively large for the young and those with a high levels of dietary sugar. In order to understand the full welfare impact on these individuals we would also need to know the size of any saving from averted internalities achieved by the tax. We do not measure these internalities. However, the larger reductions in sugar among younger consumers (compared with that for high overall sugar consumers) makes it more likely that averted internalities will outweigh the direct consumer welfare loss from higher prices for this group.

A common concern about excise style taxes is that they are regressive; the poor typically spend a higher share of their income on the taxed good, and end up bearing a disproportionate share of the burden of the tax. However, if the tax plays the role of correcting an internality, then the distributional analysis needs to account for the fact that low income consumers might also save more from averted internalities, and this may overturn the regressivity of the traditional economic burden of taxation (Gruber and Koszegi (2004)). ${ }^{3}$ We show that compensating variation associated with a tax on sugary soft drinks is around $20 \%$ higher for those in the bottom half of the distribution of total annual grocery expenditure ${ }^{4}$ (a proxy for income) compared with those in the top half. However, some evidence suggests that low income individuals might suffer more from internalities (e.g. Allcott et al. (2019a), Haushofer and Fehr (2014) and Mani et al. (2013)), and the reduction in sugar is also larger for these individuals, leaving open the possibility that they will benefit more from averted internalities, and that therefore the full effect on their welfare is less negative than the compensating variation suggests.

Our work contributes to a burgeoning literature that aims at understanding the effects of soda taxes. This include a set of papers that estimate the impact of the implementation of specific soda taxes on prices and purchases (e.g. Bollinger and Sexton (2018), Rojas and Wang (2017) and Seiler et al. (2018)), and a set of papers that simulate the effects of soda taxes using estimates of behavior in the market

\footnotetext{
${ }^{3}$ Allcott et al. (2019a) consider the optimal tax rate for a government with preferences for redistribution. If internalities are concentrated among the poor, all else equal, this raises the optimal rate. On the other hand, if, all else equal, rich people have relatively weak preferences for soft drinks this lowers the optimal rate as soft drinks consumption becomes a tag for (in)ability.

${ }^{4}$ Grocery expenditure includes expenditure on food, drink (including alcohol), pet food, toiletries and cleaning products.
} 
based on a period and location in which no soda tax is in place (e.g. Harding and Lovenheim (2017), Bonnet and Réquillart (2013), Wang (2015), Allcott et al. (2019a) and Chernozhukov et al. (2019)). Our work is more closely related to this second literature. We add to this literature by using panel data to better model individual level heterogeneity in preferences. This enables us to focus on the distribution and targeting of effects that a soda tax will have, rather than considering the average effects. We are also the first to provide evidence on responses in the on-the-go segment of the market.

In focusing on choice behavior on-the-go we face a couple of challenges. First, while a strength of our data is that it is novel, it means there are not many alternative data source to compare it with. We show that broad patterns of consumption by age in our data are consistent with other data sources. We also discuss how potential measurement error in price may impact analysis. Second, there may be dependence of on-the-go demand on at-home purchases. Following Browning and Meghir (1991) we test for this dependence, and we also allow for it in our on-the-go demand model. We find that, once we account for individual level preference heterogeneity, evidence of demand linkages between on-the-go and at-home soft drinks consumption is weak.

We consider three main potential issues regarding the robustness of our demand estimates. First, our approach entails estimating fixed effects in a non-linear model and therefore may suffer from an incidental parameters problem (Hahn and Newey (2004), Arellano and Hahn (2007)). We show that any resulting bias is minimal using the split sample jackknife bias correction procedure suggested in Dhaene and Jochmans (2015).

Second, while a novelty of this paper is to be the first to study individual level on-the-go behavior, it is important to consider whether our main conclusion about the targeting of the tax could be unwound by demand patterns in the at-home segment of the market. We estimate at-home demand using household level data and show that household level responses at-home do not undo the relatively good targeting at the young.

Third, in our main results we assume that the tax is $100 \%$ passed-through to prices. Using recent data on prices of the two major soft drinks brands after the implementation of a new soda tax in the UK in 2018, we show that pass-through was very close to $100 \%$. As a robustness check we show that this is similar to what is predicted using our demand model together with a supply side model of Bertrand-Nash price competition between manufacturers. Our equilibrium passthrough estimates suggest that an excise style tax on sugary soft drinks is slightly 
over shifted on to consumer prices. Firms' pricing response therefore acts to moderately amplify the price differential that the tax creates between sugary and diet varieties. We show that the patterns of demand response across individuals is very similar under $100 \%$ and simulated equilibrium tax pass-through.

The rest of this paper is structured as follows. In Section 2 we introduce the data and describe the non-alcoholic drinks market. In Section 3 we describe our model of consumer demand and summarize estimates of the demand model. In Section 4 we present results of the soda tax simulation, consider how well targeted the tax is, show the effects on consumer welfare and its distributional implications. In Section 5 we consider possible concerns about the robustness of our results. A final section concludes. In an Appendix we provide further details on the data and demand estimates and present estimates of demand in the at-home segment and details of our analysis of the supply side of the market and implied equilibrium pass-through of the tax.

\section{The non-alcoholic drinks market}

We model behavior in the market for non-alcoholic drinks, considering consumers' choice between alternative drinks and substitution towards snacks. Non-alcoholic drinks include soft drinks (i.e. carbonated drinks - often referred to as soda - with and without sugar, energy drinks, and other sugar-sweetened non-alcoholic drinks), alternative sugary drinks (non-alcoholic drinks such as pure fruit juice and milk based drinks such as shakes), and bottled water. "Soda taxes" are typically imposed on soft drinks that contain sugar (and sometimes also on diet varieties). Pure fruit juices that do not contain added sugar and drinks that are predominantly composed of milk are typically exempt.

We focus on behavior when purchasing on-the-go. This is for two reasons. First, it is an important part of the market and an important source of sugar, particularly in children (Han and Powell (2013)), yet little attention has been paid to modeling choice behavior on-the-go, largely due to the lack of high quality data. The existing literature on soda taxes studies their impact on purchases made in grocery stores for future consumption at home; but close to half of sugar obtained from sugar sweetened soft drinks products is purchased for immediate consumption on-thego. ${ }^{5}$ Second, studying on-the-go behavior provides the opportunity to model and exploit data on individual level purchases, including those made by teenagers and

\footnotetext{
${ }^{5}$ CDC (2016) and National Diet and Nutrition Survey Public Health England (2018); see Appendix A.1 for further details.
} 
young adults. This provides an important opportunity to study the preferences of individuals, rather than the aggregate preferences of the household.

A limitation of our data is that it does not include purchases in restaurants or bars; this accounts for around one-quarter of on-the-go purchases. ${ }^{6}$ The other threequarters of the on-the-go purchases are made from vending machines, convenience stores, kiosks and larger grocery stores when consumed immediately, which are included in our data.

We also have data on purchases made in the at-home segment by the households to which the individuals in our on-the-go data belong. We use these data in three ways. First, they allow us to obtain a measure of the sugar intensity of the individuals' entire diet (based on total at-home calories purchases of the household she belongs to). We show how preferences and outcomes vary along this dimension. Second, we consider possible demand linkages between the segments - for instance, at-home household purchases might influence on-the-go purchases. We describe the within individual correlation between on-the-go and at-home purchases. We include a measure of the inventory of at-home drinks based on household purchases in our model of demand for on-the-go purchases and find that it has little impact on choices once we control for individual heterogeneity. We also use our model of behavior in the at-home segment to assess whether our conclusions regarding the individual targeting of soda taxes on they young could plausibly be undone by off-setting behavior of the household in the at-home segment and show that this is unlikely to be the case. Third, we use the at-home data in a robustness check where we model supply-side responses to the introduction of a tax using information on both segments.

\section{$2.1 \quad$ Purchases}

We use data from the Kantar Worldpanel and the associated food on-the-go survey. These data are collected by the market research firm Kantar. The Worldpanel data cover the at-home segment of the market. It tracks the grocery purchases made and brought into the home by a sample of households that are representative of the British population. The food on-the-go survey tracks food and drink purchases made by individuals on-the-go for immediate consumption. Individuals in the on-the-go survey are randomly drawn from households in the Worldpanel.

Households in the Worldpanel data scan the barcode of all grocery purchases made and brought into the home. These include all food, drink (including alcohol),

\footnotetext{
${ }^{6}$ Calculations is based on National Diet and Nutrition Survey Public Health England (2018).
} 
pet food, toiletries and cleaning products; this gives us comprehensive information on the total grocery baskets of the households to which the individuals in our on-the-go sample belong. ${ }^{7}$ Our main interest is behavior recorded in the on-the-go survey. To our knowledge the Kantar food on-the-go survey is unique. Participating individuals record all purchases of snacks and non-alcoholic drinks for consumption outside the home (with the exception of those made in bars and restaurants) using mobile phones. In both the Worldpanel and food on-the-go survey we know what products (at the barcode, or UPC, level) were purchased and the transaction price. We also observe information on the store of purchase, household and individual attributes and product attributes.

We use information on the on-the-go behavior of 5,555 individuals ${ }^{8}$. To estimate demand we use information only on the individuals that report purchasing soft drinks. ${ }^{9}$ Our estimation sample contains 2,449 individuals. ${ }^{10}$ The individuals who do not purchase soft drinks at current prices are unlikely to be induced to purchase soft drinks by the introduction of the tax.

We have data over the period June 2009-December 2014. We define a choice occasion as a day in which an individual makes an on-the-go purchase of either a non-alcoholic drink or a snack (defined as confectionery, nuts, potato chips and fruit). We exploit the panel structure of the data to estimate consumer specific preferences. In the estimation sample we observe individuals, on average, on 252 choice occasions. In total our sample consists of 616,544 choice occasions. In Table 2.1 we provide details on the distribution of observations per consumer. Over $95 \%$ of consumers are observed for more than 25 choice occasions, and for over $60 \%$ of consumers we observe 100 or more choice occasions.

These consumers purchase a drink product on $59 \%$ of choice occasions. When purchasing drinks individuals choose a single product $83 \%$ of the time. On the remaining choice occasions the consumer chooses multiple (typically two) products. In this case we randomly select one purchase and use this in demand estimation. ${ }^{11}$

\footnotetext{
${ }^{7}$ The Kantar Worldpanel (and similar data collected in the US by AC Nielsen) have been used in a number of papers studying consumer grocery demand (see, for instance, Aguiar and Hurst (2007), Dubois et al. (2014) and Kaplan and Menzio (2015)).

${ }^{8}$ See Appendix C.1 for further details on the at-home data

${ }^{9}$ Strictly speaking, we use individuals that purchase at least 15 non-alcoholic drinks and at least 10 soft drinks over the 5 and half years period. These individuals account for around $95 \%$ of sugar from non-alcoholic drink purchases on-the-go.

${ }^{10}$ To provide a reality check we compare this to the Living Cost and Food Survey for the years 2009-2014 and find a similar figure.

${ }^{11}$ If instead we treat multiple purchases as separate choice occasion it leads essentially no difference in parameter estimates.
} 
Table 2.1: Time series dimension of estimation sample

\begin{tabular}{lcc}
\hline \multirow{2}{*}{$\begin{array}{l}\text { Number of choice } \\
\text { occasions observed }\end{array}$} & \multicolumn{2}{c}{ Individuals } \\
& on-the-go \\
& N & $\%$ \\
\hline$<25$ & 95 & 3.9 \\
$25-49$ & 285 & 11.6 \\
$50-74$ & 272 & 11.1 \\
$75-99$ & 235 & 9.6 \\
$100-249$ & 769 & 31.4 \\
$250+$ & 793 & 32.4 \\
\hline Total & 2449 & 100.0 \\
\hline
\end{tabular}

Notes: The table shows the number of choice occasions on which we observe individuals making purchase choices based on the 2,449 individuals in the estimation sample. A choice occasion is a day in which the individual purchases a snack.

\subsection{Brands, products, prices and stores}

In Table 2.2 we describe the products available in the on-the-go non-alcoholic drinks market in the UK, their market shares and mean prices. Products we classify as "soft drinks" are available in brands owned by Coca Cola Enterprises, Pepsico, GlaxoSmithKline (GSK) and Barrs. There are a large number of small brands (each with a market share below $2 \%$ ). We aggregate these small brands into a composite "Other" brand; in aggregate this accounts for around $16 \%$ of the market.

We do not drop these niche brands as we are ultimately interested in the total sugar consumers get on-the-go. The implicit assumption of this aggregation is that product differentiation among these niche brands is not important to consumers. We additionally include fruit juice, flavored milk and fruit (or flavored) water, which together account for just under $10 \%$ of the market, and bottled water which account for another $11 \%$. Many brands are available in two different sizes. See further details in Appendix A.2 on how we define products.

For each transaction we observe the type of store in which the purchase occurred and the transaction level price. From these transaction level prices, and for each product, we compute the average monthly price in each type of store. We use this average monthly price in demand estimation. National chains in the UK set national prices (see Competition Commission (2000)), we therefore use national prices for these, as well as for vending machines. For independent stores we compute prices that vary regionally. 
Table 2.2: Products

\begin{tabular}{|c|c|c|c|c|}
\hline Firm & Brand & Product & $\%$ & price \\
\hline \multicolumn{5}{|c|}{ Soft drinks } \\
\hline \multirow[t]{24}{*}{ CocaCola } & & & 42.55 & \\
\hline & Coke & & 26.88 & \\
\hline & & Coca Cola 330 & 4.02 & 0.65 \\
\hline & & Coca Cola Diet 330 & 5.06 & 0.65 \\
\hline & & Coca Cola 500 & 7.65 & 1.15 \\
\hline & & Coca Cola Diet 500 & 10.16 & 1.15 \\
\hline & Dr Pepper & & 3.29 & \\
\hline & & Dr Pepper 330 & 0.46 & 0.63 \\
\hline & & Dr Pepper Diet 500 & 0.18 & 1.11 \\
\hline & & Dr Pepper 500 & 2.64 & 1.11 \\
\hline & Fanta & & 3.83 & \\
\hline & & Fanta 330 & 0.62 & 0.60 \\
\hline & & Fanta Diet 500 & 0.29 & 1.11 \\
\hline & & Fanta 500 & 2.92 & 1.11 \\
\hline & Cherry Coke & & 2.91 & \\
\hline & & Cherry Coke 330 & 0.49 & 0.62 \\
\hline & & Cherry Coke 500 & 1.57 & 1.11 \\
\hline & & Cherry Coke Diet 500 & 0.85 & 1.11 \\
\hline & Oasis & & 3.69 & \\
\hline & & Oasis 500 & 3.48 & 1.12 \\
\hline & & Oasis Diet 500 & 0.21 & 1.12 \\
\hline & Sprite & & 1.96 & \\
\hline & & Sprite 330 & 0.25 & 0.64 \\
\hline & & Sprite 500 & 1.71 & 1.12 \\
\hline \multirow[t]{5}{*}{ Pepsico } & & & 10.32 & \\
\hline & & Pepsi Diet 330 & 1.69 & 0.58 \\
\hline & & Pepsi 330 & 0.97 & 0.58 \\
\hline & & Pepsi Diet 500 & 5.62 & 1.00 \\
\hline & & Pepsi 500 & 2.03 & 1.00 \\
\hline \multirow[t]{8}{*}{ GSK } & & & 7.22 & \\
\hline & Lucozade Energy & & 4.46 & \\
\hline & & Lucozade Energy 380 & 2.40 & 0.95 \\
\hline & & Lucozade Energy 500 & 2.06 & 1.14 \\
\hline & Ribena & & 2.76 & \\
\hline & & Ribena 288 & 0.69 & 0.68 \\
\hline & & Ribena 500 & 1.58 & 1.11 \\
\hline & & Ribena Diet 500 & 0.50 & 1.11 \\
\hline \multirow[t]{5}{*}{ Barrs } & & & 2.31 & \\
\hline & & Irn Bru 330 & 0.71 & 0.58 \\
\hline & & Irn Bru Diet 330 & 0.36 & 0.58 \\
\hline & & Irn Bru 500 & 0.87 & 1.03 \\
\hline & & Irn Bru Diet 500 & 0.37 & 1.03 \\
\hline \multicolumn{5}{|c|}{ Composite soft drinks } \\
\hline & & Other & 14.25 & 1.17 \\
\hline & & Other Diet & 1.98 & 1.53 \\
\hline \multicolumn{5}{|c|}{ Alternative drinks } \\
\hline & Fruit juice & & 7.51 & 1.10 \\
\hline & Flavoured milk & & 1.64 & 1.01 \\
\hline & Fruit water & & 0.85 & 0.90 \\
\hline & Water & & 11.38 & 0.71 \\
\hline
\end{tabular}

Notes: Market shares are based on transactions made by the 2,449 individuals in the estimation sample between June 2009 and December 2014. Prices are the means across all choice occasions. 
Table 2.3: Retailer types

\begin{tabular}{llrr}
\hline & & $\mathrm{N}$ & $\%$ \\
\hline Retailer types & & & \\
\cline { 1 - 2 } National store & Large & 128,649 & 20.9 \\
& Small & 88,570 & 14.4 \\
Vending machines & & 48,435 & 7.9 \\
Convenience store & North & 153,727 & 24.9 \\
& Midlands & 83,081 & 13.5 \\
& South & 114,082 & 18.5 \\
\hline Total & & 616,544 & 100.0 \\
\hline
\end{tabular}

Notes: The table shows the number and share of purchases made by 2,449 individuals in the estimation sample in each retailer type between June 2009 and December 2014. Large national stores include Aldi, Asda, Lidl, Morrisons, Sainsbury's, Tesco and Waitrose. Small national chains include Budgens, Co-op, Costcutter, Greggs, Holland and Barrett, Iceland, Londis, MESS, Netto, Spar and a few others.

In Appendix A.3 we provide more details of how we use transaction level prices to construct the price series we utilize in estimation. Effectively, this entails computing means across transaction prices. It is possible this procedure introduces some measurement error; this is a standard problem faced in many discrete choice settings in which the prices of the alternatives not chosen are not directly observed. Schennach (2013) and Blundell et al. (2019) consider how to consistently estimate continuous demand models with measurement error in prices, based on the measurement error being of the form of "Berkson" errors (Berkson (1950)). We are not aware of solutions to this problem in the case of discrete demand. We have undertaken some simple Monte Carlo simulations that suggest that in our specific case the impact of measurement error on our estimates are unlikely to be large (see Appendix A.3 for more details). Extending results on consistent estimation with "Berkson" errors to discrete choice demand settings is an interesting avenue for future work.

Table 2.3 describes the number and share of purchases of non-alcoholic drinks across retailer types. For convenience stores we distinguish between those in different regions of Great Britain. The largest share of purchases are made in stores belonging to small national chains or convenience stores. The large national supermarket chains account together for around one-fifth of purchases, and vending machines account for around $8 \%$. In our demand model we allow for the product availability to vary across the retailer types. ${ }^{12}$

\footnotetext{
${ }^{12}$ In particular, we consider a brand-size to be available in a retailer type if we observe at least 100 transactions for that product-retailer type across the 5 and half years covered by our data. There is no evidence of temporal variation in product availability over this time.
} 


\subsection{Demand linkages between on-the-go and at-home}

We study the demand behavior of individuals while on-the go. However, it is possible that an important margin of substitution is between at-home and on-the-go consumption. In this section we present a simple test of separability of demand for soft drinks at-home and on-the-go. At-home purchases are brought into the home for future consumption, so we do not directly observe at-home consumption. We therefore follow the literature on dynamic demand (e.g. Hendel and Nevo (2006a), Hendel and Nevo (2006b)) by constructing a proxy measure of the inventory of at-home soft drinks the household has access to.

Denote by $Q_{i \tau}^{o}$ the individual $i$ 's date $\tau$ on-the-go soft drinks demand and $Q_{i \tau}^{h}$ their at-home demand. Consider demand functions of the following form:

$$
\begin{aligned}
& Q_{i \tau}^{o}=D_{i}^{o}\left(\Pi_{r(i) \tau}^{o}, Q_{i \tau}^{h}\right) \\
& Q_{i \tau}^{h}=D_{i}^{h}\left(\Pi_{r(i) \tau}^{h}, \mathcal{I}_{f(i) \tau}^{h}\right),
\end{aligned}
$$

where $\Pi_{r(i) \tau}^{o}$ and, $\Pi_{r(i) t}^{h}$ capture the prices of on-the-go and at-home soft drinks in the region $r$ where individual $i$ resides and $\mathcal{I}_{f(i) \tau}^{h}$ denotes the inventory held by the individual's household $f(i)$ at-home at time $\tau$. The at-home demand function $D_{i}^{h}(.,$. embeds the sharing rule governing how household level demand translates into individual $i$ at-home consumption. Under this demand structure, non-separability between on-the-go and at-home choices arise through the (possible) dependence of on-the-go demand on at-home demand.

Following Browning and Meghir (1991) and the subsequent literature, we test weak separability in on-the-go demand with respect to at-home demand by testing the exclusion of $Q_{i \tau}^{h}$ in $D_{i}^{o}(.,$.$) conditional on prices \Pi_{r(i) \tau}^{o}$. In our context we do not directly observe individual demand at home; instead we observe household purchases and can infer a household's inventory using their purchase history.

Similarly to Hendel and Nevo (2006b), we measure this inventory as the cumulative sum of past at-home purchases minus a household specific average consumption level. ${ }^{13}$ This measure will be high after recent at-home purchases and will deplete to zero following a sufficiently long period of no at-home purchases.

Substituting in at-home consumption, we can re-write on-the-go demand as

$$
Q_{i \tau}^{o}=D_{i}^{o}\left(\Pi_{r(i) \tau}^{o}, D_{i}^{h}\left(\Pi_{r(i) \tau}^{h}, \mathcal{I}_{f(i) \tau}^{h}\right)\right)=\widetilde{D}_{i}^{o}\left(\Pi_{r(i) \tau}^{o}, \Pi_{r(i) \tau}^{h}, \mathcal{I}_{f(i) \tau}^{h}\right)
$$

\footnotetext{
${ }^{13}$ Specifically, we compute the household's average consumption as the mean at-home volume they purchase over their time in the sample - denote this by $c_{f(i)}$. We then compute the at-home inventory as $\mathcal{I}_{f(i) \tau}=\max \left\{0, \mathcal{I}_{f(i) \tau-1}+Q_{i \tau}^{h}-c_{f(i)}\right\}$.
} 
Assuming that at-home demand is monotonic and differentiable in inventory (i.e. $\left.\partial D_{i}^{h}\left(\Pi_{r(i) \tau}^{h}, \mathcal{I}_{f(i) \tau}^{h}\right) / \partial \mathcal{I}_{f(i) \tau}^{h} \neq 0\right)$, testing for separability between demand on-thego and demand at-home is equivalent to using the reduced form demand to test for separability between the on-the-go soft drink demand and at-home inventories, conditional on prices. ${ }^{14}$

We thus consider the following regression model:

$$
\begin{aligned}
Q_{i \tau}^{o} & =\lambda \mathcal{I}_{f(i) \tau}^{h}+\beta^{o} \ln \Pi_{r(i) \tau}^{o}+\beta^{h} \ln \Pi_{r(i) \tau}^{h}+\nu_{i}+\varepsilon_{i \tau} \\
& =\lambda \mathcal{I}_{f(i) \tau}^{h}+\gamma_{r(i) \tau}+\nu_{i}+\varepsilon_{i \tau}
\end{aligned}
$$

Testing for separability between at-home and on-the-go demands boils down to testing the hypothesis that $\lambda=0$. We measure consumer $i$ 's on-the-go soft drinks demand on date $\tau, Q_{i \tau}^{o}$, with an indicator variable equal to one if the consumer chooses to purchase. ${ }^{15}$ Rather than construct prices indices, $\Pi_{r(i) \tau}^{o}$ and $\Pi_{r(i) \tau}^{h}$, we include year-month-region effects, $\gamma_{r(i) \tau}$, which control for the effect of prices. $\nu_{i}$ is an individual fixed effect, and $\varepsilon_{i \tau}$ is an individual specific deviation.

For each individual in the full on-the-go sample we consider one observation for every day (regardless of whether a drink is purchased or not) between the individual's first and final day in the sample. We report coefficient estimates in Table 2.4. In column (1) we report the correlation between on-the-go purchases and inventory at-home. In column (2) we add in individual fixed effects, which results in the coefficient on inventory dropping by an order of magnitude. On average, in our full sample of 5,555 individuals, the probability someone purchases soft drinks on-the-go on any day is around 4\%. The average at-home inventory held is 1.0 litre, with a standard deviation of 1.5. Therefore the inventory coefficient in column (2) means a one standard deviation increase in at-home inventory leads to a 0.19 percentage point increase in the probability of buying on-the-go (i.e. $1.5 * 0.00128^{*} 100$ ). While statistically significant (this regression is estimated using over 8 million observations), the magnitude of the effect is very small. Column (3) shows that controlling for prices through year-month-region effects has little impact on the coefficient on at-home inventory.

\footnotetext{
${ }^{14}$ This follows from $\frac{\partial D_{i}^{o}\left(p_{r(i) \tau}^{o}, Q_{i \tau}^{h}\right)}{\partial Q_{i \tau}^{h}}=\frac{\partial \widetilde{D}_{i}^{o}\left(p_{r(i) \tau}^{o}, p_{r(i) \tau}^{h}, \mathcal{I}_{f(i) \tau}^{h}\right)}{\partial \mathcal{I}_{f(i) \tau}^{h}} / \frac{\partial D_{i}^{h}\left(p_{r(i) \tau}^{h}, \mathcal{I}_{f(i) \tau}^{h}\right)}{\partial \mathcal{I}_{f(i) \tau}^{h}}$.

${ }^{15}$ Similar results hold if we use quantity purchased.
} 
Table 2.4: Separability test between demand on-the-go and at-home

\begin{tabular}{lccc}
\hline & $(1)$ & $(2)$ & $(3)$ \\
\hline At-home inventory & 0.00131 & 0.00128 & 0.00017 \\
& $(0.00005)$ & $(0.00005)$ & $(0.00005)$ \\
Constant & 0.03623 & 0.03627 & 0.03748 \\
& $(0.00008)$ & $(0.00008)$ & $(0.00008)$ \\
\hline Time-region effects & No & No & Yes \\
Individual effects & No & Yes & Yes \\
$\mathrm{R}^{2}$ & 0.00011 & 0.00121 & 0.18854 \\
\hline
\end{tabular}

Notes: Tables shows the conditional correlation between the on-the-go soft drinks purchases and at-home inventory of soft drinks. We drop the top percentile of at-home inventory. There are 8,180,656 observations, one for every day between the first and final day in the sample for each of the 5,555 individuals in the full on-the-go sample.

Our interpretation of this is that accounting for rich individual heterogeneity is crucial in capturing demand patterns and, conditional on this, there is little evidence that demand linkages between on-the-go and at-home soft drinks demand are of first order importance. In our demand model we incorporate rich individual level preference heterogeneity. Nonetheless, there remains the possibility that, while not being key in driving overall on-the-go soft drinks demand, at-home purchases could be important in driving exactly what products individuals choose. We therefore allow for the possibility that at-home inventories of different types of drinks impact consumer on-the-go product choice (see discussion on page 18 and estimates in Table 3.2). While it would be interesting to study more broadly the interactions between household demand and individual on-the-go demand, we leave this for future work.

\subsection{Demographics}

Soda taxes are primarily justified on the grounds that they address externalities and internalities. There is evidence that added sugar consumed in liquid form raises the risk of developing a number of diseases. ${ }^{16}$ This gives rises to externalities through increases in public health costs, and also potentially to internalities.

A number of recent papers have focused on the internality correcting rationale of taxation; including in food and drink markets (O'Donoghue and Rabin (2006), Haavio and Kotakorpi (2011), Allcott et al. (2019a)), cigarette markets (Gruber and Koszegi (2004)), and energy markets (Allcott et al. (2014)). A large theory literature posits that not all individuals fully account for future costs of consumption (for

\footnotetext{
${ }^{16}$ See Allcott et al. (2019b) and Scientific Advisory Committee on Nutrition (2015) for summaries of the evidence.
} 
a survey see Rabin (1998)), often offering food and drink consumption as the motivating example. There also exists both experimental evidence that people have behavioral biases with respect to food and drink consumption (see, for instance, Read and Van Leeuwen (1998) and Gilbert et al. (2002)), and circumstantial evidence from the existence of a multi-billion pound dieting industry (Cutler et al. (2003)). We do not seek to measure the size of internalities. Rather, we focus on how effective soda taxes are at reducing sugar consumption among those demographics (the young, high sugar consumers, and those with low incomes) that are highlighted by policymakers as the groups whose consumption they would most like to change.

Lowering the sugar intake of young people is a stated aim of public policy (for instance, see CDC (2016), Public Health England (2015)). On average the young get a relatively large fraction of their calories from sugar, so excess sugar consumption is more severe among this group (see details in Appendix A.1). This tendency has increased over time. ${ }^{17}$ Medical evidence suggests that exposure to sweetened beverages early in life can establish strong lifelong preferences for these products (Mennella et al. (2016)). The young are particularly susceptible to suffer from internalities from excess sugar. The consequences of poor nutrition early in life are profound: with excess sugar associated with poor mental health and school performance in children, and poor childhood nutrition thought to be an important determinant of later life health, social and economic outcomes and of persistent inequality. ${ }^{18}$ It is likely that young people are less inclined to take account of the long term consequences of poor dietary choices (for instance, Ameriks et al. (2007) show that the young suffer more from self-control problems than older people).

Those with high sugar diets are a group that policymakers have also targeted (for instance, see CDC (2016), Public Health England (2015)). Consuming more sugar is associated with higher instances of diet related disease and associated medical expenditures. If the marginal social costs from sugar consumption are increasing (e.g. at lower levels of sugar consumption the probability of developing type II diabetes is trivially small, but this probability rises non-linearly in sugar consumption) this would reinforce the rationale for focusing on this group. Supporting this hypothesis

\footnotetext{
${ }^{17}$ For instance, Cavadini et al. (2000) document an increase in soft drink consumption in the US for 11-18 years old of almost 300\% for boys, and over 200\% for girls between 1965 and 1996 , and Nielsen and Popkin (2004) document a contemporaneous fall in the share of calories children get from milk.

${ }^{18}$ See, for instance Cawley (2010), Gortmaker et al. (2009), Han and Powell (2013), Currie (2009), Currie et al. (2010), Azaïs-Braesco et al. (2017), Baum and Ruhm (2009), and for more description of consumption patterns see Ng et al. (2012), Rugg-Gunn et al. (2007)).
} 
Hall et al. (2011) show that adults with greater adiposity (more fat) experience larger health gains from a given reduction in energy intake.

Our focus on how responses vary with a measure of income is motivated, in part, by concerns that soda taxes are likely to be regressive. A second reason to focus on low income individuals is that there is some evidence that they are more likely to exhibit behavior that creates internalities than those on higher incomes (see Haushofer and Fehr (2014) and Mani et al. (2013)). If all consumers suffer from the same marginal internality, higher levels of soft drink consumption among low income individuals would mean total internality costs are higher for this group.

Allcott et al. (2019a) provide evidence that marginal internalities may actually be higher for low income consumers, implying any internalities may be even more concentrated among this group. ${ }^{19}$

We construct a measure of total annual dietary sugar as the share of total household calories that are from added sugar using data on the entire household shopping basket. We measure income using household total annual equivalized grocery expenditure; we equivalize using the standard OECD modified equivalence scale. ${ }^{20}$ There are other demographics that might also be of interest, and in Appendix B we show how the estimated preference parameters vary by gender and the household's socio-economic status (which is a good proxy for education level).

In Table 2.5 we describe the age distribution of the total on-the-go sample. We estimate demand using the 2,449 individuals who are "soft drink purchasers". The table also summarizes other aspects of purchase behavior. Young consumers (relative to older ones): (i) are more likely to be soft drink purchasers, (ii) conditional on being so, obtain more sugar from these products, and (iii) purchase soft drinks more often and are more likely to buy sugar varieties - it is this rather than any tendency to be more likely to buy the largest single portion size (500ml bottles) that is key driving the higher sugar levels.

Tables 2.6 and 2.7 show the same statistics for deciles of the distribution of total annual dietary sugar and total annual equivalized grocery expenditure. Individuals from households with more sugar in their total diet are both more likely to be soft drink purchasers and, conditional on this, to get large quantities of sugar from

\footnotetext{
${ }^{19}$ Allcott et al. (2019a) use soft drinks consumption of people who state they have no self control problems and of dieticians, conditional on demographic controls, as a measure of soft drinks consumption of non-biased consumers and measure the degree of mis-optimization relative to this benchmark.

${ }^{20}$ Grocery expenditure includes spending on food, drink (including alcohol), pet food, toiletries and cleaning products. In Dubois et al. (2019) we show that equivalized grocery expenditure is strongly correlated with current income; expenditure is often viewed as a better proxy for lifetime income than current income (e.g. Poterba (1989)) so we use that as our main measure.
} 
these products. A similar pattern holds across the total annual equivalized grocery expenditure distribution; individuals with lower total annual grocery expenditure are more likely to be soft drink purchasers and obtain a relatively high amount of sugar from these products.

Table 2.5: Descriptive statistics by age groups

\begin{tabular}{lcccccc}
\hline & \multicolumn{7}{c}{ Age group } \\
& $13-21$ & $22-30$ & $31-40$ & $41-50$ & $51-60$ & $60+$ \\
\hline \% of sample & 11.1 & 13.8 & 20.3 & 21.5 & 17.2 & 16.1 \\
Fraction of soft drink purchasers & .44 & .5 & .53 & .48 & .38 & .26 \\
Conditional on purchase: & & & & & & \\
$\quad$ Mean sugar from soft drinks per year $(\mathrm{g})$ & 2036 & 1784 & 1356 & 1378 & 1265 & 1057 \\
$\quad$ Mean number of purchases per year & 46.3 & 43.2 & 38.7 & 34.1 & 33.4 & 28.8 \\
$\quad$ Fraction of sugary products & 0.73 & 0.67 & 0.60 & 0.61 & 0.62 & 0.62 \\
$\quad$ Fraction of 500ml bottles & 0.74 & 0.72 & 0.69 & 0.70 & 0.69 & 0.68 \\
\hline
\end{tabular}

Notes: Row 1 shows the fraction of individual-year observations in each age group. Row 2 shows the fraction of each age that are soft drink purchasers, defined as in footnote 9. The remaining rows show means for the set of soft drink purchasers of; total annual sugar from these products, number of annual purchases, fraction of purchases for sugary rather than diet varieties, and fraction of purchases for the larger $500 \mathrm{ml}$ bottle size.

Table 2.6: Descriptive statistics by total annual dietary sugar

\begin{tabular}{lcccccccccc}
\hline & \multicolumn{8}{c}{ Decile of distribution of share of calories from added sugar } \\
& 1 & 2 & 3 & 4 & 5 & 6 & 7 & 8 & 9 & 10 \\
\hline Upper bound of deciles & 8.4 & 9.9 & 11 & 11.9 & 12.9 & 13.8 & 14.9 & 16.3 & 18.4 & 24.7 \\
Fraction of soft drink purchasers & .33 & .41 & .42 & .41 & .45 & .45 & .46 & .49 & .47 & .48 \\
Conditional on purchase: & & & & & & & & & & \\
$\quad$ Mean sugar from soft drinks per year $(\mathrm{g})$ & 1035 & 1347 & 1277 & 1210 & 1296 & 1356 & 1541 & 1574 & 2020 & 1760 \\
$\quad$ Mean number of purchases per year & 35.9 & 39 & 36.2 & 34.1 & 35.4 & 36.3 & 37.7 & 37.7 & 43.3 & 37.9 \\
$\quad$ Fraction of sugary products & 0.55 & 0.58 & 0.59 & 0.60 & 0.64 & 0.66 & .66 & .66 & .66 & .7 \\
$\quad$ Fraction of 500ml bottles & 0.65 & 0.67 & 0.67 & 0.70 & 0.71 & 0.73 & .72 & .71 & .71 & .73 \\
\hline
\end{tabular}

Notes: Row 1 shows the upper bound of the decile of total annual dietary sugar. Row 2 shows the fraction of each age that are soft drink purchasers, defined as in footnote 9. The remaining rows show means for the set of soft drink purchasers of; total annual sugar from these products, number of annual purchases, fraction of purchases for sugary rather than diet varieties, and fraction of purchases for the larger 500ml bottle size.

Table 2.7: Descriptive statistics by total annual equivalized grocery expenditure

\begin{tabular}{lccccccccccc}
\hline & \multicolumn{9}{c}{ Decile of distribution of } \\
& 1 & 2 & 3 & 4 & 5 & 6 & 7 & 8 & 9 & 10 \\
\hline Upper bound of decile & .8 & 1.1 & 1.3 & 1.5 & 1.7 & 1.9 & 2.1 & 2.5 & 3.1 & 5.1 \\
Fraction of soft drink purchasers & .48 & .44 & .44 & .44 & .48 & .44 & .4 & .43 & .44 & .39 \\
Conditional on purchase: & & & & & & & & & & \\
$\quad$ Mean sugar from soft drinks per year $(\mathrm{g})$ & 1664 & 1454 & 1683 & 1426 & 1583 & 1514 & 1312 & 1291 & 1233 & 1440 \\
$\quad$ Mean number of purchases per year & 41.5 & 36.4 & 42.8 & 35.9 & 37.6 & 37.4 & 34.3 & 35 & 34.2 & 39.1 \\
$\quad$ Fraction of sugary products & 0.66 & 0.65 & 0.62 & 0.64 & 0.65 & 0.63 & .66 & .61 & .63 & .62 \\
$\quad$ Fraction of 500ml bottles & 0.67 & 0.70 & 0.69 & 0.68 & 0.70 & 0.70 & .72 & .72 & .72 & .72 \\
\hline
\end{tabular}

Notes: Row 1 gives the upper bound of the decile, measured in £1000, of total annual equivalized grocery expenditure. Row 2 shows the fraction of each age that are soft drink purchasers, defined as in footnote 9. The remaining ture. Row 2 shows the fraction of each age that are soft drink purchasers, defined as in footnote 9. The remaining
rows show means for the set of soft drink purchasers of; total annual sugar from these products, number of annual purchases, fraction of purchases for sugary rather than diet varieties, and fraction of purchases for the larger $500 m l$ bottle size. 


\section{$3 \quad$ Model and estimated coefficients}

In this section we develop a model of consumer choice in the non-alcoholic drinks market. What distinguishes our approach from previous work is: (i) we focus on modeling the preferences of individuals using information on their purchases onthe-go, and (ii) we exploit the long panel nature of our data to estimate individual specific preference parameters, giving us the ability to relate individual specific preferences and counterfactual effects to a wide range of demographics and measures of individual behavior. ${ }^{21}$

\subsection{Demand model}

We index consumers by $i \in\{1, \ldots, N\}$. We observe each consumer on many choice occasions, indexed by $\tau=\{1, \ldots, \mathcal{T}\}$. A choice occasion $\tau$ refers to a consumer visiting a retailer $r(\tau)$ at time $t(\tau)$ and purchasing either a non-alcoholic drink or a snack. $^{22}$ Denote the available set of drinks products in retailer $r=\{1, \ldots, R\}$ during choice occasion $\tau$ as $\Omega_{r(\tau)}$.

We index the $J$ non-alcoholic drinks products (i.e. the "inside goods") by $j$ with $j=\left\{1, \ldots, j^{\prime}\right\}$ for the soft drinks and $j=\left\{j^{\prime}+1, \ldots, J\right\}$ for the alternative drinks. These products are reported in Table 2.2. We allow for the possibility that consumers instead choose either a sugary or a non-sugar snack. We refer to these as "outside options", and we indicate the sugary snack by $j=\overline{0}$ and the non-sugar snack by $j=\underline{0}$. The choice set facing a consumer on choice occasion $\tau$ contains the subset $\Omega_{r(\tau)}$ of the $J$ drinks products available in retailer $r$ plus the two outside options. Typically several soft drinks products belong to a single brand - we denote the brand that product $j$ belongs to as $b(j)$. Products within a brand differ based on whether they are a sugary or diet variety and in their pack size.

We assume the payoff associated with selecting a product $j$ on choice occasion $\tau$ takes the form:

$$
\begin{aligned}
U_{i j \tau}=\alpha_{i} p_{j r(\tau) t(\tau)}+ & \beta_{i} s_{j}+\gamma_{i} w_{j}+\delta_{d(i)}^{\kappa} \kappa_{i j \tau}+\delta_{d(i)}^{\mathfrak{a}} \mathfrak{a}_{b(j) t(\tau)}+ \\
& \delta_{d(i)}^{h} h_{c(i) t(\tau)}+\delta_{d(i)}^{z} z_{j}+\xi_{d(i) b(j) t(\tau)}+\zeta_{d(i) b(j) r(\tau)}+\epsilon_{i j \tau}
\end{aligned}
$$

\footnotetext{
${ }^{21}$ We estimate a similar model of demand in the at-home segment; details are reported in Appendix C.

${ }^{22}$ We treat the decision to visit a store as exogenous.
} 
and the payoffs from selecting the outside options are given by:

$$
\begin{aligned}
& U_{i \overline{0} \tau}=\beta_{i}+\epsilon_{i \overline{0} \tau} \\
& U_{i \underline{0} \tau}=\epsilon_{i \underline{0} \tau},
\end{aligned}
$$

where $\left(\epsilon_{i \underline{0} \tau}, \epsilon_{i \overline{0} \tau}, \epsilon_{i 1 \tau}, . ., \epsilon_{i J \tau}\right)$ are distributed type I extreme value independently across individuals, options and time.

$p_{j r(\tau) t(\tau)}$ denotes the price of product $j$, which varies through time $(t)$ and across retailer types $(r) . s_{j}$ is a dummy variable indicating whether the product contains sugar and $w_{j}$ is a dummy variable for whether the product is a drink (as opposed to a snack). We include individual specific preferences over these three key product characteristics. For the remaining characteristics we restrict heterogeneity to vary across demographic groups, where we denote by $d(i)$ the group to which individual $i$ belongs. These groups distinguish between individuals on the basis of gender and age (below 40 and 40 and above).

A convenient feature of modeling purchases made on-the-go for immediate consumption is that it minimizes concerns about dynamics in demand arising from consumer stockpiling (a situation considered in Wang (2015)); by definition the consumption occasions that we are considering do not involve storage. Another form of dynamics in demand would arise if there are intertemporal non-separabilities in preferences. An obvious form of non-separability is that recent at-home purchases impact on-the-go demands. In Section 2.3 we provide evidence that, once fixed unobserved individual heterogeneity is accounted for, this form of demand linkage is not of first order importance for the decision to purchase a soft drink in our setting. In our demand model we allow for the possibility that at-home inventories impact the choice of what specific (if any) drink an individual chooses. We do this by controlling for $\kappa_{i j \tau}$; a measure of the inventory of drinks the individual has access to due to recent at-home purchases - this is defined analogously to the inventory measure we use on page 11 . We include a $j$ index on this variable to indicate that it varies across products. In practice we compute separate at-home inventory variables for sugary soft drinks, diet soft drinks, fruit juices, flavored milk and waters and let each measure impact the on-the-go utility of products belonging to that set.

We also include a measure of weekly regional brand level advertising expenditure, $\mathfrak{a}_{b(j) t(\tau)}$ (variation by region arises due to the geographic span of regional TV channels), ${ }^{23}$ and the effects of temperature $\left(h_{c(i) t(\tau)}\right)$ in location $c(i)$ where the con-

\footnotetext{
${ }^{23}$ We measure weekly advertising expenditure in the AC Nielsen Advertising Digest. We compute product specific stocks based on a monthly depreciation rate of 0.9 . This is similar to the rate used in Dubois et al. (2018) using similar data in the potato chips market.
} 
sumer lives at time $t(\tau) .{ }^{24}$ We include size-carton type effects $\left(z_{j}\right)$, time-varying brand effects $\left(\xi_{d(i) b(j) t(\tau)}\right)$ (at the year and quarter level) and retailer-brand effects $\left(\zeta_{d(i) b(j) r(\tau)}\right)$.

Denote by $\boldsymbol{\alpha}=\left(\alpha_{1}, \ldots, \alpha_{N}\right)^{\prime}, \boldsymbol{\beta}=\left(\beta_{1}, \ldots, \beta_{N}\right)^{\prime}$ and $\boldsymbol{\gamma}=\left(\gamma_{1}, \ldots, \gamma_{N}\right)^{\prime}$ the vectors of individual preference parameters. These enable the model to capture within individual correlation in choices across choice occasions. We do not place any a priori restriction on the joint distribution of these variables. We use the large $\mathcal{T}$ dimension of our data to recover estimates of individual specific parameters $(\boldsymbol{\alpha}, \boldsymbol{\beta}, \boldsymbol{\gamma})$, while the large $N$ dimension allows us to identify nonparametrically the joint probability distribution function $f\left(\alpha_{i}, \beta_{i}, \gamma_{i}\right)$ using the empirical probability distribution function of estimated $(\boldsymbol{\alpha}, \boldsymbol{\beta}, \boldsymbol{\gamma})$. We can also construct the distribution of preferences conditional on observable consumer characteristics, $X ; f\left(\alpha_{i}, \beta_{i}, \gamma_{i} \mid X\right)$. These observable characteristics can be demographic variables or measures of the overall diet or grocery purchasing behavior of the household to which the individual belongs.

A number of papers (see, for instance, Berry et al. (1995), Nevo (2001) and Berry et al. (2004)) show that incorporating consumer level preference heterogeneity is important for enabling choice models to capture realistic switching patterns across products. ${ }^{25} \mathrm{~A}$ few paper use non-parametric methods to relax parametric restrictions on random coefficient distributions. ${ }^{26}$ Like these papers we model consumer specific preferences, however in contrast to them, we treat the preferences as parameters to be estimated and thereby avoid having to make independence assumptions to integrate out the density. This allows us to flexibly relate the preference parameters and individual specific effects of policy simulations to observable attributes of consumers. Unlike in a random coefficient approach we do not need to a priori specify how the preference distribution depends on exogenous attributes of consumers, and we can relate individual specific effects to any observable attributes of consumers (such as other aspects of their grocery purchasing behavior). ${ }^{27}$

\footnotetext{
${ }^{24}$ These data are from the Met Office Historic station data, are reported monthly for 35 locations in the UK, and are available at https://www.metoffice.gov.uk/public/weather/climatehistoric/\#?tab=climateHistoric

${ }^{25}$ Lewbel and Pendakur (2017) show similar results apply in non-linear continuous choice models, with the incorporation of random coefficients resulting in their model much more effectively capturing the distributional impacts of taxation.

${ }^{26}$ Burda et al. (2008) exploit Bayesian Markov Chain Monte Carlo techniques and Train (2008) uses an expectation-maximization algorithm to estimate the random coefficient distribution. Train (2008) applies the method either with a discrete random coefficient distribution or with mixtures of normals. Bajari et al. (2007) discretize the random coefficient distribution and use linear estimation techniques to estimate the frequency of consumers at each fixed point.

${ }^{27}$ In an earlier version of this paper, Dubois et al. (2019), we compare our estimates to those obtained with a standard random coefficients model, and show that the two models yield similar
} 
One potential concern is that our estimates may be subject to an incidental parameter problem that is common in non-linear panel data estimation. Even if both $N \rightarrow \infty$ and $\mathcal{T} \rightarrow \infty$, asymptotic bias may remain, although it shrinks as the sample size rises (Hahn and Newey (2004), Arellano and Hahn (2007)). The long $\mathcal{T}$ dimension of our data helps lower the chance that the incidental parameter problem leads to large biases. We implement the split sample jackknife procedure suggested in Dhaene and Jochmans (2015) and in Section 5.1 show that our maximum likelihood and jackknife estimates are similar and that the bias correction does not materially affect our results.

Another benefit of having large $\mathcal{T}$ for each individual is that we can allow for consumers who may have sufficiently strong distaste for some product sets such that they will never choose to buy them. We identify consumers that never purchase products with particular characteristics (e.g. options that contain sugar) over the long time dimension of our data as having zero probability of purchasing products with that characteristic. This is in contrast to standard logit discrete choice demand models where it is assumed that all consumers have non-zero purchase probabilities for all products available to them.

In particular, any individuals that never purchase sugary drinks or snacks reveal a strong distaste for sugar (which we denote by $\beta_{i}=-\infty$ ), and any individuals who never purchase non-sugary drinks or non-sugary snacks reveal a strong taste for sugar (which we denote by $\beta_{i}=\infty$ ). For individuals that sometimes purchase sugary options and at other times non-sugary options, their sugar preferences is such that $\beta_{i} \in(-\infty, \infty)$.

To specify the set of options that consumers have non-zero probabilities for, it is useful to define the product sets $\Omega_{s}$ and $\Omega_{n}$, which denote the sets of sugary drinks and non-sugary drinks. We can then define consumer $i$ specific sets of options with non-zero purchase probabilities, denoted by $\Omega_{i}$, as

$$
\Omega_{i}=\left\{\begin{array}{rlrl}
\Omega_{s} \cup \Omega_{n} \cup\{\overline{0}\} \cup\{\underline{0}\} & \text { if } & \beta_{i} \in(-\infty, \infty) \\
\Omega_{n} \cup\{\underline{0}\} \text { if } & \beta_{i}=-\infty \\
\Omega_{s} \cup\{\overline{0}\} \text { if } & \beta_{i}=+\infty .
\end{array}\right.
$$

We measure the consumer level product sets $\Omega_{i}$ thanks to the large $\mathcal{T}$ dimension of observed consumer level choices. We ignore the finite sample measurement error on $\Omega_{i}$ as Monte Carlo simulations show that such error is negligible in our application where $\mathcal{T}$ is relatively large. ${ }^{28}$

estimates of market level demand curves, but the random coefficient model is not able to capture the rich correlation in preferences and consumer attributes.

${ }^{28}$ Further details available from authors on request. 
For drinks products $j \in\{1, \ldots, J\}$ we define:

$$
\begin{aligned}
v_{i j r(\tau) t(\tau)} & \equiv \alpha_{i} p_{j r(\tau) t(\tau)}+\beta_{i} s_{j} 1_{\left\{\beta_{i} \in(-\infty, \infty)\right\}}+\gamma_{i} w_{j} \\
\eta_{i j r(\tau) t(\tau)} & \equiv \delta_{d(i)}^{\kappa} \kappa_{i j \tau}+\delta_{d(i)}^{\mathfrak{a}} \mathfrak{a}_{b(j) t(\tau)}+\delta_{d(i)}^{h} h_{c(i) t(\tau)}+\delta_{d(i)}^{z} z_{j}+\xi_{d(i) b(j) t(\tau)}+\zeta_{d(i) b(j) r(\tau)}
\end{aligned}
$$

such that equation (3.1) can be written

$$
U_{i j \tau}=v_{i j r(\tau) t(\tau)}+\eta_{i j r(\tau) t(\tau)}+\epsilon_{i j \tau} .
$$

The assumption that $\left(\epsilon_{i \underline{\underline{0}} \tau}, \epsilon_{i \overline{0} \tau}, \epsilon_{i 1 \tau}, \ldots, \epsilon_{i J \tau}\right)$ are idiosyncratic shocks independently distributed type I extreme value means that the consumer level choice probabilities are given by the multinomial logit formula, such that the choice probability of consumer $i$ on choice occasion $\tau$ purchasing any drinks product $j \in \Omega_{r(\tau)}$ can be written $^{29}$

$$
P_{i \tau}(j)=\frac{1_{\left\{j \in \Omega_{i}\right\}} \exp \left(v_{i j r(\tau) t(\tau)}+\eta_{i j r(\tau) t(\tau)}\right)}{1_{\left\{\underline{0} \in \Omega_{i}\right\}}+1_{\left\{\overline{0} \in \Omega_{i}\right\}} \exp \left(\beta_{i}\right)+\sum_{k \in \Omega_{i} \cap \Omega_{r(\tau)}} \exp \left(v_{i k r(\tau) t(\tau)}+\eta_{i k r(\tau) t(\tau)}\right)}
$$

Denote consumer $i$ 's sequence of choices across all choice occasions as $\boldsymbol{y}_{i}=$ $\left(y_{i r(1) t(1)}, \ldots, y_{i r(\mathcal{T}) t(\mathcal{T})}\right)$; then the probability of observing $\boldsymbol{y}_{i}$ is given by:

$$
\mathcal{L}_{i}\left(\boldsymbol{y}_{i}\right)=\prod_{\tau=1}^{\mathcal{T}} P_{i \tau}\left(y_{i r(\tau) t(\tau)}\right)
$$

and, denoting the demographic specific preference parameters $\boldsymbol{\eta}$, the associated log-likelihood function is:

$$
l(\boldsymbol{\alpha}, \boldsymbol{\beta}, \boldsymbol{\gamma}, \boldsymbol{\eta})=\sum_{i} \ln \mathcal{L}_{i}\left(\boldsymbol{y}_{i}\right)
$$

which is globally concave with respect to all parameters.

\subsection{Identification}

Our main identification challenge is to pin down the causal impact of price on demand. Our strategy for doing this relies on two sources of price variation. First, conditional on brand-time and retailer type-drink type effects, we exploit crossretailer type variation in the relative prices of different drinks products. This arises because we observe individuals making purchases in different retailers across time (and thereby facing different price vectors). An important identifying assumption is that retailer choice is not driven by shocks to demand for a specific drinks product,

\footnotetext{
${ }^{29}$ Of course the probability that consumer $i$ at occasion $\tau$ purchases a good $j \notin \Omega_{r(\tau)}$ is zero.
} 
but rather variation in where individuals shop is driven by other factors in daily life, in which individuals move between home, school, leisure or work. Second, we exploit variation in prices within brand across different containers and sizes. We allow for the possibility of time varying shocks to brand level demand, but we assume there is no aggregate shocks within brand for different container types. We discuss each source of variation in turn. ${ }^{30}$

The price vector an individual faces at the point of purchase depends on which retailer they visit. These retailers include a set of large national retailers that price nationally, smaller retailers with regionally varying prices and vending machines (see Table 2.3). We include demographic group specific time varying brand effects $\xi_{d(i) b(j) t(\tau)}$ and retailer type effects, interacted with the drink types, $\zeta_{d(i) b(j) r(\tau)} \cdot{ }^{31}$ The former capture aggregate (demographic specific) fluctuations in brand demand over time and the latter capture any differential propensity of consumers to choose different drink types across retailers. Conditional on these, the cross-retailer differences in prices provide a useful source of price variation.

There are a number of potential concerns with exploiting this type of price variation that we need to address. First, an issue would arise if individual level demand shocks to specific soft drinks products drive store choice; for instance, if consumers that have a demand shock in favor of Coca Cola are driven by this to choose a retailer that temporarily has a low price for that product, and, if instead they had a demand shock in favor of Pepsi they would have selected a retailer with a relatively low Pepsi price. Such behavior would occur either if consumers could predict fluctuating relative prices across retailers or if they visited several retailers in search of a low price draw for the product they are seeking. We find either scenario unlikely in the case of soft drinks.

Second, an issue would arise if there are time varying retailer type specific demand shocks that are contemporaneously correlated with prices. In the UK market the vast majority of soft drinks advertising is done nationally and by the manufacturer, and we control for this in demand, including the regional variation due to regional broadcasting of some TV channels. ${ }^{32}$ We also control for regional vari-

\footnotetext{
${ }^{30}$ In a previous Working Paper version of the paper (Dubois et al. (2019)) we provide descriptive statistics that illustrate the price variation individuals face, and that the monthly prices we use in estimation reflect actual variation in underlying transaction prices.

${ }^{31}$ Specifically, the time varying brand effects include Coca Cola, Coca Cola other brands, Pepsi, Glaxo brands, Irn Bru, the composite "other" soft drinks, non-soft drinks, and each of the two outside options interacted with year and quarter effects. The retailer type-drink type effects include branded soft drinks, the composite "other" soft drinks, fruit juice, water, and each of the two outside options interacted with the store types shown in Table 2.3.

${ }^{32}$ Targeted price discounts through use of coupons - common in the US (see Nevo and Wolfram (2002)) - is not a common feature of the UK market.
} 
ation in weather conditions. Conditional on these (and retailer type effects), we assume the residual cross retailer type price variation is driven by cost differences, by random price reduction strategies and by store specific decisions related to unanticipated excess stock.

The second source of price variation we exploit is non-linear pricing across container sizes. This price variation is not collinear with the size effects, and the extent of non-linear pricing varies over time and retailers. This source of identifying variation would be invalid if there were systematic shocks anticipated by firms to consumers' valuation of container sizes that were differential across brand after conditioning on time varying brand effects and container size and type effects. It seems more plausible that such tilting of brand price schedules is driven by cost variations that are not proportional to pack size, differential pass-through of cost shocks and differences in how brand advertising affects demands for different pack sizes. This identification argument is similar to that in Bajari and Benkard (2005). In an application to the computer market they assume that, conditional on observables, unobserved product characteristics are the same for products that belong to the same model. We assume that, conditional on time-varying brand characteristics, unobserved size specific attributes do not vary differentially across brands.

The main source of variation in the sugar content of products is between sugary and diet varieties (with most brands being available in each variety). We identify consumer specific preference parameters for sugary versus diet products (rather than a preference for a marginal increase in sugar quantity). We assume that the brand effects are common across sugary and diet varieties, and that the taste for sugary varieties is additively separable. This means that, for example, we do not allow the individual sugar taste to be different for Coke versus Pepsi.

\subsection{Pass-through of a tax on sugary soft drinks}

An important issue in estimating the impact of a tax on consumption is the extent to which the tax is shifted onto prices. Here we present preliminary evidence of the pass-through of the recent UK soda tax to the price of soft drinks available in the on-the-go market. This suggests pass-through is around 100\%, and accords with much of the mounting evidence of complete pass-through of soda taxes in other jurisdiction. We also simulate tax pass-through using a demand and supply model. To do this we use our on-the-go demand estimates along with those for the at-home segment (reported in Appendix C) and couple it with a Nash-Bertrand pricing model. We report the equilibrium pass-through results in Section 5.3; the results are similar to our descriptive evidence of tax pass-through. 
There is a growing literature that estimates the pass-through of soda taxes to prices using data covering the implementation of the tax. ${ }^{33}$ The most common finding is that pass-through was full or near to full (i.e. prices rose by the full amount of the tax). ${ }^{34}$ There are a few papers that find low pass-through, mainly studying Berkley. ${ }^{35}$ A key difference between the Berkeley setting and many of the other jurisdictions that have implemented soda taxes is that Berkeley is comparatively small, meaning that cross-border shopping is easier and there will be more competitive pressure on firms to keep prices down. The studies that look at larger jurisdictions are more relevant to the UK setting, because the taxes cover a wider geographical area, and therefore cross-border shopping is likely to be less important.

The broad finding (with the exception of Berkeley) of around full pass-through of soda taxes is consistent with studies that look at pass-through of other taxes. These include Besley and Rosen (1999), which exploits variation in state and local sales taxes in the US and looks at the impact on prices of a number of products and finds slight over-shifting for soft drinks products, Delipalla and O'Donnell (2001), which analyzes the incidence of cigarette taxes in several European countries and Kenkel (2005), which uses data on how the price of alcoholic beverages changed in Alaska.

There is also a related literature that estimates pass-through of cost shocks. Much of this finds under-shifting (see, for instance, Goldberg and Hellerstein (2013) and Nakamura and Zerom (2010)). An important reason for incomplete passthrough of cost shocks is that often not all cost components are affected by the shock. For instance, exchange rate movements do not directly impact the cost of non-traded inputs (Goldberg and Hellerstein (2013)). In a context where firms' marginal costs are observable (in the wholesale electricity market), Fabra and Reguant (2014) find changes in marginal costs are close to fully shifted to prices.

We provide descriptive evidence of pass-through of the recently introduced Soft Drinks Industry Levy in the UK using an event study design for prices (per liter) of the two main brands, Coca Cola and Pepsi. The tax was introduced on 1 April 2018. We use data on transaction prices from the Kantar on-the-go survey for sugary Coca Cola and Pepsi products covering the year before and after this date.

\footnotetext{
${ }^{33}$ Griffith et al. (2019) provide a review.

${ }^{34}$ Papers that find full or near-full pass-through include Aguilar et al. (2018), Berardi et al. (2016), Capacci et al. (2019), Castello and Lopez-Casasnovas (2018), Cawley et al. (2018), Cawley et al. (2018), Cawley et al. (2018), Colantuoni and Rojas (2015), Colchero et al. (2015), Goncalves and dos Santos (2019), Powell et al. (2020), Seiler et al. (2018), Silver et al. (2017).

${ }^{35}$ Bollinger and Sexton (2018), Cawley and Frisvold (2017), Etilé et al. (2018), Falbe et al. (2015), Rojas and Wang (2017),
} 
Denoting transactions by $\iota$, we estimate the regression

$$
\text { trans. } \text { price }_{\iota}=a+b \times I_{\iota}[\operatorname{tax}]+X_{\iota} c+e_{\iota}
$$

where $I_{\iota}[\operatorname{tax}]$ is an indicator variable equal to 1 if the transaction took place on or after 1 April 2018, and $X_{\iota}$ includes dummy variables for brand, pack size, month and store type. We report coefficient estimates in Table 3.1, both for all sugary Coca Cola and Pepsi products together, and estimated separately by the two main on-the-go pack sizes (330ml can and $500 \mathrm{ml}$ bottles).

The Soft Drinks Industry Levy placed a tax of 24 pence per liter on the sugar variants of Coke and Pepsi. This tax rate is subject to 20\% VAT; therefore a price increase of 28.8 pence per liter associated with the tax represents full pass-through. The estimates in Table 3.1 suggest that prices of these products increased by 28 pence when all considered together. The prices of smaller pack sizes increased by slightly less, 24.1 pence per liter, and prices of larger pack size increased by slightly more, 29.4 pence. In Appendix E we report simulated pass-through based on our demand estimates and a classical supply side Nash-Bertrand pricing oligopoly model. We find similar patterns; the structural model does a reasonable job of predicting the pass-through patterns that have resulted from the recently introduced UK soda tax.

Table 3.1: Pass-through of UK sugar tax

\begin{tabular}{lccc}
\hline & All & $330 \mathrm{ml}$ & $500 \mathrm{ml}$ \\
\hline After tax & 0.280 & 0.241 & 0.294 \\
& $(0.012)$ & $(0.019)$ & $(0.016)$ \\
Constant & 2.310 & 2.007 & 2.291 \\
& $(0.026)$ & $(0.057)$ & $(0.032)$ \\
\hline $\mathrm{N}$ & 10179 & 3920 & 6259 \\
\hline
\end{tabular}

Notes: We regress the price of Coca Cola (including Cherry Coke) and Pepsi products that were subject to the Soft Drinks Industry Levy on a dummy variable that is equal to 1 after the implementation of the tax on 1 April 2018. The data runs from 1 April 2017 to 31 March 2019. All regressions include brand dummies, pack size dummies, month dummies and store type dummies. Standard errors are reported in parentheses.

\subsection{Estimated preference coefficients and elasticities}

In Table 3.2 we summarize the distribution of estimated consumer specific preference parameters (upper section) obtained by maximizing the likelihood function (equation 3.3). We report means, standard deviations, skewness and kurtosis of the estimates parameters, as well as the covariance between them. These numbers are 
based on the finite portion of the joint preference distribution. In the lower part of the table we report the coefficients on the at-home inventory, product advertising and air temperature. These coefficients vary across demographic groups (age and gender).

Table 3.2: Demand model estimates

\begin{tabular}{|c|c|c|c|}
\hline Variable & & Estimate & $\begin{array}{l}\text { Standard } \\
\text { error }\end{array}$ \\
\hline \multicolumn{4}{|c|}{ Moments of distribution of consumer specific preferences } \\
\hline \multirow[t]{4}{*}{ Price $\left(\alpha_{i}\right)$} & Mean & -3.1461 & 0.0228 \\
\hline & Standard deviation & 2.3311 & 0.0157 \\
\hline & Skewness & -0.9726 & 0.0340 \\
\hline & Kurtosis & 4.3029 & 0.1291 \\
\hline \multirow[t]{4}{*}{ Drinks $\left(\gamma_{i}\right)$} & Mean & 2.0180 & 0.0396 \\
\hline & Standard deviation & 2.4239 & 0.0171 \\
\hline & Skewness & 0.6235 & 0.0361 \\
\hline & Kurtosis & 3.9720 & 0.0711 \\
\hline \multirow[t]{4}{*}{ Sugar $\left(\beta_{i}\right)$} & Mean & 0.4456 & 0.0079 \\
\hline & Standard deviation & 1.5047 & 0.0111 \\
\hline & Skewness & -0.3126 & 0.0528 \\
\hline & Kurtosis & 4.5575 & 0.1642 \\
\hline Price-Drinks & Covariance & -4.9696 & 0.0744 \\
\hline Price-Sugar & Covariance & 0.2080 & 0.0277 \\
\hline Drinks-Sugar & Covariance & -0.0482 & 0.0293 \\
\hline \multicolumn{4}{|l|}{ Demographic specific preferences } \\
\hline \multirow{4}{*}{ At-home inventory $\left(\delta_{d(i)}^{\kappa}\right)$} & Female, $<40$ & 0.0860 & 0.0042 \\
\hline & Female, +40 & 0.0439 & 0.0037 \\
\hline & Male,$<40$ & 0.0693 & 0.0042 \\
\hline & Male,+40 & 0.0637 & 0.0038 \\
\hline \multirow{4}{*}{ Advertising $\left(\delta_{d(i)}^{\mathfrak{a}}\right)$} & Female,$<40$ & 0.0011 & 0.0010 \\
\hline & Female, +40 & 0.0002 & 0.0010 \\
\hline & Male,$<40$ & 0.0040 & 0.0009 \\
\hline & Male, +40 & 0.0037 & 0.0009 \\
\hline \multirow{4}{*}{ Temperature* Drinks $\left(\delta_{d(i)}^{h}\right)$} & Female,$<40$ & 0.0214 & 0.0025 \\
\hline & Female, +40 & 0.0185 & 0.0023 \\
\hline & Male,$<40$ & 0.0229 & 0.0023 \\
\hline & Male, +40 & 0.0225 & 0.0022 \\
\hline Demographic specific size-carton size effects $\left(\delta_{d(i)}^{z}\right)$ & \multicolumn{3}{|c|}{ Yes } \\
\hline \multirow{2}{*}{\multicolumn{2}{|c|}{$\begin{array}{l}\text { Time-demographic-brand effects }\left(\xi_{d(i) b(j) t}\right) \\
\text { Retailer-demographic-brand effects }\left(\zeta_{d(i) b(j) r(\tau)}\right)\end{array}$}} & & \\
\hline & & \multicolumn{2}{|c|}{ Yes } \\
\hline
\end{tabular}

Notes: We estimate demand on a sample of 2,449 individuals who we observe on 616,544 on-the-go choice occasions. Consumers choose between the products listed in Table 2.2 and the outside options of purchasing a sugary or non-sugary snack. Estimates of the consumer specific preferences are summarized in the table. Moments of distribution are computed using estimates of consumer specific preference parameters. These moments are based on consumers with finite parameters and omit the top and bottom percentile of each distribution. Standard errors of these moments are computed using the delta method.

In Figure 3.1 we plot the marginal preference distributions for price, and the drink and sugar product attributes. These are based on individual level preference estimates, so we have a measure of statistical significance for each individual; this is represented by the shading, which indicates consumers with negative, positive and indifferent (i.e. not statistically significantly different from zero) preferences 
for each attribute. Table 3.2 shows that moments of each of these distributions are estimated with a high degree of precision. It is clear that the univariate preference distributions depart significantly from normality (which is typically imposed in random coefficient models) - this is apparent both in the negative skew for price preferences and the positive skew for drinks preferences, as well as the infinite portions of sugar preference distribution.

Figure 3.1: Univariate distributions of consumer specific preference parameters on-the-go
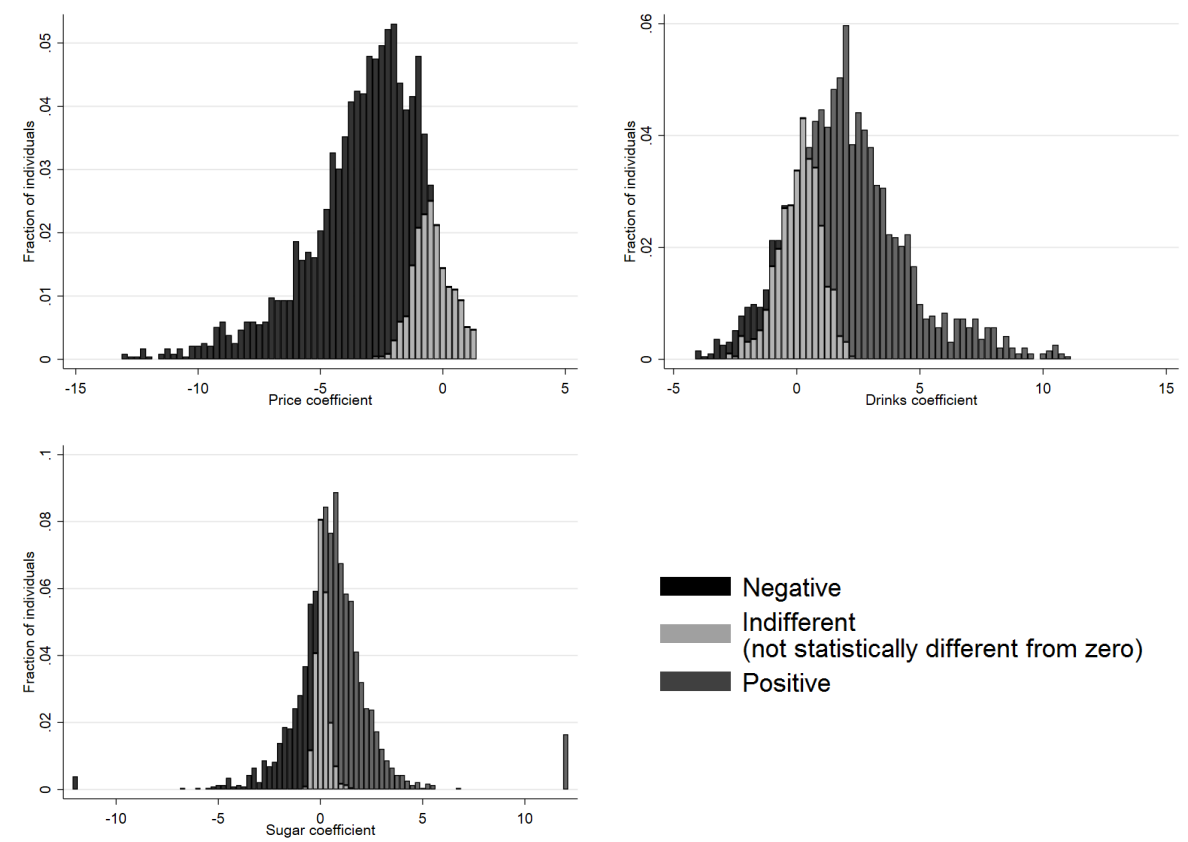

Notes: Distributions are based on individual level preference parameter estimates for the 2,449 individuals in the on-the-go estimation sample. We trim the top and bottom percentile of the finite portion of each distribution. The shading denote statistical significance of individual level preference estimates at the $95 \%$ level.

The estimates of the consumer specific preference parameters reveal a large degree of heterogeneity across individuals - the standard deviation for price preferences is 2.3 (with a coefficient of variation of 0.7 ), while the standard deviation for drinks and sugar preferences are 2.4 and 1.6. Price sensitive consumers tend to have relatively strong drinks preferences (the correlation coefficient between price and drinks preferences is -0.9). ${ }^{36}$ We show contour plots of the bivariate preference distributions in Appendix B.

The lower section of Table 3.1 shows the demographic specific preferences estimates for at-home inventories, product level advertising and temperature. As in the descriptive analysis in Section 2.3, the impact of recent at-home purchases of

\footnotetext{
${ }^{36}$ The coefficient of variation of price preferences is given by the ratio of the reported standard deviation and mean $(2.33 / 3.15=0.73)$ and the correlation coefficient of price and drinks preferences is given by the reported covariance divided by the product of the reported standard deviations $(-5.00 /(2.33 * 2.42)=-0.89)$
} 
drinks on utility on-the-go from drinks is positive and very small. For instance, allowing the at-home inventory to fully deplete to zero for sugary soft drinks, results on average in an increase in annual volume per person demanded of on-the-go sugary soft drinks of just 0.33 liters (equivalent to 1 can of Coca Cola). Higher levels of advertising for a product has a statistically significant and positive effect on utility from that product for males (but not females). All demographic groups obtain more utility from drinks on hotter days.

Table 3.3: Category level price elasticity

\begin{tabular}{|c|c|c|c|c|c|}
\hline & \multirow{2}{*}{$\begin{array}{c}\text { Own } \\
\text { demand } \\
\text { effect }\end{array}$} & \multicolumn{3}{|c|}{$\begin{array}{l}\text { Effect of } 1 \% \text { price increase on: } \\
\text { cross demand for: }\end{array}$} & \multirow{2}{*}{$\begin{array}{c}\text { Total } \\
\text { drinks } \\
\text { demand }\end{array}$} \\
\hline & & $\begin{array}{l}\text { diet } \\
\text { soft drinks }\end{array}$ & $\begin{array}{l}\text { sugary } \\
\text { alternatives }\end{array}$ & $\begin{array}{l}\text { non-sugary } \\
\text { alternatives }\end{array}$ & \\
\hline \multirow[t]{2}{*}{ Soft drinks } & -1.29 & & 1.271 & 1.719 & -0.703 \\
\hline & {$[-1.30,-1.27]$} & & {$[1.248,1.287]$} & {$[1.704,1.739]$} & {$[-0.706,-0.690]$} \\
\hline \multirow[t]{2}{*}{ Sugary soft drinks } & -1.58 & 0.609 & 0.956 & 0.739 & -0.468 \\
\hline & {$[-1.60,-1.56]$} & {$[0.596,0.614]$} & {$[0.937,0.968]$} & {$[0.731,0.752]$} & {$[-0.471,-0.459]$} \\
\hline
\end{tabular}

Notes: We simulate the effect of a $1 \%$ price increase for all soft drinks (row 1) and all sugary soft drinks (row 2) and report the change in demand for those product sets in column 1. In column 2-4 we report the effect on demand for alternative product sets and in the final column we report the change in demand for all drinks. 95\% confidence bands are shown in brackets.

We report price elasticities for all products in Table B.1 in Appendix B. A couple of interesting patterns are apparent. First, consumers are more willing to switch from sugary soft drinks products to alternative sugary soft drinks and from diet products to diet alternatives than they are between sugary and diet products. Second, the price elasticities for the $500 \mathrm{ml}$ products are smaller in magnitude than for the $330 \mathrm{ml}$ versions; consumers that choose to buy the larger bottle variants rather than smaller cans tend to be less willing to switch away from their chosen product in response to a price increase. Table 3.3 reports the effect on demand of a marginal increase in the price of all sugary soft drinks and in the price of all soft drinks (i.e. both sugary and diet). The own price elasticity for soft drinks is -1.29. This is smaller than the own price elasticity of any individual soft drink product. The own price elasticity for sugary soft drinks is -1.58 . This is larger than for all soft drinks, reflecting that some consumers respond to an increase in the price of sugary soft drinks by switching to diet alternatives. ${ }^{37}$

\footnotetext{
${ }^{37}$ To calculate the confidence intervals on elasticities we obtain the variance-covariance matrix for the parameter vector estimates using standard asymptotic results. We then take 100 draws of the parameter vector from the joint normal asymptotic distribution of the parameters and, for each draw, compute the elasticity, using the resulting distribution across draws to compute Monte Carlo confidence intervals. Note these bands will not necessarily be symmetric around the estimate.
} 


\subsection{Relationship with individual attributes}

A key feature of our model is that it allows us to flexibly relate preference parameters to the characteristics of individual consumers. This enables us to address the question of how effective soda taxes are at targeting the demographic groups whose behavior policymakers would like to change.

Figure 3.2: Preference variation with age

(a) price preferences

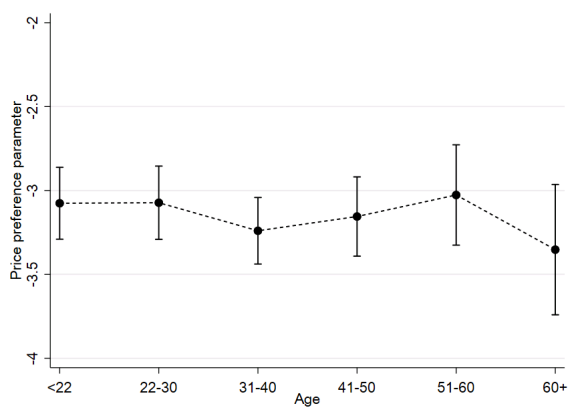

(c) infinite sugar preferences

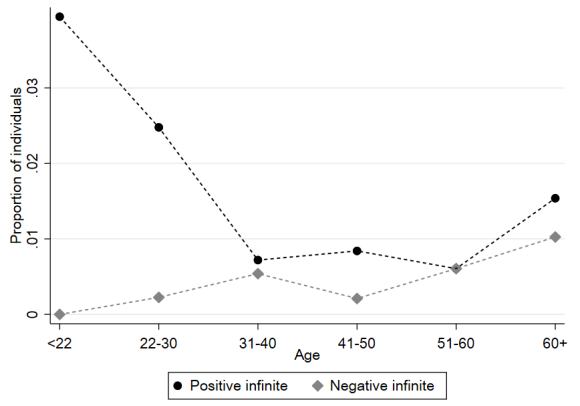

(b) drink preferences

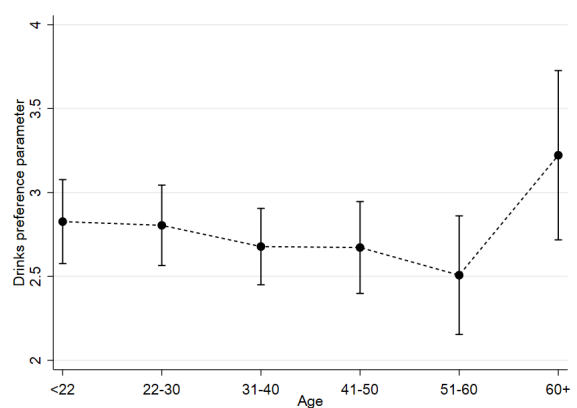

(d) finite sugar preferences

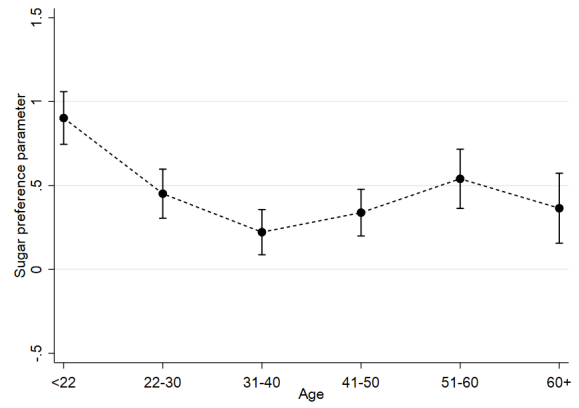

Notes: Figures show how the mean of price preferences, the mean of drinks preferences, the share of consumers with infinite sugar preferences and the mean of finite sugar preferences vary by age groups. 95\% confidence intervals are shown by bars.

In Figure 3.2 we show how features of the preference distribution vary with age. ${ }^{38}$ Panels (a) and (b) show how preferences over price and drinks vary across consumers based on six age bands. There is relatively little variation in the average of these preferences across age groups, with the exception that the oldest group have relatively strong preferences for drinks (indicating, all else equal, a relatively high likelihood that they choose a drink over a snack). However, there is considerable variation in sugar preferences across age. Panel (c) shows how the fraction of consumers with infinitely negative and positive sugar preferences varies with age a higher fraction of individuals aged below 30 have infinitely positive sugar preferences (i.e. are only ever observed buying sugary varieties) than older individuals.

\footnotetext{
${ }^{38}$ The confidence bands in Figures 3.2-4.2 capture both estimation error in individual level parameters and statistical uncertainty associated with the reported mean effects being based on a sample of individuals.
} 
Panel (d) shows that, for those individuals with finite sugar preferences $(98.5 \%$ of the sample), the mean sugar preference for the youngest group of individuals is considerably higher than for those aged 22-30, who in turn tend to have stronger sugar preferences than those aged above 30 .

Figure 3.3: Preference variation with total annual dietary sugar

(a) price preferences

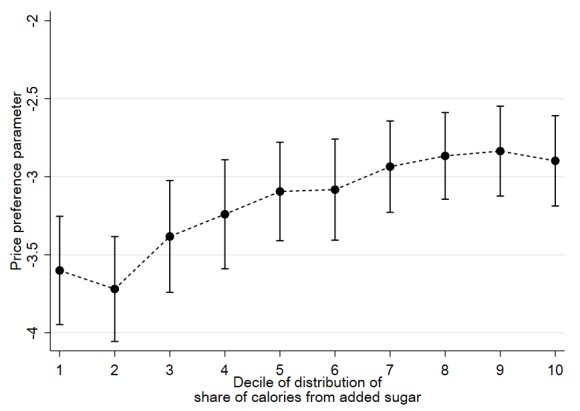

(c) infinite sugar preferences

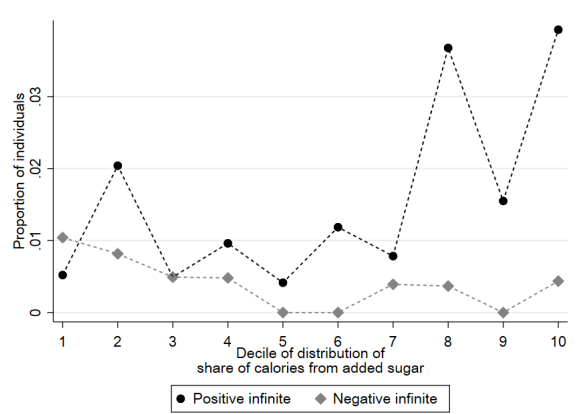

(b) drink preferences

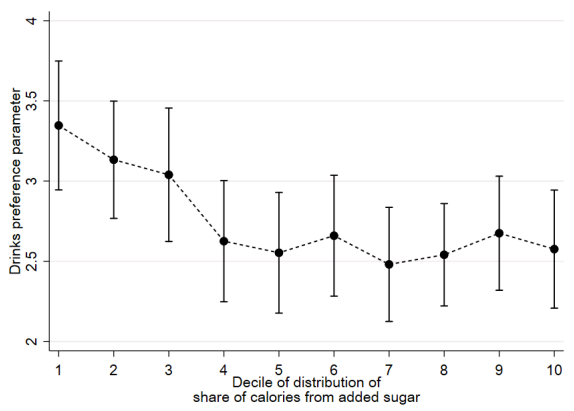

(d) finite sugar preferences

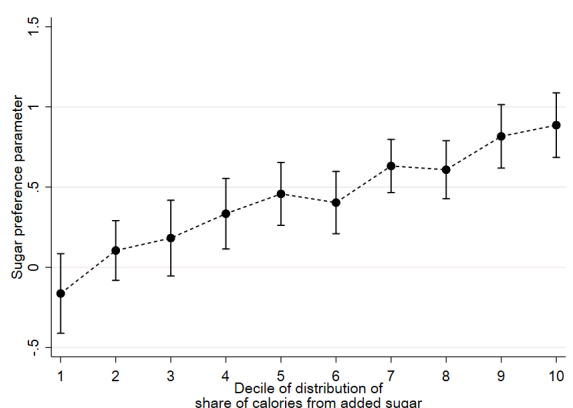

Notes: Figures show how the mean of price preferences, the mean of drinks preferences, the share of consumers with infinite sugar preferences and the mean of finite sugar preferences vary by deciles of the distribution of total annual dietary sugar. $95 \%$ confidence intervals are shown by bars.

Figure 3.3 summarizes variation in preferences across deciles of the distribution of total annual dietary sugar (measured as the share of household total at-home calories from added sugar). Preferences governing on-the-go drinks demand are strongly related to total annual dietary sugar. Individuals in higher deciles of the added sugar distribution are likely to be less price sensitive and are more likely to have strong (or infinite) preferences for sugar than those from lower deciles of the added sugar distribution. The strong association between added sugar decile and sugar preferences is not mechanical - the former is measured based on household level at-home purchases across all groceries, the latter is estimated from individual choice on-the-go among drinks products. Conversely, the drinks preference parameters are higher for those in the bottom three deciles of the added sugar distribution relative to those in higher deciles. 
Figure 3.4 shows that there is also a relationship between preferences and deciles of the distribution of total annual equivalized grocery expenditure (a proxy for income). There is a gradient for price, drink and sugar preference parameters; those from low income households typically have somewhat stronger drink and sugar preferences parameters and are typically more price sensitive than richer individuals.

Figure 3.4: Preference variation with total annual equivalized grocery expenditure

(a) price preferences

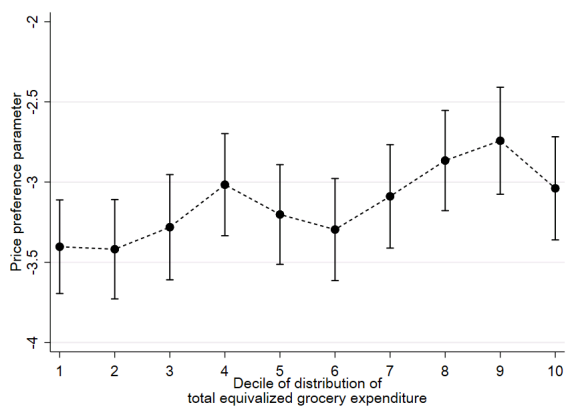

(c) infinite sugar preferences

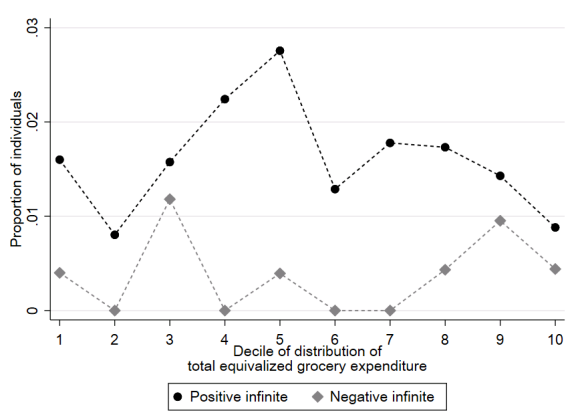

(b) drink preferences

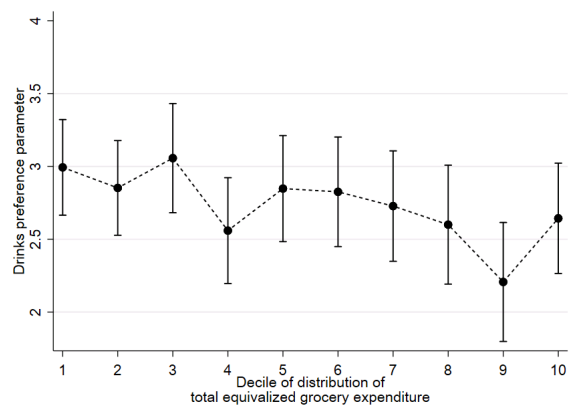

(d) finite sugar preferences

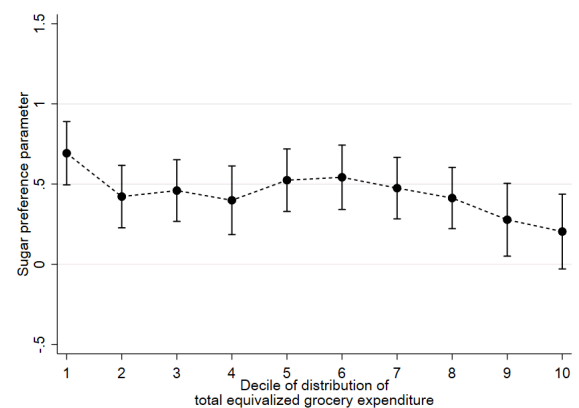

Notes: Figures show how the mean of price preferences, the mean of drinks preferences, the share of consumers with infinite sugar preferences and the mean of finite sugar preferences vary by deciles of the distribution of total annual equivalized grocery expenditure. 95\% confidence intervals are shown by bars.

\section{Effects of a soda tax on sugar intake on-the-go}

We use our demand estimates to simulate the introduction of a tax levied on sugary soft drinks. We consider a tax rate of 25 pence per liter. This is close to the tax rate that has very recently been introduced in the UK, and it corresponds to around 1 cents per ounce - similar to the soda tax rates in place in the US. In our simulation we apply the tax rate to sugar sweetened soft drinks (treating pure fruit juices and 
drinks containing milk as exempt). This tax base corresponds to that in the UK and several of the US taxes. ${ }^{39}$

Concretely, denote the set of sugary soft drinks (i.e. those products the tax applies to) by $\Omega_{w s}$ and let $\pi$ denote the tax rate and $l_{j}$ the volume (in liters) of product $j$. We assume post-tax prices, $\tilde{p}_{j r t}$ are related to pre-tax prices according to:

$$
\tilde{p}_{j r t}= \begin{cases}p_{j r t}+\pi l_{j} & \forall j \in \Omega_{w s} \\ p_{j r t} & \forall j \notin \Omega_{w s} .\end{cases}
$$

We study the impact of the tax on individual on-the-go sugar consumption. In Section 5.2 we provide evidence that variation in responses to price changes across households in the at-home segment are unlikely to undo our conclusions about the targeting of the policy on individuals based on on-the-go demand estimates. Based on the evidence of close to $100 \%$ tax pass-through of soda taxes (discussed in Section 3.3 ) we present our main results assuming $100 \%$ pass-through. In Section 5.3 we show that our findings are robust to simulated pass-through based on an equilibrium oligopoly pricing model.

\subsection{How well targeted is the tax?}

Our tax simulation suggests that consumers that purchase soft drinks will, on average, lower the total amount of sugar they purchase from soft drinks on-the-go by around $245 \mathrm{~g}$ per year; the average percentage reduction is $21 \%$. Some of this reduction is offset by switching to alternative (non-taxed) drinks that contain sugar - the average reduction in sugar from non-alcoholic drinks is $222 \mathrm{~g}$. There is also some substitution away from drinks towards alternative snacks. Our demand model captures switching towards both non-sugary and sugary alternatives. Switching towards sugary snacks is relatively modest - the overall average reduction in sugar on-the-go resulting from the tax is $216 \mathrm{~g}$. The limited degree of switching from drinks to snacks is consistent with experimental evidence that calories from liquids do not displace those from solids (see, for instance, DiMeglio and Mattes (2000), DellaValle et al. (2005) and Flood et al. (2006)). The distribution of reductions in sugar on-the-go is right skewed with the $75^{\text {th }}, 90^{\text {th }}$, and $95^{\text {th }}$ percentiles being $267 \mathrm{~g}$, $539 \mathrm{~g}$ and $806 \mathrm{~g}$.

\footnotetext{
${ }^{39}$ Though not Philadelphia, which also taxes artificially sweetened soft drinks. In an earlier version of this paper, Dubois et al. (2019), we show simulations of a broader tax that also applies to diet soft drinks.
} 
Key to understanding the effectiveness of a soda tax is whether it successfully achieves reductions in sugar amongst the targeted groups of consumers - the young, those in low-income households and those with high total annual dietary sugar. In Figure 4.1 we show how the effects of the tax vary across these characteristics. Panels (a)-(c) show how the mean reduction for soft drink purchasers in sugar from soft drinks, all non-alcoholic drinks and from all sugar purchased on-the-go varies across the distribution of individual age, total annual dietary sugar and total annual equivalized grocery expenditure. ${ }^{40}$ Panels (d)-(e) show how the mean reduction in sugar on-the-go varies jointly with pairs of age, total dietary sugar, and total equivalized expenditure.

Panels (a)-(c) show that the tax on sugary soft drinks achieves relatively large reductions in sugar among the young and those from households with relatively low total equivalized expenditure (our proxy for income), but it is not successful at targeting those individuals with high total dietary sugar (in particular, those in the higher deciles of the distribution).

Young consumers are both more likely to be impacted by the policy and, conditional on this, exhibit bigger level responses than older groups. While the average percent reduction in sugar on-the-go is slightly lower for those aged below $22(14 \%$ vs $15 \%$ across all individuals), this group obtains a relatively large amount of sugar from products targeted by the tax. This means their level reductions are larger. A similar, if less stark, pattern is true across the equivalized expenditure distribution - those in low deciles are more likely to be soft drink purchasers (and therefore impacted by the tax), and conditional on being so exhibit larger level reductions in sugar. ${ }^{41}$ Individuals with high total annual dietary sugar are more likely to be soft drinks purchasers (and therefore be impacted by the policy) than those lower down the dietary sugar distribution. However, conditional on being affected by the policy, their response is smaller on average in level terms (and much smaller in percentage terms - for instance the reduction for the top decile of the dietary sugar distribution is over 4 percentage points below that for the bottom decile).

The difference in responses across the three targeted variables can be understood by the pattern of preference variation. While the young, those with high levels of dietary sugar, and with low equivalized expenditure all have relatively strong sugar

\footnotetext{
${ }^{40}$ Tables 2.5-2.7 show how the fraction of individuals who are soft drink purchasers varies across these dimensions.

${ }^{41}$ Individuals in the bottom half of the equivalized expenditure distribution lower their sugar on-the-go slightly more in percentage terms than those in the top half ( $16 \%$ vs. 14\%). This finding mirrors Allcott et al. (2019a) who find in the US that low income households are slightly more price elastic.
} 
preferences, unlike the other groups those with higher levels of dietary sugar also are relatively price insensitive.

Figure 4.1: Reductions in sugar from drinks
(a) by age
(b) by total annual dietary sugar
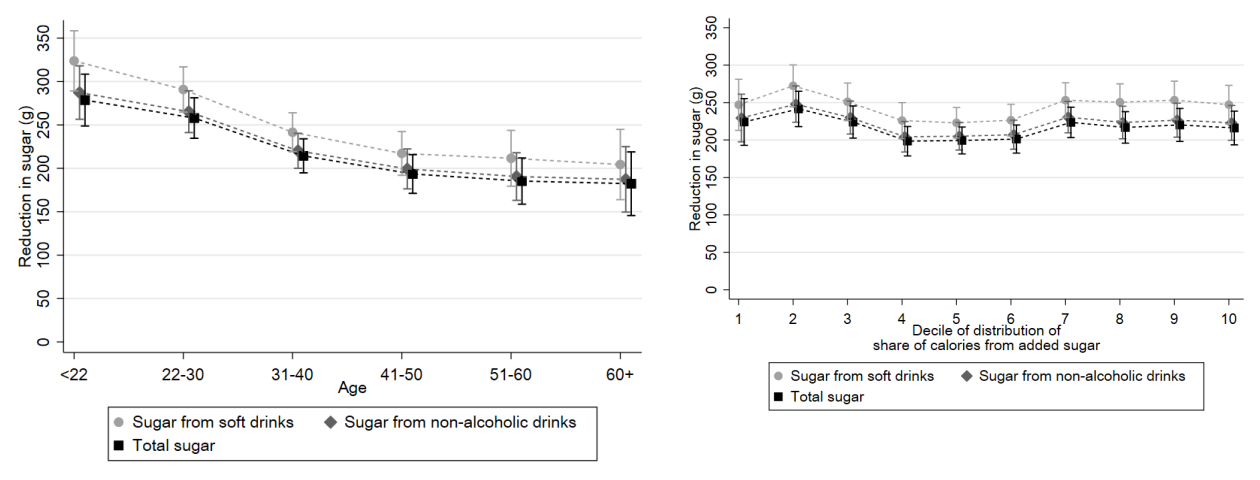

(c) by total annaul equivalized grocery (d) by age and total annual dietary expenditure sugar
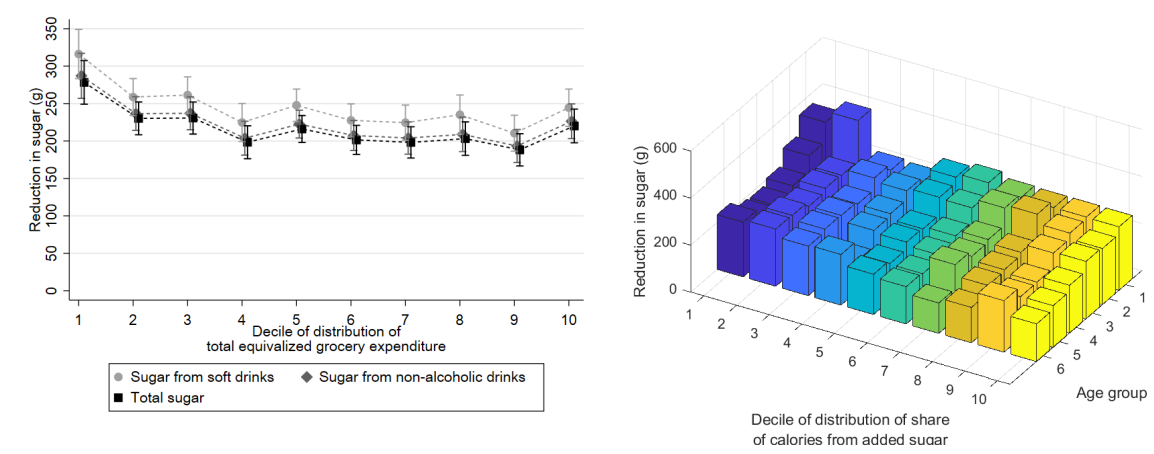

(f) by total annual dietary sugar and (e) by age and total annaul equivalized total annaul equivalized grocery expengrocery expenditure

diture
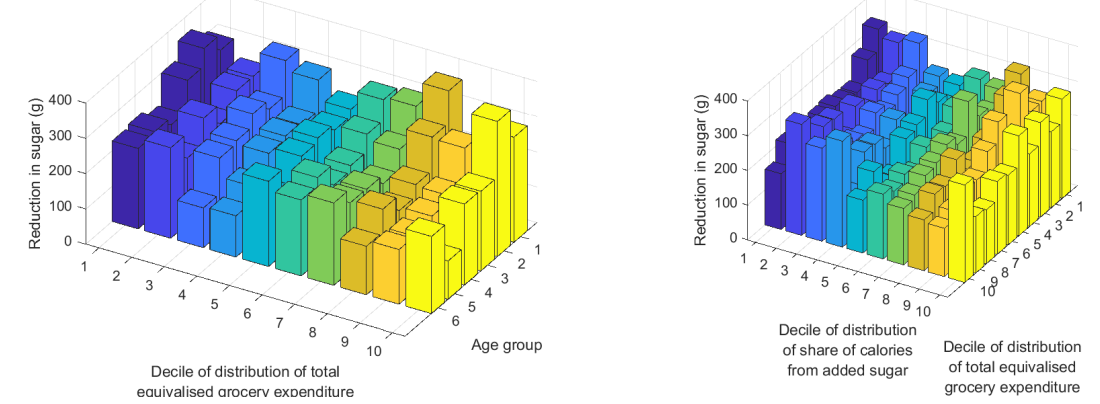

Notes: Figure is based on the 2,449 individuals in the on-the-go estimation sample. It shows how average reduction in annual sugar on-the-go varies across the distributions of individual age, total annual dietary sugar and total annual equivalized grocery expenditure. Panels (a)-(c) show numbers for soft drinks, all non-alcoholic drinks and all on-the-go purchases (95\% confidence bands are shown by bars); panels $(d)-(f)$ show numbers for all on-the-go purchases. In panels $(d)-(f)$ age groups are $1=<22,2=22-30,3=31-40,4=41-50,5=51-60,6=60+$.

A number of things emerge from panels (d)-(f). The pattern of relatively large responses among the young broadly holds across the deciles of both the total dietary sugar and equivalized expenditure distributions. This suggests the tax is relatively 
effective at achieving sugar reductions among young people in low income households. Similarly, those individuals from households in the bottom couple of deciles of the equivalized expenditure distributions exhibit relatively large reductions in sugar across all deciles of the total dietary sugar distribution. Among older people, the smallest reductions in sugar are for individuals in the top half of the total dietary sugar distribution.

\subsection{Consumer welfare and redistribution}

To the extent that a tax raises prices it imposes an economic burden on consumers; with the tax in place consumers can obtain less for a given amount of expenditure than under zero tax. In the case of a tax on sugary soft drinks, consumers that buy sugary soft drinks will incur a welfare loss through this channel. In Figure 4.2 we describe this effect; we use our demand estimates to compute compensating variation - the monetary amount an individual would require to be paid to be indifferent to the imposition of the tax based on their estimated preferences - using the standard Small and Rosen (1981) formula; see Appendix D for details.

Panels (a)-(c) show how compensating variation varies across soft drink purchasers by an individual's age, total annual dietary sugar, and total equivalized expenditure. Panels (d)-(f) show how it varies jointly with pairs of age, total annual dietary sugar, and total equivalized expenditure. Compensating variation is higher for younger individuals, for those with high dietary sugar, and for those from households in the bottom half of the equivalized expenditure distribution. This is mainly driven by these groups obtaining more sugar from soft drinks than other groups. The relatively large compensating variations of the young hold broadly across individuals' positions in the total annual dietary sugar or total annual equivalized grocery expenditure distribution. Panel (f) shows that for high dietary sugar individuals compensating variation is relatively large across the distribution of equivalized expenditure, however, for low dietary sugar individuals the largest compensating variations are among those at the bottom of the equivalized expenditure distribution.

If consumers fully account for all costs associated with their soft drink consumption, then compensating variation would capture the total effects of the tax on consumer welfare and we could conclude that the tax makes all purchasers of sugary soft drinks worse off, with the largest effects being among the young, those with high levels of dietary sugar, and those from relatively poor households. However, if sugary soft drink consumption is associated with future costs that are not taken account of by the individual at the point of consumption, then compensating 
variation based on revealed preference captures only part of the total consumer welfare effect of the tax. ${ }^{42}$

Figure 4.2: Revealed consumer welfare effect
(a) by age
(b) by total annual dietary sugar
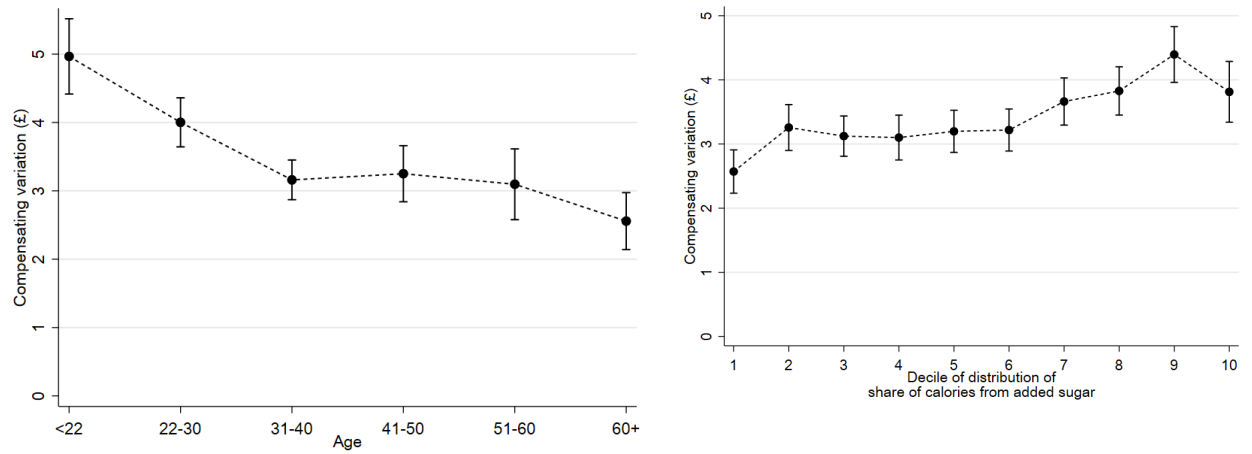

(c) by total annual grocery equivalized (d) by age and total annual dietary expenditure sugar
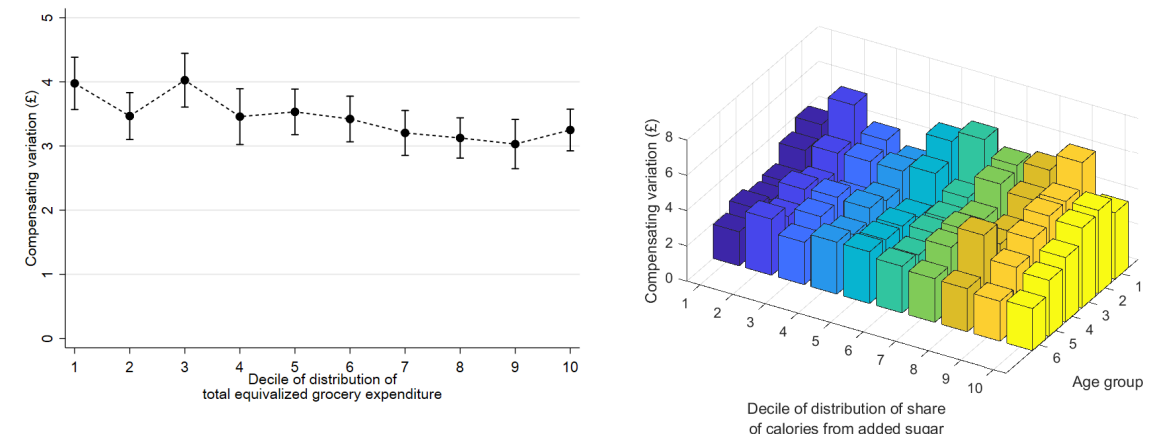

(e) by age and total annual grocery equivalized expenditure

(f) by total dietary sugar and total annual grocery equivalized expenditure
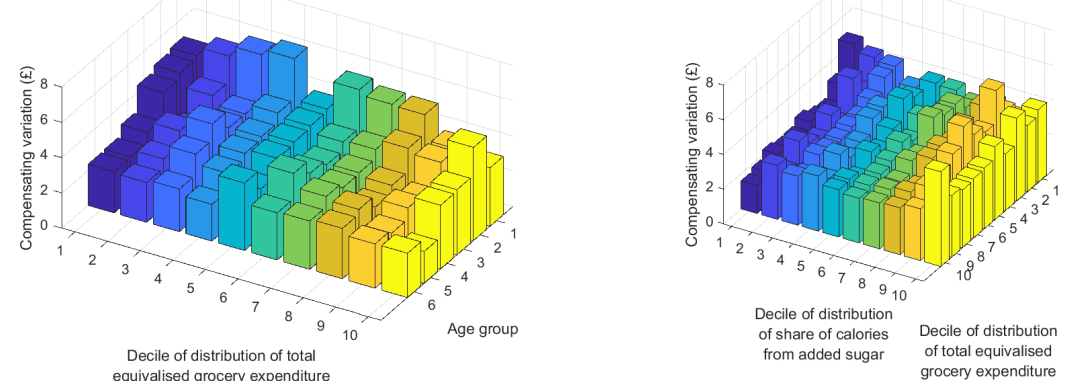

Notes: Figure is based on the 2,449 individuals in the on-the-go estimation sample. It shows how average compensating variation varies across the distributions of individual age, total dietary sugar and total equivalized grocery expenditure. In panels (a)-(c) $95 \%$ confidence bands are shown by bars. In panels $(d)-(f)$ age groups are $1=<22$, $2=22-30,3=31-40,4=41-50,5=51-60,6=60+$

Policymakers have particularly focused on concerns about high consumption amongst children and young adults. The average compensating variation for individuals aged 13-21 who are soft drink purchasers is $£ 4.94$, while the average

\footnotetext{
${ }^{42}$ Plus savings in averted public health externalities, and the use of tax revenue raised from the tax may indirectly impact on consumer welfare.
} 
reduction in sugar for this group is $280 \mathrm{~g}$. If the internality associated with drinking the amount of sugar in a can of Coca Cola is above $£ 0.62$, then for the average person aged 13-21 the soda tax will be welfare improving. If tax revenue, which is $£ 3.14$ per person, is redistributed lump-sum to soft drink purchasers then this threshold would be $£ 0.23$ per can of Coca Cola (or $£ 0.02$ per ounce).

A common concern about excise taxes is that they are regressive. This is typically based on the observation that those with lower incomes tend to be relatively heavy consumers of the taxed products (which, for a small change in price, is a good approximation to compensating variation based on revealed preference). Table 2.7 confirms that, in the case of sugary soft drinks, poorer individuals (those with low total annual equivalized grocery expenditure) are more likely to be soft drink purchasers and to get more sugar from these products; those in the bottom half of the distribution are around $10 \%$ more likely to be soft drink purchasers than those in the top half, and conditional on being one, on average obtain 15\% more sugar from these products. Our demand estimates suggest that compensating variation for a tax on sugary soft drinks is around $19 \%$ higher, on average, for soft drink purchasers in the bottom half of total equivalized grocery expenditure distribution than for those in the top half (see Figure 4.2(c)).

However, if some consumers impose internalities on themselves, then compensating variation measured on the basis of revealed preference provides an incomplete picture of the redistributive effects of the tax (a point made by Gruber and Koszegi (2004) in the case of cigarette taxation). The mean sugar reductions from the tax are somewhat higher on average among those towards the bottom of the equivalized grocery expenditure distribution compared to those further up (for instance, the average reduction in sugar for those in the bottom half of the distribution is $20 \%$ higher than those in the top half). Therefore, if internalities exist and the marginal internality from sugar consumption is constant across the expenditure distribution, the larger reductions in sugar among low spending individuals will act to offset the compensating variation difference. If, at the margin, internalities are larger for poorer individuals (as argued, for instance, by Allcott et al. (2019a)), this will increase the likelihood that overall the tax is progressive. 


\section{Robustness}

\subsection{Bias correction for incidental parameters problem}

In our non-linear model with fixed effects maximum likelihood estimates of the parameters may suffer from an incidental parameters problem (Neyman and Scott (1948)). Even if both $N \rightarrow \infty$ and $T \rightarrow \infty$, if $N$ and $T$ grow at the same rate $\left(\frac{N}{T} \rightarrow\right.$ $\rho$ where $\rho$ is a non zero constant), our fixed effect estimator will be asymptotically biased (Arellano and Hahn (2007)).

A range of bias correction methods exist that reduce the bias from order $1 / T$ to $1 / T^{2}$ (see surveys in Arellano and Hahn (2007), Arellano and Bonhomme (2011)). We use panel jackknife methods (Hahn and Newey (2004)), employing the split sample procedure suggested in Dhaene and Jochmans (2015). This entails obtaining estimates of the model parameters $\theta=(\boldsymbol{\alpha}, \boldsymbol{\beta}, \boldsymbol{\gamma}, \boldsymbol{\eta})$ based on splitting the sample into two non-overlapping random sub-samples. Each sub-sample contains one half of the choice occasions for each individual. We denote the maximum likelihood estimate for the full sample $\widehat{\theta}$ and the estimate for the two subsamples $\widehat{\theta}_{(1, T / 2)}$ and $\widehat{\theta}_{(T / 2, T)}$. The jackknife (bias corrected) estimator is:

$$
\widetilde{\theta}_{\text {split }}=2 \widehat{\theta}-\frac{\widehat{\theta}_{(1, T / 2)}+\widehat{\theta}_{(T / 2, T)}}{2} .
$$

In Figure 5.1 we graph the difference between the jackknife (bias corrected) and maximum likelihood sugar preference parameters for the on-the-go segment. Panel (a) shows the distribution of estimates (for those with finite sugar preferences) for the maximum likelihood and jackknife estimates. Panel (b) shows how the difference in these estimates relates to the number of choice occasions a consumer is observed on in the sample. Panels (c) and (d) show how the difference relates to consumers' age and total dietary sugar.

The difference between the two estimates is small; the standard deviation of the sugar preference parameter estimates is 1.6, while the average absolute difference between the jackknife and maximum likelihood estimates is 0.02 . The difference is decreasing in $T$; individuals in the sample for a relatively small number of choice occasions tend to have higher differences than those in the sample relatively many times. However, conditional on $T$, the average difference between the jackknife and maximum likelihood estimates is zero - a positive difference is equally likely as a negative difference. Indeed, the distribution of the maximum likelihood and jackknife estimates of the preference parameters are almost indistinguishable and the 
difference between the jackknife and maximum likelihood estimates is completely unrelated to individuals' age or total annual dietary sugar.

In Appendix B.1 we show that similar conclusions to those for sugar hold for estimated price and drink preferences; the maximum likelihood and jackknife procedures yield almost identical preference distributions, any individual level differences are relatively small and are equally likely to be positive or negative and there is no systematic relationship with the key demographic variables of interest. For instance, the average absolute difference between the jackknife and maximum likelihood price estimates is 0.05 (relative to a mean price preferences of -3.15). As a consequence, our results regarding the effectiveness of soda taxes are robust to the bias correction procedure.

Figure 5.1: Sugar preference parameters

(a) kernel density

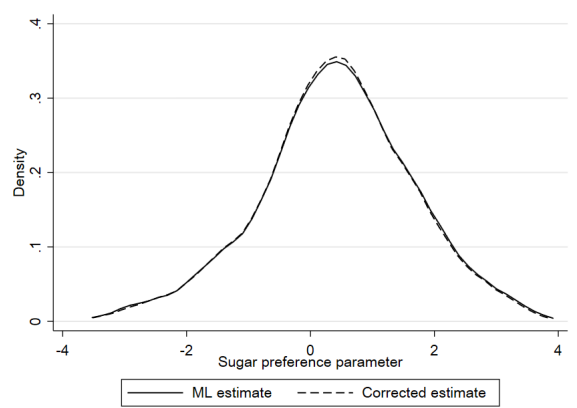

(c) bias by age

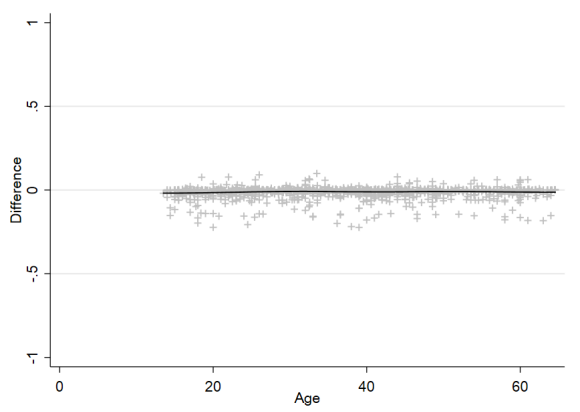

(b) bias by $\mathrm{T}$

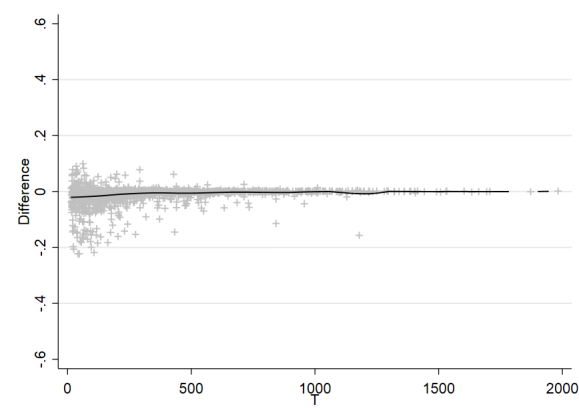

(d) bias by total annaul dietary sugar

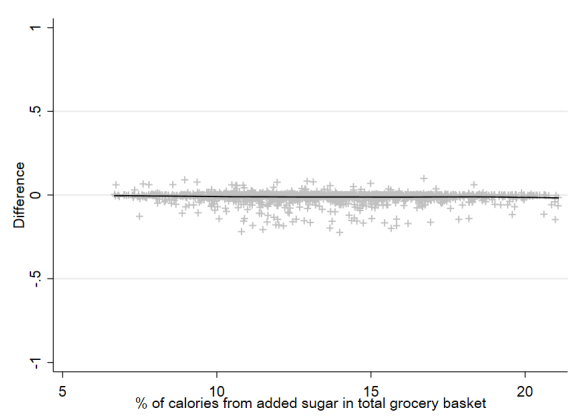

Notes: Graphs are based on preferences estimates in the on-the-go segment. In panels (b)-(d) markers represent consumer level differences. Lines are local polynomial regressions.

\subsection{Effects in the at-home segment}

Our main interest in this paper is the on-the-go segment of the soft drinks market, which has been much less well studied than the at-home segment. To say anything about individual level outcomes with household level at-home data would require 
placing structure on how purchases are shared within the household. Our use of on-the-go data enables us to avoid this.

A possible issue is that our conclusion that soda taxes are well targeted at young people could be unwound by at-home demand responses. To assess this possibility we estimate a model of demand in the at-home segment, which we specify similarly to our on-the-go demand model. We provide details in Appendix C.2. We assume consumers solve a static problem, controlling for at-home inventories, which allow for non-separabilities over time in purchasing that arise through the storable nature of drinks (allowing, for instance, for the possibility that a household that has recently bought drinks is, as a consequence of the recent purchase, less likely to buy them on the next choice occasion). Hendel and Nevo (2006b) and Wang (2015) provide evidence that in the US soft drinks market consumers behave in a forwardlooking way, intertemporally switching the timing of purchases when buying on sale. Hendel and Nevo (2006a) show that this behavior can bias static demand estimates. This is a threat to our at-home demand estimates (and underlines an advantage of studying on-the-go demand). ${ }^{43}$ In our at-home demand model we also treat retailer choice as exogenous, assuming it is not driven by demand shocks for drinks.

Figure 5.2: Reductions in sugar from drinks in on-the-go and at-home segments

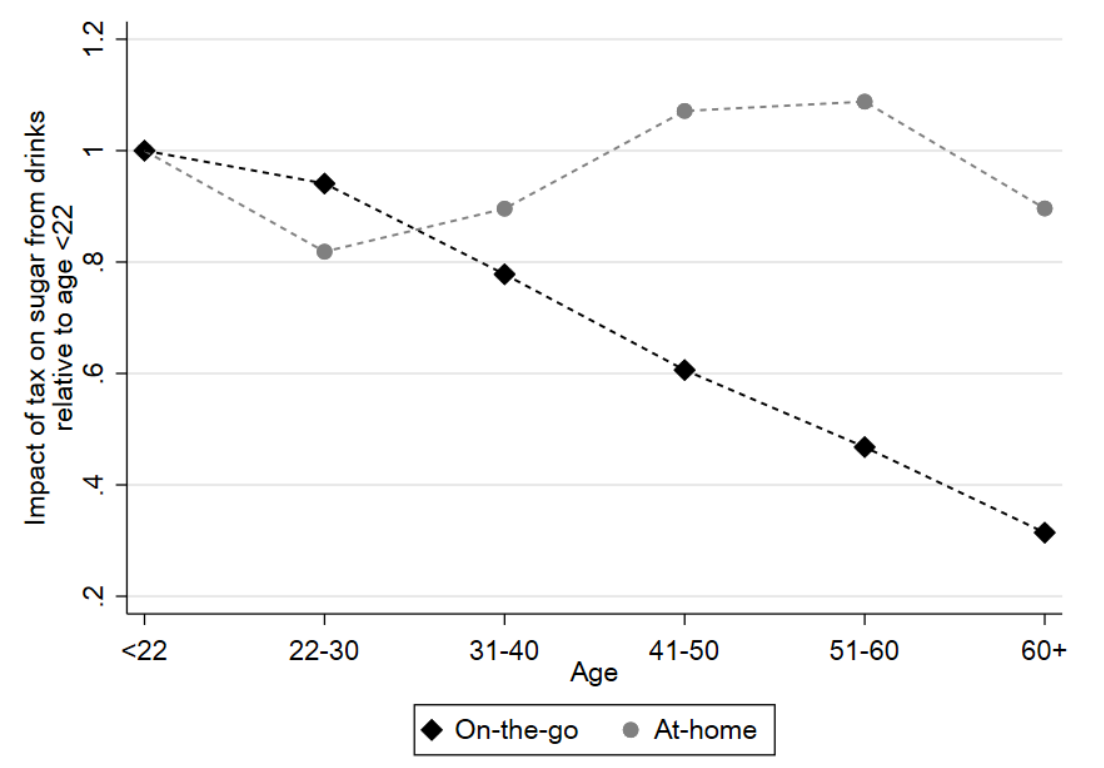

Notes: Figure is based on the 5,550 individuals in the full on-the-go sample, and data on the households to which they belong in the at-home data. It shows the reduction in sugar from drinks achieved by the tax by age groups in both on-the-go and at-home segments. Numbers are expressed relative to the average reduction for those aged younger than 22.

\footnotetext{
${ }^{43}$ Note, O'Connell and Smith (2019) present evidence that in the UK households tend to respond to sales by switching across brands, pack types and sizes, and, on average, there is little evidence in changes in the timing of purchases. This suggests any biases from ignoring forwardlooking dynamics are likely to be much smaller in the UK drinks market compared to the US context.
} 
We use these estimates to simulate the impact of the soda tax on individual level demands in the at-home segment assuming a naive within household sharing rule based on the OECD equivalence scale. In Figure 5.2 we report the reduction in sugar from drinks achieved by the tax for each age group relative to those aged younger than 22. Numbers reported in this graph are for the full sample of on-thego individuals (i.e. including soft drink purchasers and non-soft drink purchasers). The black line shows the on-the-go relationship. It is strongly decreasing across age groups reflecting that a) older individuals are less likely to be on-the-go soft drinks purchasers (see Table 2.5) and b) conditional on being soft drink purchasers, the tax lowers their sugar from on-the-go drinks by less that it does for younger individuals (see Figure 4.1(a)). The grey line shows the relationship based on at-home demands. There is no obvious patterns with age - the households that the young individuals in our on-the-go sample belong to, on average, respond approximately as strongly than those older individuals belong to. This suggests at-home demand responses are not likely to unwind (nor reinforce) our conclusion about the effective targeting of soda taxes at young individuals.

\subsection{Supply}

The results in Section 4 are based on the assumption that the prices of taxed products increase one-for-one with the tax (100\% pass-through) and the prices of substitute goods remain unchanged. We provide evidence in Section 3.3 that this is the central estimate in the literature and is what seems to have happened after the recent introduction of a soda tax in the UK. In this section we report results based on an equilibrium model of tax pass-through. We model the supply side of the market in the standard way (see Berry et al. (1995), Nevo (2001)), assuming drinks firms compete in each market in a Nash-Bertrand pricing game. ${ }^{44}$

A product that is available for purchase for on-the-go and at-home consumption has a market demand curve that depends on preferences in both segments. Therefore in computing equilibrium tax pass-through it may be important to account for the supply linkage through the influence of on-the-go and at-home preferences on market demand curves and hence firm pricing. We use our on-the-go and athome demand estimates to derive market level demand curves. We can estimate

\footnotetext{
${ }^{44}$ We define markets by retailer-year. The retailers include the main supermarkets, Asda, Morrisons, Sainsbury's and Tesco as well discounters, other national stores and convenience stores, in the north, midlands and south. We assume drinks firms set final consumer prices. This is consistent with efficient contracting between drinks firms and retailers and can be sustained by side payments between retailers and drinks firms (see Villas-boas (2007), Bonnet and Dubois $(2010)$ ).
} 
product level marginal costs using these demand estimates and assuming prices are the equilibrium outcome of the Nash-Bertrand game. Using the demand and supply model we can simulate the impact of the soda tax on equilibrium prices. We provide details in Appendix E.

In the top panel of Table 5.1 we report simulated price increases across all products subject to the tax and across small variants $(288-330 \mathrm{ml})$ and large variants (500ml) separately. This is the structural model analogue to the descriptive evidence in Table 3.1. The demand and supply model predicts average pass-through of $116 \%$ (given by $0.29 / 0.25$ ). It also predicts pass-through that is higher for $500 \mathrm{ml}$ bottles (124\%) than for smaller sizes (104\%). For large sizes demand is less elastic, and in response to the tax, it is optimal for firms to pass-through more of the price increase to these products, with the resulting increase in profits from intra-marginal consumers off-setting the profit reduction associated with consumers switching away from these products. This pattern of differential pass-through accords with the descriptive evidence in Table 3.1. In the bottom panel of Table 5.1 we report the average price changes for drinks not subject to the tax; in equilibrium firms marginally lower the price of substitute drinks.

Table 5.1: Price changes under equilibrium pass-through

\begin{tabular}{|c|c|c|c|}
\hline & All & $330 \mathrm{ml}$ & $500 \mathrm{ml}$ \\
\hline \multicolumn{4}{|l|}{ Sugar sweetened drinks } \\
\hline No. products & 20 & 9 & 11 \\
\hline Pre-tax price & 2.07 & 1.96 & 2.16 \\
\hline Price rise & 0.29 & 0.26 & 0.31 \\
\hline $\operatorname{Tax}$ & 0.25 & 0.25 & 0.25 \\
\hline \multicolumn{4}{|l|}{ Alternative drinks } \\
\hline No. products & 16 & 4 & 12 \\
\hline Pre-tax price & 2.11 & 2.13 & 2.10 \\
\hline Price rise & -0.02 & -0.02 & -0.02 \\
\hline $\operatorname{Tax}$ & 0.00 & 0.00 & 0.00 \\
\hline
\end{tabular}

Notes: We simulate the equilibrium pricing response to the soda tax based on a Nash-Bertrand pricing game. The top panel reports the impact for products subject to the tax. The bottom panel reports the impact for drinks products exempt from the tax.

In Figure 5.3 we show how the total reduction in sugar on-the-go due to the tax varies with age, total dietary sugar and equivalized grocery expenditure under $100 \%$ tax pass-through (repeating information in Figure 4.1) and under equilibrium tax pass-through based on our demand and supply model. The figure makes clear that the patterns of price changes across these key targeted demographics is the same 
under the alternative pass-through assumptions. The only difference is a constant level shift; the fact that the equilibrium model predicts that firms' optimal response amplifies the price differential between sugary and alternative drinks created by the tax results in somewhat higher reductions in sugar relative to under $100 \%$ passthrough.

Figure 5.3: Reductions in sugar from drinks under 100\% and equilibrium passthrough

(a) by age

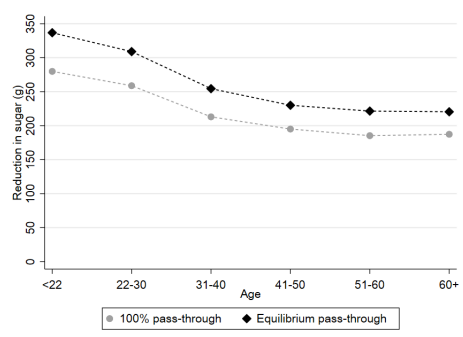

(b) by total annual dietary sugar

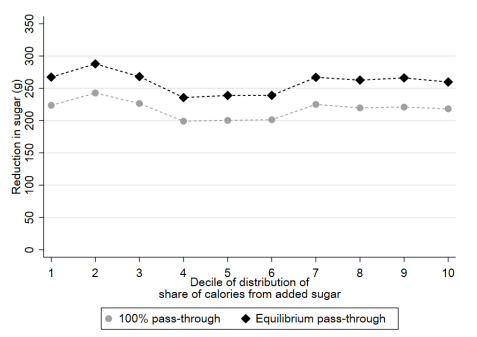

(c) by total annaul equivalized grocery expenditure

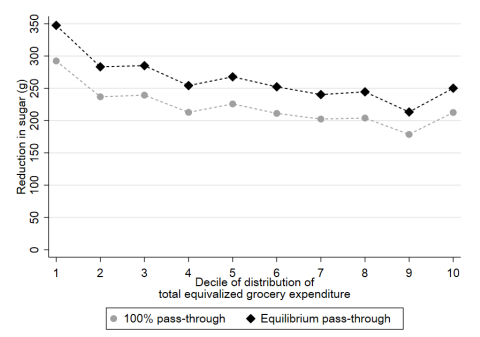

Notes: Figure shows how the average reduction in annual sugar on-the-go varies across the distributions of individual age, total dietary sugar and total equivalized grocery expenditure under $100 \%$ and equilibrium tax pass-through.

\section{Summary and conclusion}

Excise taxes have traditionally been applied to alcohol, tobacco and gambling, in part to tackle socially costly consumption. Recently there has been a drive to extend them to cover some of foods and drinks, with soda taxes being at the vanguard of this move. In the case of sugar, there is clear evidence that most individuals exceed official recommendations on how much to consume (Griffith et al. (2020)). Policymakers have targeted young people, individuals with high total dietary sugar and low income people. We evaluate how well targeted a soda tax on those groups whose behavior policymakers wish to change.

We provide an analysis based on individual level choice behavior while on-the-go; to our knowledge we are the first to study this segment of the market. Our results show that young consumers would lower their sugar consumption by more than older individuals in response to a soda tax. The tax does therefore succeed in achieving relatively large reductions in sugar among one targeted group. However, the young also loose out most in terms of direct consumer surplus loss due to higher prices. If young people's soft drinks consumption give rise to future costs that the partially ignore at the point on intake, then gains from averted internalities may outweigh this loss in consumer surplus. The performance of the tax in terms of reducing the 
on-the-go sugar intake of those with the most sugary diets is less good. Those with high total dietary sugar are relatively price inelastic and so respond less to the tax, so their sugar consumption falls by less than more moderate sugar consumers. If internalities are important, the redistributive properties of the tax are likely to be more attractive than suggested by an analysis based purely on traditional economic tax incidence. The traditional economic burden of the tax falls, to a moderate extent, disproportionately on low income households, but the poor also lower their sugar consumption to a somewhat larger extent and therefore if they benefit from averted internalities this could outweigh the loss of consumer surplus.

We provide evidence of the pricing responses of soft drinks manufacturers to the tax. However, firms may respond by adjusting other elements of their strategies. For instance, they may change the extent and focus of their advertising and they may introduce new products that are outside the scope of the tax. Our results therefore provide a picture to the short-medium run impact of soda taxes. An important direction for future work will be to incorporate these elements of firm response into analysis of these forms of tax. 


\section{References}

Adams, A., L. Cherchye, B. De Rock, and E. Verriest (2014). Consume now or later? Time inconsistency, collective choice, and revealed preference. American Economic Review 104(12), 4027-4070.

Aguiar, M. and E. Hurst (2007). Life-Cycle Prices and Production. American Economic Review 97(5), 1533-1559.

Aguilar, A., E. Gutierrez, and E. Seira (2018). The Effectiveness of Sin Food Taxes: Evidence from Mexico. LACEA working paper series No. 0010, 41.

Allcott, H., B. B. Lockwood, and D. Taubinsky (2019a). Regressive Sin Taxes, with an Application to the Optimal Soda Tax. Quarterly Journal of Economics 134(3), $1557-1626$.

Allcott, H., B. B. Lockwood, and D. Taubinsky (2019b). Should we tax soda? an overview of theory and evidence. Journal of Economic Perspectives 33(2).

Allcott, H., S. Mullainathan, and D. Taubinsky (2014). Energy policy with externalities and internalities. Journal of Public Economics 112, 72-88.

Ameriks, J., A. Caplin, J. Leahy, and T. Tyler (2007). Measuring Self-Control Problems. American Economic Review 97(3).

Arellano, M. and S. Bonhomme (2011). Nonlinear Panel Data Analysis. Annual Review of Economics 3(1), 395-424.

Arellano, M. and J. Hahn (2007). Understanding bias in nonlinear panel models: Some recent developments. In Econometric Society Monographs, Volume 43, pp. 381.

Azaïs-Braesco, V., D. Sluik, M. Maillot, F. Kok, and L. A. Moreno (2017). A review of total \& added sugar intakes and dietary sources in Europe. Nutrition Journal 16, 6 .

Bajari, P. and C. L. Benkard (2005). Demand Estimation with Heterogeneous Consumers and Unobserved Product Characteristics: A Hedonic Approach. Journal of Political Economy 113(6), 1239-1276.

Bajari, P., J. T. Fox, and S. P. Ryan (2007). Linear regression estimation of discrete choice models with nonparametric distributions of random coefficients. American Economic Review 97(2), 459-463.

Baum, C. L. and C. J. Ruhm (2009). Age, socioeconomic status and obesity growth. Journal of Health Economics 28(3), 635-648.

Berardi, N., P. Sevestre, M. Tépaut, and A. Vigneron (2016). The impact of a 'soda tax' on prices: Evidence from French micro data. Applied Economics 48(41), 3976-3994. 
Berkson, J. (1950). Are There Two Regressions? Journal of the American Statistical Association 45(250), 164-180.

Berry, S., J. Levinsohn, and A. Pakes (1995). Automobile Prices in Market Equilibrium. Econometrica 63(4), 841-890.

Berry, S., J. Levinsohn, and A. Pakes (2004). Differentiated products demand systems from combination of micro and macro data: The new car market. Journal of Political Economy 112(1), 68-105.

Berry, S. T. (1994). Estimating Discrete-Choice Models of Product Differentiation. RAND Journal of Economics 25, 242-262.

Besley, T. J. and H. S. Rosen (1999). Sales Taxes and Prices: An Empirical Analysis. National Tax Journal 52(2), 157-78.

Blundell, R., J. Horowtiz, and M. Parey (2019). Estimation of a nonseparable heterogenous demand function with shape restrictions and Berkson errors. CWP67/18.

Bollinger, B. K. and S. Sexton (2018). Local Excise Taxes, Sticky Prices, and Spillovers: Evidence from Berkeley's Soda Tax. SSRN Electronic Journal.

Bonnet, C. and P. Dubois (2010). Inference on vertical contracts between manufacturers and retailers allowing for nonlinear pricing and resale price maintenance. RAND Journal of Economics 41(1), 139-164.

Bonnet, C. and V. Réquillart (2013). Tax incidence with strategic firms in the soft drink market. Journal of Public Economics 106, 77-88.

Browning, M. and C. Meghir (1991). The Effects of Male and Female Labor Supply on Commodity Demands. Econometrica 59(4), 925-951.

Burda, M., M. Harding, and J. Hausman (2008). A Bayesian mixed logit-probit model for multinomial choice. Journal of Econometrics 147(2), 232-246.

Capacci, S., O. Allais, C. Bonnet, and M. Mazzocchi (2019). The impact of the French soda tax on prices and purchases: An ex post evaluation. Plos ONE $14(10), \mathrm{e} 0223196$.

Castello, J. V. and G. Lopez-Casasnovas (2018). Impact of SSB taxes on consumption. CRES-UPF Working Paper no. 201804-110 Universitat Pompeu Fabra, https://www.upf.edu/documents/3223410/7582912/CRESWP201804110.pdf/c888c03c06e $2-7 \mathrm{c} 2 \mathrm{~b}-415 \mathrm{f}-\mathrm{accae} 486 \mathrm{a} 9 \mathrm{c} 7$.

Cavadini, C., A. M. Siega-Riz, and B. M. Popkin (2000). US adolescent food intake trends from 1965 to 1996. Archives of Disease in Childhood 83(1), 18-24.

Cawley, J. (2010). The economics of childhood obesity. Health Affairs 29(3), 364371. 
Cawley, J., C. Crain, D. Frisvold, and D. Jones (2018). The Pass-Through of the Largest Tax on Sugar-Sweetened Beverages: The Case of Boulder, Colorado. NBER Working Paper 25050.

Cawley, J., D. Frisvold, A. Hill, and D. Jones (2018). The Impact of the Philadelphia Beverage Tax on Prices and Product Availability. NBER Working Paper 24990.

Cawley, J. and D. E. Frisvold (2017). The Pass-Through of Taxes on SugarSweetened Beverages to Retail Prices: The Case of Berkeley, California. Journal of Policy Analysis and Management 36(2), 303-326.

Cawley, J., B. Willage, and D. Frisvold (2018). Pass-Through of a Tax on SugarSweetened Beverages at the Philadelphia International Airport. Journal of the American Medical Association 319(3), 305-306.

CDC (2016, September). Cut Back on Sugary Drinks. http://www.cdc.gov/nutrition/data-statistics/sugar-sweetened-beveragesintake.html.

Chernozhukov, V., J. Hausman, and W. Newey (2019). Demand analysis with many prices. NBER Working Paper 02138.

Colantuoni, F. and C. Rojas (2015). The impact of soda sales taxes on consumption: Evidence from scanner data. Contemporary Economic Policy 33(4).

Colchero, M. A., J. C. Salgado, M. Unar-Munguía, M. Molina, S. Ng, and J. A. Rivera-Dommarco (2015). Changes in Prices After an Excise Tax to Sweetened Sugar Beverages Was Implemented in Mexico: Evidence from Urban Areas. PLOS ONE 10(12), e0144408.

Competition Commission (2000). Supermarkets Inquiry. Technical report.

Currie, J. (2009). Healthy, Wealthy, and Wise: Socioeconomic Status, Poor Health in Childhood, and Human Capital Development. Journal of Economic Literature $47(1), 87-122$.

Currie, J., S. DellaVigna, E. Moretti, and V. Pathania (2010, August). The Effect of Fast Food Restaurants on Obesity and Weight Gain. American Economic Journal: Economic Policy 2(3), 32-63.

Cutler, D., E. Glaeser, and J. Shapiro (2003). Why Have Americans Become More Obese? Journal of Economic Perspectives 17(3), 93-118.

Delipalla, S. and O. O'Donnell (2001). Estimating tax incidence, market power and market conduct: The European cigarette industry. International Journal of Industrial Organization 19(6), 885-908.

DellaValle, D. M., L. S. Roe, and B. J. Rolls (2005). Does the consumption of caloric and non-caloric beverages with a meal affect energy intake? Appetite 44(2), 187193. 
Dhaene, G. and K. Jochmans (2015). Split-panel Jackknife Estimation of Fixedeffect Models. Review of Economic Studies 82(3), 991-1030.

DiMeglio, D. P. and R. D. Mattes (2000). Liquid versus solid carbohydrate: Effects on food intake and body weight. International journal of obesity 24(6), 794.

Dubois, P., R. Griffith, and A. Nevo (2014). Do Prices and Attributes Explain International Differences in Food Purchases? American Economic Review 104(3), $832-867$.

Dubois, P., R. Griffith, and M. O'Connell (2018). The Effects of Banning Advertising in Junk Food Markets. Review of Economic Studies 1(1), 396-436.

Dubois, P., R. Griffith, and M. O'Connell (2019, January). How well targeted are soda taxes? CEPR DP 12484.

Etilé, F., S. Lecocq, and C. Boizot-Szantai (2018). The Incidence of Soft-Drink Taxes on Consumer Prices and Welfare: Evidence from the French "Soda Tax". PSE Working Paper, 50.

Fabra, N. and M. Reguant (2014). Pass-Through of Emissions Costs in Electricity Markets. American Economic Review 104(9), 2872-2899.

Falbe, J., N. Rojas, A. H. Grummon, and K. A. Madsen (2015). Higher Retail Prices of Sugar-Sweetened Beverages 3 Months After Implementation of an Excise Tax in Berkeley, California. American Journal of Public Health 105(11), 2194-2201.

Flood, J. E., L. S. Roe, and B. J. Rolls (2006). The Effect of Increased Beverage Portion Size on Energy Intake at a Meal. Journal of the American Dietetic Association 106(12), 1984-1990.

Gilbert, D. T., M. J. Gill, and T. D. Wilson (2002). The Future Is Now: Temporal Correction in Affective Forecasting. Organizational Behavior and Human Decision Processes 88(1), 430-444.

Global Food Research Program (GFRP) (2019). Sugary Drink Taxes around the World. http://globalfoodresearchprogram.web.unc.edu/multicountry-initiative/resources/.

Goldberg, P. K. and R. Hellerstein (2013). A structural approach to identifying the sources of local currency price stability. Review of Economic Studies 80(1), $175-210$.

Goncalves, J. and P. dos Santos (2019). Brown Sugar, how come you taste so good? The impact of a Soda Tax on prices and consumption. GEE (Office for Strategy and Studies of the Ministry of Economy) Paper 124, 26.

Gortmaker, S. L., M. W. Long, and Y. Wang (2009). The negative impact of sugar-sweetened beverages on children's health. A Research Synthesis. 
Griffith, R., M. O'Connell, K. Smith, and R. Stroud (2019). The evidence on the effects of soft drink taxes. IFS Briefing Note, IFS, London.

Griffith, R., M. O'Connell, K. Smith, and R. Stroud (2020). What's on the menu? Policies to reduce young people's sugar consumption. Fiscal Studies 1.

Gruber, J. and B. Koszegi (2004). Tax incidence when individuals are timeinconsistent: The case of cigarette excise taxes. Journal of Public Economics 88(9-10), 1959-1987.

Haavio, M. and K. Kotakorpi (2011). The political economy of sin taxes. European Economic Review 55(4), 575-594.

Hahn, J. and W. Newey (2004). Jackknife and analytical bias reduction for nonlinear panel models. Econometrica 72(4), 1295-1319.

Hall, K. D., G. Sacks, D. Chandramohan, C. C. Chow, Y. C. Wang, S. L. Gortmaker, and B. A. Swinburn (2011). Quantification of the effect of energy imbalance on bodyweight. The Lancet 378(9793), 826-837.

Han, E. and L. M. Powell (2013). Consumption patterns of sugar sweetened beverages in the United States. Journal of the Academy of Nutrition and Dietetics 113(1), 43-53.

Harding, M. and M. Lovenheim (2017). The effect of prices on nutrition: Comparing the impact of product- and nutrient-specific taxes. Journal of Health Economics 53, 53-71.

Haushofer, J. and E. Fehr (2014). On the psychology of poverty. Science 344(6186), $862-867$.

Hendel, I. and A. Nevo (2006a). Measuring the implications of sales and consumer inventory behavior. Econometrica 74 (6), 1637-1673.

Hendel, I. and A. Nevo (2006b). Sales and Consumer Inventory. RAND Journal of Economics 37(3), 543-561.

Kaplan, G. and G. Menzio (2015). The morphology of price dispersion. International Economic Review 56(4), 1165-1206.

Kenkel, D. S. (2005). Are alcohol tax hikes fully passed through to prices? Evidence from Alaska. American Economic Review: Papers $\&$ Proceedings 95 (2).

Lewbel, A. and K. Pendakur (2017). Unobserved Preference Heterogeneity in Demand Using Generalized Random Coefficients. Journal of Political Economy $125(4)$.

Mani, A., S. Mullainathan, E. Shafir, and J. Zhao (2013). Poverty Impedes Cognitive Function. Science 341(6149), 976-980. 
Mennella, J. A., N. K. Bobowski, and D. R. Reed (2016). The development of sweet taste: From biology to hedonics. Reviews in Endocrine and Metabolic Disorders 17(2), 171-178.

Nakamura, E. and D. Zerom (2010). Accounting for Incomplete Pass-Through. Review of Economic Studies 77(3), 1192-1230.

Nevo, A. (2001). Measuring market power in the ready-to-eat cereal industry. Econometrica 69(2), 307-342.

Nevo, A. and C. Wolfram (2002). Why Do Manufacturers Issue Coupons? An Empirical Analysis of Breakfast Cereals. The RAND Journal of Economics 33(2), 319-339.

Neyman, J. and E. L. Scott (1948). Consistent Estimates Based on Partially Consistent Observations. Econometrica 16(1), 1.

Ng, S. W., C. Ni Mhurchu, S. A. Jebb, and B. M. Popkin (2012). Patterns and trends of beverage consumption among children and adults in Great Britain, 1986-2009. British Journal of Nutrition 108(03), 536-551.

Nielsen, S. J. and B. M. Popkin (2004). Changes in beverage intake between 1977 and 2001. American Journal of Preventive Medicine 27(3), 205-210.

O'Connell, M. and K. Smith (2019). Corrective tax design in oligopoly. mimeo https://martinoconnell85.github.io/Mywebsite/CorrectiveTaxDesigninOligopoly.pdf.

O'Donoghue, T. and M. Rabin (2006). Optimal sin taxes. Journal of Public Economics 90(10-11), 1825-1849.

Poterba, J. M. (1989). Lifetime Incidence and the Distributional Burden of Excise Taxes. American Economic Review 79(2), 325-330.

Powell, L. M., J. Leider, and P. T. Léger (2020, February). The Impact of a Sweetened Beverage Tax on Beverage Volume Sold in Cook County, Illinois, and Its Border Area. Annals of Internal Medicine.

Public Health England (2015). Sugar Reduction: The Evidence for Action.

Public Health England (2018, March). National Diet and Nutrition Survey (NDNS). https://www.gov.uk/government/collections/national-diet-and-nutrition-survey.

Rabin, M. (1998). Psychology and Economics. Journal of Economic Literature 36(1), 11-46.

Read, D. and B. Van Leeuwen (1998). Predicting hunger: The effects of appetite and delay on choice. Organizational behavior and human decision processes 76 (2), 189-205.

Rojas, C. and E. Y. Wang (2017). Do Taxes for Soda and Sugary Drinks Work? Scanner Data Evidence from Berkeley and Washington. SSRN Electronic Journal. 
Rugg-Gunn, A. J., E. S. Fletcher, J. N. S. Matthews, A. F. Hackett, P. J. Moynihan, S. Kelly, J. Adams, J. C. Mathers, and A. Adamson (2007). Changes in consumption of sugars by English adolescents over 20 years. Public Health Nutrition 10(4), 354-63.

Schennach, S. (2013). Regressions with Berkson errors in covariates - A nonparametric approach. The Annals of Statistics 41, 1642-1668.

Scientific Advisory Committee on Nutrition (2015). SACN Carbohydrates and Health Report. https://www.gov.uk/government/publications/sacncarbohydrates-and-health-report.

Seiler, S., A. Tuchman, and S. Yao (2018). The impact of soda taxes: Pass-through, tax avoidance, and nutritional effects. SSRN Electronic Journal http://dx.doi.org/10.2139/ssrn.3302335.

Silver, L. D., S. W. Ng, S. Ryan-Ibarra, L. S. Taillie, M. Induni, D. R. Miles, J. M. Poti, and B. M. Popkin (2017). Changes in prices, sales, consumer spending, and beverage consumption one year after a tax on sugar-sweetened beverages in Berkeley, California, US: A before-and-after study. PLOS Medicine 14(4), e1002283.

Small, K. A. and H. S. Rosen (1981). Applied Welfare Economics with Discrete Choice Models. Econometrica 49(1), 105-130.

Train, K. E. (2008). EM algorithms for nonparametric estimation of mixing distributions. Journal of Choice Modelling 1(1), 40-69.

Villas-boas, S. B. (2007). Vertical Relationships between Manufacturers and Retailers: Inference with Limited Data. Review of Economic Studies 74 (2), 625-652.

Wang, E. Y. (2015). The impact of soda taxes on consumer welfare: Implications of storability and taste heterogeneity. The RAND Journal of Economics 46(2), 409-441.

WHO (2015). Sugars intake for adults and children. 


\title{
ONLINE APPENDiX
}

\section{How well targeted are soda taxes?}

\author{
Pierre Dubois, Rachel Griffith and Martin O'Connell
}

\section{A Data appendix}

\section{A.1 Patterns of sugar consumption}

In this appendix we use data from the National Diet and Nutrition Survey 20082011, which is an intake study of a representative sample of 3,073 UK adults and children. In Figure A.1 we document widespread excess consumption of added sugar. Panel (a) shows the cumulative distribution of calories from added sugar per day (separately for females and males) and panel (b) shows the cumulative distribution of the share of calories from added sugar. In both graphs we denote recommended medical levels with vertical lines. In the case of the level of calories from added sugar, the American Heart Association recommends no more than 100 calories per day from added sugar for females, and no more than 150 for males. In the case of the share of calories from added sugar, the World Health Organization recommends that ideally fewer than $5 \%$ of calories should be obtained from added sugar. The figure makes clear that the majority of individuals exceed these targets by a considerable amount.

Figure A.1: Cumulative density of calories from added sugar

(a) Calories from added sugar

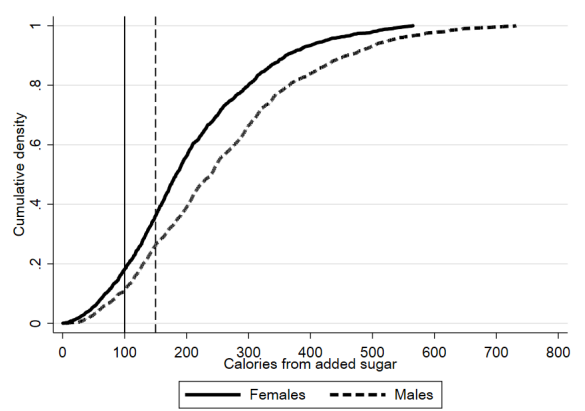

(b) $\%$ of calories from added sugar

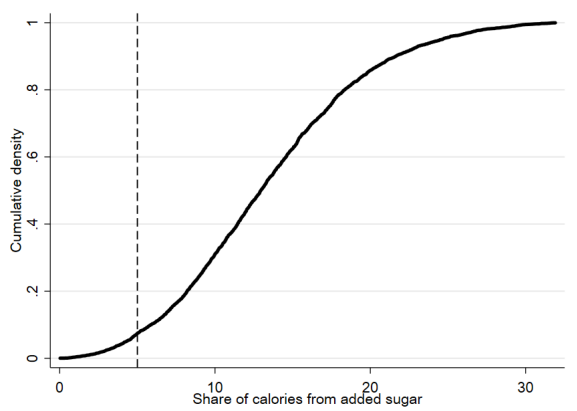

Notes: Numbers using National Diet and Nutrition Survey 2008-2011 for a representative sample of 3,073 UK adults and children. For each distribution we trim the top percentile. Vertical lines denote medical guidelines.

In Figure A.2 we show local polynomial regressions describing how the calories from (the sugar in) soft drinks vary with age, share of calories from added sugar and equivalized household income. The figure shows that young individuals, those 
with a high share of calories from added sugar, and those from relatively low income households obtain relatively large amounts of calories from soft drinks.

Figure A.2: Sugar from soft drinks
(a) by age
(b) by calories from added sugar
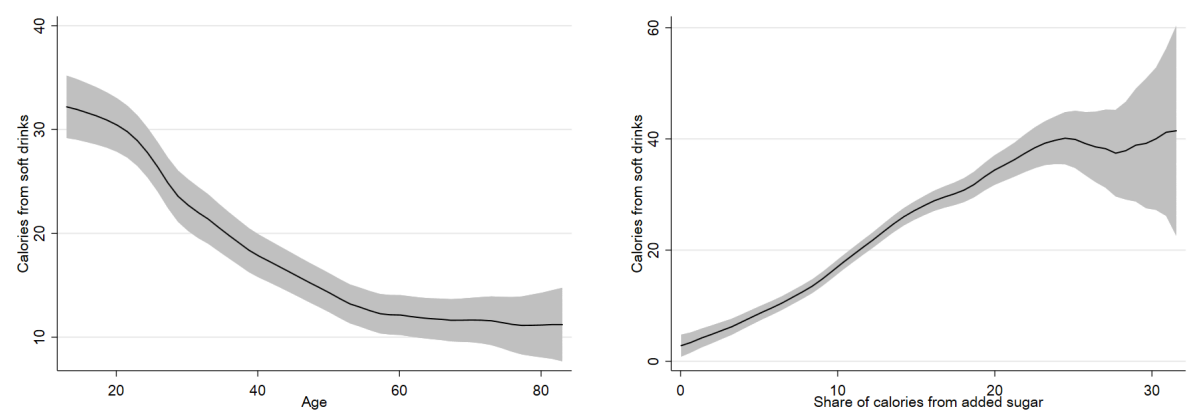

(c) by equivalized income

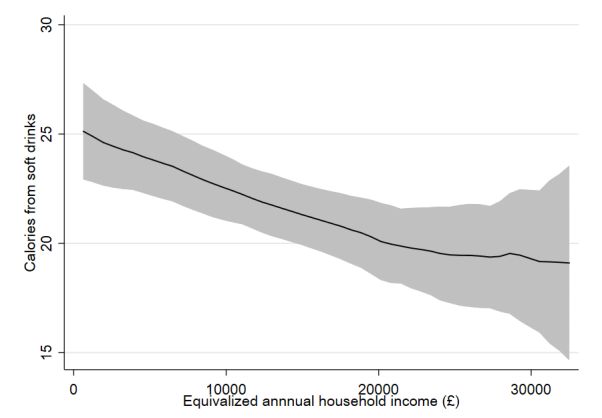

Notes: Numbers using National Diet and Nutrition Survey 2008-2011 for a representative sample of 3,073 UK adults and children. Lines are based on local polynomial regressions. Shaded area are 95\% confidence bands. For each variable we trim the top percentile of the distribution.

In Figures A.3 and A.4 we repeat Figures A.1 and A.2 with US data. Specifically, we use National Health and Nutrition Examination Study over 2007-2014, a sample of 39,189 adults and children. The same patterns hold in the US. Notice, the level of calories from soft drinks reported for the US in the National Health and Nutrition Examination Study is higher than those reported in the UK in the National Diet and Nutrition Survey. This may partially reflect differences in consumption levels between the two countries, but it may also reflect differences in reporting between the two surveys. 
Figure A.3: Patterns in the US: Cumulative density of calories from added sugar

(a) Calories from added sugar

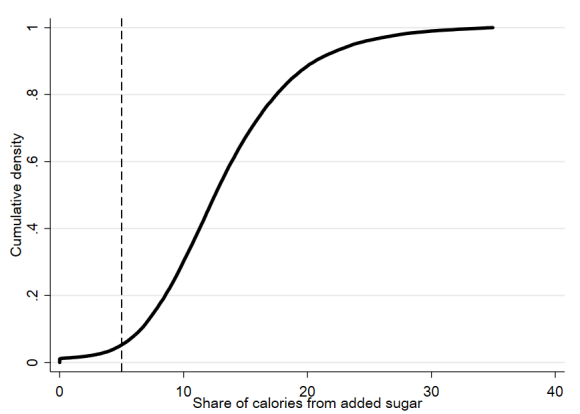

(b) $\%$ of calories from added sugar

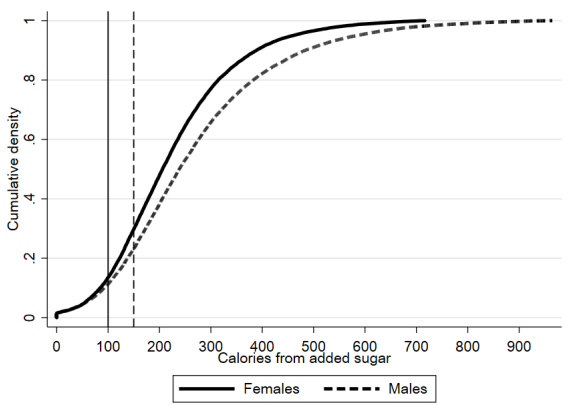

Notes: Numbers using National Health and Nutrition Examination Study 2007-2014 for a representative sample of 39,189 US adults and children. For each distribution we trim the top percentile. Vertical lines denote medical guidelines.

Figure A.4: Patterns in the US: Sugar from soft drinks

(a) by age

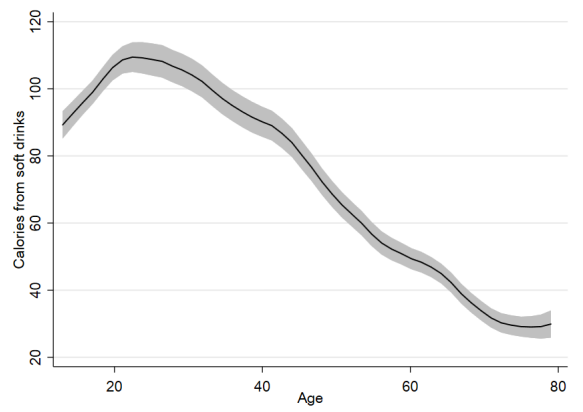

(b) by calories from added sugar

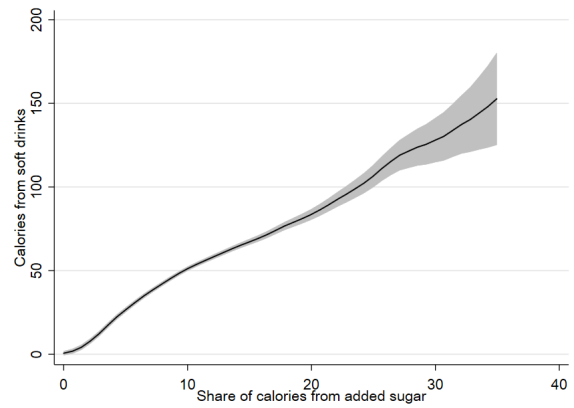

(c) by equivalized income

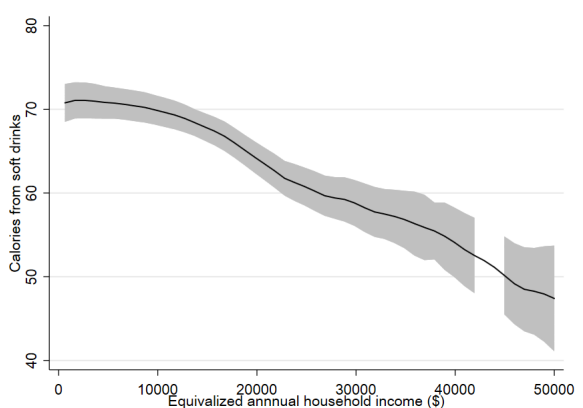

Notes: Numbers using National Health and Nutrition Examination Study 2007-2014 for a representative sample of 39,189 US adults and children. Lines are based on local polynomial regressions. Shaded area are $95 \%$ confidence bands. For each variable we trim the top percentile of the distribution.

\section{A.2 Product definition}

We consider the market for chilled non-alcoholic drinks. In the raw data there are 2,950 unique product codes (UPCs) consisting of 1,065 brands (as defined by Kan- 
tar). We use data on the 598 UPCs in 89 brands that comprise $82 \%$ of transactions. We drop niches UPCs that have very small market shares as follows:

- 975 brands that individually have a market share of less than $0.15 \%$, accounting for 2,232 UPCs. Together these account for 15\% of the market; see spreadsheet.

- 87 UPCs that are for sizes smaller than $200 \mathrm{ml}$, which together account for $2 \%$ of the market; see spreadsheet.

- 33 UPCs that are for odd size-brand combinations, that individually have small market shares (the largest is $0.18 \%$, the mean is $0.04 \%$ ), which together account for $1 \%$ of the market; see spreadsheet.

This leaves us with 598 UPCs in 89 brands. We group these into 37 products as follows:

- 30 branded soft drink products, e.g. Coca Cola 330ml, Coca Cola 500ml, Coca Cola Diet 330ml, etc.; we aggregate over 104 UPCs, for example, the product Coca Cola $500 \mathrm{ml}$ is the aggregate of 2 UPCs that differ in the shape of bottle (COCA COLA CONTOUR PET 500ML with a market share of $7.5 \%$ and COCA COLA PET 500ML with a market share of $0.2 \%$ ); together these 30 branded soft drink products account for $60 \%$ market share; see spreadsheet

- Other soda products

- regular: we aggregate 184 UPCs that individually have market shares that range from 1.6\% (Red Bull 250ml) to 0.0002\% (Orangina Rouge $500 \mathrm{ml}$ ) with a mean market share of $0.08 \%$, and together account for $14 \%$ of the market; see spreadsheet.

- diet: we aggregate 22 UPCs that individually have market shares that range from $0.4 \%$ (7UP Free Lemon+Limeade 600ml) to $0.001 \%$ (Lucozade Sport Lite 500ml) and together account for $1.9 \%$ of the market; see spreadsheet.

- Fruit juice: we aggregate 100 UPCs that individually all have market shares below $1 \%$ and together account for $7.9 \%$ of the market; see spreadsheet.

- Flavoured milk: we aggregate 30 UPCs that individually have market shares below $0.25 \%$ and together account for $1.8 \%$ of the market; see spreadsheet. 
- Fruit water: we aggregate 11 UPCs that are different flavours of Volvic Touch of Fruit Water that together account for just under 1\% of the market; see spreadsheet.

- Water: we aggregate 146 UPCs for bottled water, which together have a market share of $12 \%$; see spreadsheet.

\section{A.3 Measurement of prices}

We compute the transaction level price as expenditure made for a UPC over units purchased. For products that entail some aggregation over sizes, we adjust prices so they are in terms of the most popular size. For instance, Pepsi $500 \mathrm{ml}$ involves aggregating over $500 \mathrm{ml}$ and $600 \mathrm{ml}$ size; for transactions involving $600 \mathrm{ml}$ Pepsi, we adjust the price according to $p * 5 / 6$. Similarly, for the composite products we express price in terms of the most common size.

For each product we compute the mean monthly price (across transactions) in each retailer type. If a product-retailer type-month involves fewer than 3 transactions, we replace the price with a missing value. For product-retailer type-months with missing prices we interpolate (across weeks). We smooth the resulting price series using a local polynomial non-parametric regression.

Figures A.5 and A.6 show the difference between the price the consumer actually pays for the chosen product (the transaction price) and the smoothed price used in the demand model estimation. They show that measurement error exists and exists for all stores and if anything is slightly lower for vending machines.

Figure A.5: Difference between transaction price and smoothed price

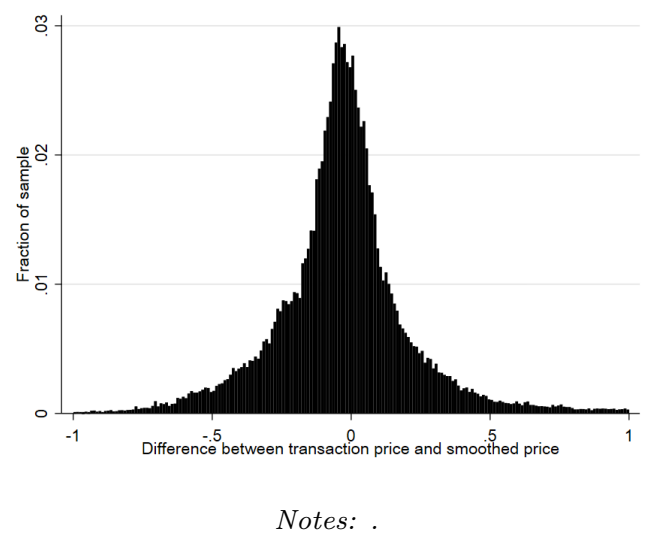


Figure A.6: Difference between transaction price and smoothed price, by store type

(a) National-large

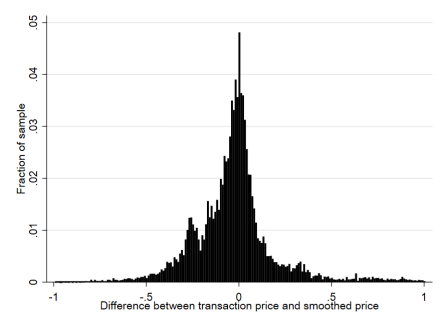

(d) Regional - south

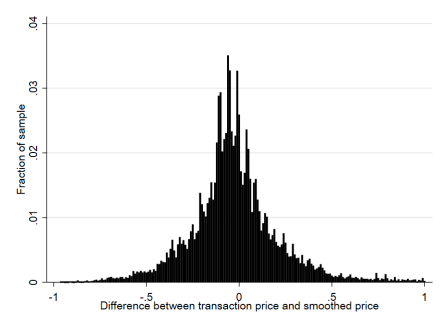

(b) National-small

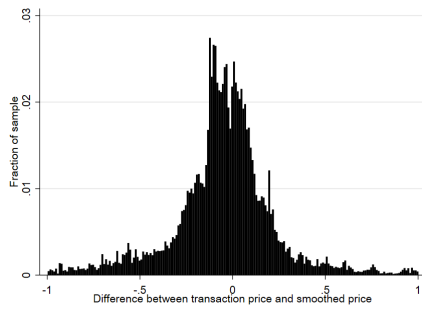

(e) Regional - midlands

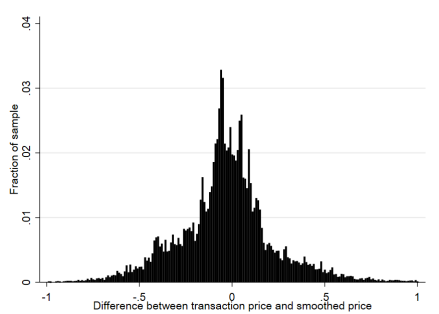

Notes: . (c) Vending machine

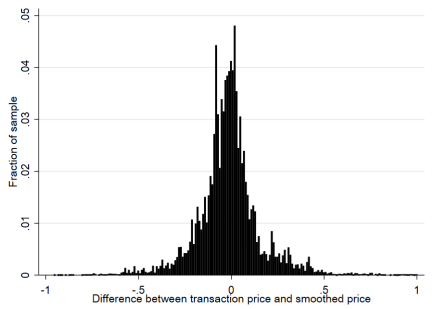

(f) Regional - north

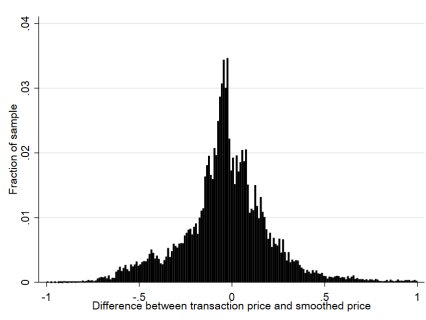

Measurement error in non-linear models is more problematic than in linear models, and even classical additive measurement error can bias parameter estimates, unlike in linear models. However, it is useful to consider more closely the type of measurement error we face here. The measurement errors introduced by using imputed prices instead of true prices can be thought of coming from two errors. First, there is an error when using a mean instead of the true variable. These errors are "Berkson" errors (Berkson (1950)), i.e. additive on the unobserved true price and independent of the average price used in estimation. Second, we also make an error on the true mean price in a region-store chain when using transaction prices because the sampling of transactions is not independent of prices.

Blundell et al. (2019) argue that "Berkson" errors are commonplace when we observe an average price in a group rather than the true individual price, and can lead to bias in estimates of demand. They are not classical measurement errors independent of the true unobserved variable. Schennach (2013) proposes a solution with instrumental variables in the context of non-parametric models with a continuous outcome variable. In a continuous demand estimation problem, Blundell et al. (2019) develop a consistent estimator that uses external information on the true distribution of prices in the case of demand estimation with non-separable unobserved heterogeneity. Their results do not extend to a discrete choice model for differentiated products demands. 
The second source of errors is due to the imputation using transaction prices. We leave for future research the development of a consistent estimation method in the case of discrete choices. This is a complicated problem that has not been solved.

As our imputed prices potentially suffer from both error components, we do a simple Monte Carlo simulation to see what the extent of the bias might be in our setting with respect to such measurement error in prices.

We consider a data generating process where individual prices paid by each consumer are such that the prices of good $j$ for consumer $i$ at different occasions $\tau$ is:

$$
p_{i j r t \tau}=p_{j r t}+\Delta_{i j r t \tau}
$$

where $\Delta_{i j r t \tau}$ is independent of $p_{j r t}$ for all products $j$, retailers $r$, periods $t$ and purchase occasions $\tau$ of each consumer denoted $i$. We then consider the case where all $p_{i j r t \tau}$ are not observed by the econometrician but only the transaction price.

We simulate a logit model based on the random utility of consumer $i$ for good $j=1, . ., J$ on purchase occasion $\tau$ for consumer $i$ :

$$
U_{i j \tau}=\delta_{j}-\alpha_{i} p_{i j r(i) t(i) \tau}+\epsilon_{i j r(i) t(i) \tau}
$$

with outside good $U_{i 0 \tau}=\epsilon_{i 0 r(i) t(i) t \tau}$ and where $r(i) \in\{1, . ., R\}$ denotes the retailers of consumer $i$ and $t(i) \in\{1, . ., T\}$ the period where consumer $i$ shops. We randomly draw purchase occasions across periods $t(i)$ (these are like markets in our application) and for simplicity we randomly assign consumers uniformly to different retailers $r(i)$.

Preferences for consumers $i=1, \ldots, I$ are heterogeneous with $\alpha_{i}$, which is normally distributed with zero truncation (to impose that the price coefficient is negative). The price heterogeneity is calibrated to have approximately the scale of the price distribution observed for sodas in our data and the mean utilities and price coefficient are also chosen to calibrate approximately to the product market shares and the outside good market share. Consumer $i$ chooses the highest utility alternative such that her chosen good at occasion $\tau$ is

$$
y_{i \tau}=\arg \max _{j=0,1, . ., J}\left\{U_{i j \tau}\right\}
$$


Assuming all $\epsilon_{i j r(i) t(i) \tau}$ are i.i.d. type I extreme value, the choice probability of $j$ by consumer $i$ at choice occasion $\tau$ is

$$
P_{i j \tau}=P\left(y_{i \tau}=j \mid p_{i 1 r(i) t(i) \tau}, . ., p_{i J r(i) t(i) \tau}\right)=\frac{\exp \left(\delta_{j}-\alpha_{i} p_{i j r(i) t(i) \tau}\right)}{1+\sum_{k=1}^{J} \exp \left(\delta_{k}-\alpha_{i} p_{i k r(i) t(i) \tau}\right)}
$$

and the consumer $i$ own price elasticity for good $j$ is $e_{i j \tau} \equiv \frac{\partial \ln P_{i j \tau}}{\partial \ln p_{i j r(i) t(i) \tau}}=-\alpha_{i} P_{i j \tau}(1-$ $\left.P_{i j \tau}\right)$.

We observe only transaction prices $p_{i y_{i \tau} r(i) t(i) \tau}$ for the chosen product $y_{i \tau} \in$ $\{1, . ., J\}$. We compute average transaction prices by retailer and period as the empirical mean of observed transaction prices:

$$
p_{j r t}=\frac{1}{\operatorname{card}\left\{i, \tau \mid r(i)=r, t(i)=t, y_{i \tau}=j\right\}} \sum_{\left\{i, \tau \mid r(i)=r, t(i)=t, y_{i \tau}=j\right\}} p_{i y_{i \tau} r(i) t(i) \tau}
$$

The measurement error in prices introduce a bias in the logit estimates. In order to gain intuition on how large is this bias, we compare the maximum likelihood estimation of parameters using the true prices $p_{i j r(i) t(i) \tau}$ with estimates using the average transaction prices $p_{j r t}$.

While theoretically there remains an asymptotic bias, our results suggest that with sufficient observations of purchases per product-retailer the bias becomes economically irrelevant. Specifically, with sample sizes similar to those in our data we obtain a bias in the elasticity estimates that is less than $5 \%$.

Interestingly, the bias is small and positive on the individual price coefficients while if we impose a common price coefficient (same $\left.\alpha_{i}\right)$ in the true data generating process, the bias is small but negative. This shows that when the measurement error is not consumer specific, but due only to $\Delta_{i j r t \tau}$, the bias leads to an overestimation of price elasticity. Intuitively this is because the mean transaction price is underestimated (purchases occur more often when the price deviation is negative) while the outside good price normalization is constant. When the price coefficient is individual specific (as in our model), the measurement error is compounded with the price sensitivity, which introduces an additional error that is correlated with $\alpha_{i}$, and generates a bias in the other direction. Intuitively, the fact that all prices are biased (except the outside good) makes the bias on the price elasticity of demand not too large, because choices across inside goods depend on relative prices, and it also 
implies that the bias is likely to be larger the larger is the outside good market share.

We think this problem is an interesting general issue that deserves more research that is out of the scope of this paper.

\section{B Further details of on-the-go demand estimates}

In Figure B.1 we plot contour plots of the bivariate preference distributions.

Figure B.1: Bivariate distributions of consumer specific preference parameters
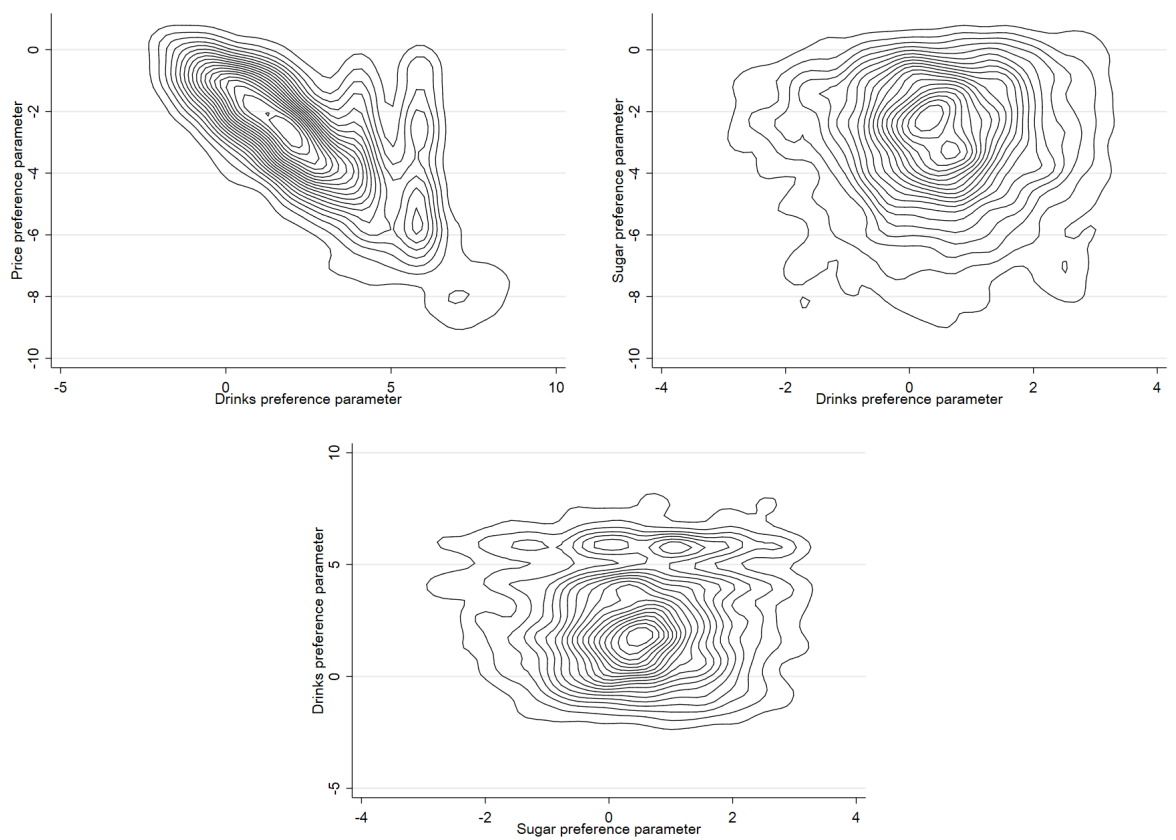

Notes: Distribution plots use consumers with finite sugar preference parameters; those having infinite sugar preferences cannot be included in this graph. We trim the top and bottom $2.5 \%$ of the distribution.

In Tables B.1 we report price elasticities for all products. 95\% confidence bands are given in brackets. In column 1 we report the percent change in demand for the product when its price increases by $1 \%$. Columns $2-5$ report how demand for alternative products (sugary soft drinks, diet soft drinks, sugary alternative drinks and non-sugary alternative drinks) would change and a final column reports what would be the overall change in demand for soft drinks and alternative juices. For example, a $1 \%$ increase in the price of a $500 \mathrm{ml}$ bottle of Coca Cola, would result in a reduction in demand for that product of $2.36 \%$. Demand for alternative sugary soft drinks would rise by around $0.223 \%$, demand for diet soft drinks would rise by $0.125 \%$, demand for alternative sugary drinks would rise by $0.201 \%$ and demand for alternative non-sugary drinks would rise by $0.129 \%$. Demand for non-alcoholic drinks as a whole would fall by $0.114 \%$. 
Table B.1: Product level price elasticities

\begin{tabular}{|c|c|c|c|c|c|c|}
\hline & $\begin{array}{c}\text { Own } \\
\text { product } \\
\text { demand }\end{array}$ & $\begin{array}{c}\text { sugary } \\
\text { soft drinks }\end{array}$ & $\begin{array}{c}\text { Effect of } 1 \% \\
\text { cross de } \\
\text { diet } \\
\text { soft drinks }\end{array}$ & $\begin{array}{l}\text { ice increase } \\
\text { land for: } \\
\text { sugary } \\
\text { alternatives }\end{array}$ & $\begin{array}{l}\text { non-sugary } \\
\text { alternatives }\end{array}$ & $\begin{array}{c}\text { Total } \\
\text { drinks } \\
\text { demand }\end{array}$ \\
\hline Coca Cola 330 & $\begin{array}{c}-2.81 \\
{[-2.85,-2.80]}\end{array}$ & $\begin{array}{c}0.096 \\
{[0.095,0.098]}\end{array}$ & $\begin{array}{c}0.055 \\
{[0.054,0.056]}\end{array}$ & $\begin{array}{c}0.084 \\
{[0.083,0.086]}\end{array}$ & $\begin{array}{c}0.092 \\
{[0.091,0.094]}\end{array}$ & $\begin{array}{c}-0.012 \\
{[-0.012,-0.012]}\end{array}$ \\
\hline Coca Cola 500 & $\begin{array}{c}-2.36 \\
{[-2.38,-2.30]}\end{array}$ & $\begin{array}{c}0.223 \\
{[0.218,0.225]}\end{array}$ & $\begin{array}{c}0.125 \\
{[0.122,0.126]}\end{array}$ & $\begin{array}{c}0.201 \\
{[0.196,0.203]}\end{array}$ & $\begin{array}{c}0.129 \\
{[0.126,0.131]}\end{array}$ & $\begin{array}{c}-0.114 \\
{[-0.114,-0.111]}\end{array}$ \\
\hline Coca Cola Diet 330 & $\begin{array}{c}-3.02 \\
{[-3.05,-3.00]}\end{array}$ & $\begin{array}{c}0.047 \\
{[0.046,0.048]}\end{array}$ & $\begin{array}{c}0.106 \\
{[0.104,0.107]}\end{array}$ & $\begin{array}{c}0.036 \\
{[0.035,0.036]}\end{array}$ & $\begin{array}{c}0.232 \\
{[0.228,0.235]}\end{array}$ & $\begin{array}{c}-0.004 \\
{[-0.005,-0.004]}\end{array}$ \\
\hline Coca Cola Diet 500 & $\begin{array}{c}-2.51 \\
{[-2.53,-2.47]}\end{array}$ & $\begin{array}{c}0.100 \\
{[0.098,0.102]}\end{array}$ & $\begin{array}{c}0.235 \\
{[0.229,0.239]}\end{array}$ & $\begin{array}{c}0.098 \\
{[0.095,0.100]}\end{array}$ & $\begin{array}{c}0.224 \\
{[0.221,0.228]}\end{array}$ & $\begin{array}{c}-0.084 \\
{[-0.085,-0.082]}\end{array}$ \\
\hline Dr Pepper 330 & $\begin{array}{c}-3.25 \\
{[-3.30,-3.23]}\end{array}$ & $\begin{array}{c}0.014 \\
{[0.014,0.015]}\end{array}$ & $\begin{array}{c}0.007 \\
{[0.007,0.008]}\end{array}$ & $\begin{array}{c}0.007 \\
{[0.007,0.008]}\end{array}$ & $\begin{array}{c}0.009 \\
{[0.009,0.010]}\end{array}$ & $\begin{array}{c}-0.001 \\
{[-0.002,-0.001]}\end{array}$ \\
\hline Dr Pepper 500 & $\begin{array}{c}-2.64 \\
{[-2.66,-2.59]}\end{array}$ & $\begin{array}{c}0.035 \\
{[0.034,0.036]}\end{array}$ & $\begin{array}{c}0.020 \\
{[0.019,0.020]}\end{array}$ & $\begin{array}{c}0.031 \\
{[0.030,0.031]}\end{array}$ & $\begin{array}{c}0.020 \\
{[0.020,0.021]}\end{array}$ & $\begin{array}{c}-0.018 \\
{[-0.018,-0.017]}\end{array}$ \\
\hline Dr Pepper Diet 500 & $\begin{array}{c}-2.85 \\
{[-2.88,-2.80]}\end{array}$ & $\begin{array}{c}0.016 \\
{[0.016,0.016]}\end{array}$ & $\begin{array}{c}0.038 \\
{[0.037,0.039]}\end{array}$ & $\begin{array}{c}0.015 \\
{[0.014,0.015]}\end{array}$ & $\begin{array}{c}0.038 \\
{[0.037,0.039]}\end{array}$ & $\begin{array}{c}-0.013 \\
{[-0.013,-0.013]}\end{array}$ \\
\hline Fanta 330 & $\begin{array}{c}-2.99 \\
{[-3.04,-2.97]}\end{array}$ & $\begin{array}{c}0.020 \\
{[0.020,0.020]}\end{array}$ & $\begin{array}{c}0.010 \\
{[0.010,0.010]}\end{array}$ & $\begin{array}{c}0.015 \\
{[0.014,0.015]}\end{array}$ & $\begin{array}{c}0.018 \\
{[0.018,0.019]}\end{array}$ & $\begin{array}{c}-0.002 \\
{[-0.003,-0.002]}\end{array}$ \\
\hline Fanta 500 & $\begin{array}{c}-2.54 \\
{[-2.57,-2.49]}\end{array}$ & $\begin{array}{c}0.036 \\
{[0.035,0.037]}\end{array}$ & $\begin{array}{c}0.020 \\
{[0.020,0.021]}\end{array}$ & $\begin{array}{c}0.033 \\
{[0.032,0.034]}\end{array}$ & $\begin{array}{c}0.023 \\
{[0.022,0.023]}\end{array}$ & $\begin{array}{c}-0.019 \\
{[-0.019,-0.018]}\end{array}$ \\
\hline Fanta Diet 500 & $\begin{array}{c}-2.74 \\
{[-2.77,-2.70]}\end{array}$ & $\begin{array}{c}0.016 \\
{[0.016,0.017]}\end{array}$ & $\begin{array}{c}0.038 \\
{[0.036,0.038]}\end{array}$ & $\begin{array}{c}0.016 \\
{[0.016,0.017]}\end{array}$ & $\begin{array}{c}0.041 \\
{[0.040,0.042]}\end{array}$ & $\begin{array}{c}-0.014 \\
{[-0.014,-0.014]}\end{array}$ \\
\hline Cherry Coke 330 & $\begin{array}{c}-2.99 \\
{[-3.03,-2.97]}\end{array}$ & $\begin{array}{c}0.014 \\
{[0.014,0.015]}\end{array}$ & $\begin{array}{c}0.006 \\
{[0.006,0.007]}\end{array}$ & $\begin{array}{c}0.009 \\
{[0.009,0.009]}\end{array}$ & $\begin{array}{c}0.011 \\
{[0.010,0.011]}\end{array}$ & $\begin{array}{c}-0.001 \\
{[-0.001,-0.001]}\end{array}$ \\
\hline Cherry Coke 500 & $\begin{array}{c}-2.59 \\
{[-2.61,-2.53]}\end{array}$ & $\begin{array}{c}0.029 \\
{[0.029,0.030]}\end{array}$ & $\begin{array}{c}0.016 \\
{[0.016,0.016]}\end{array}$ & $\begin{array}{c}0.027 \\
{[0.026,0.027]}\end{array}$ & $\begin{array}{c}0.018 \\
{[0.017,0.018]}\end{array}$ & $\begin{array}{c}-0.015 \\
{[-0.015,-0.014]}\end{array}$ \\
\hline Cherry Coke Diet 500 & $\begin{array}{c}-2.79 \\
{[-2.81,-2.74]}\end{array}$ & $\begin{array}{c}0.013 \\
{[0.013,0.013]}\end{array}$ & $\begin{array}{c}0.030 \\
{[0.029,0.031]}\end{array}$ & $\begin{array}{c}0.013 \\
{[0.012,0.013]}\end{array}$ & $\begin{array}{c}0.032 \\
{[0.031,0.033]}\end{array}$ & $\begin{array}{c}-0.011 \\
{[-0.011,-0.011]}\end{array}$ \\
\hline Oasis 500 & $\begin{array}{c}-2.55 \\
{[-2.58,-2.49]}\end{array}$ & $\begin{array}{c}0.044 \\
{[0.043,0.045]}\end{array}$ & $\begin{array}{c}0.025 \\
{[0.024,0.026]}\end{array}$ & $\begin{array}{c}0.041 \\
{[0.040,0.042]}\end{array}$ & $\begin{array}{c}0.027 \\
{[0.026,0.027]}\end{array}$ & $\begin{array}{c}-0.023 \\
{[-0.023,-0.022]}\end{array}$ \\
\hline Oasis Diet 500 & $\begin{array}{c}-2.72 \\
{[-2.74,-2.68]}\end{array}$ & $\begin{array}{c}0.020 \\
{[0.020,0.020]}\end{array}$ & $\begin{array}{c}0.047 \\
{[0.046,0.048]}\end{array}$ & $\begin{array}{c}0.020 \\
{[0.019,0.020]}\end{array}$ & $\begin{array}{c}0.047 \\
{[0.046,0.048]}\end{array}$ & $\begin{array}{c}-0.017 \\
{[-0.017,-0.017]}\end{array}$ \\
\hline Pepsi 330 & $\begin{array}{c}-2.80 \\
{[-2.84,-2.79]}\end{array}$ & $\begin{array}{c}0.035 \\
{[0.035,0.036]}\end{array}$ & $\begin{array}{c}0.018 \\
{[0.018,0.019]}\end{array}$ & $\begin{array}{c}0.030 \\
{[0.029,0.030]}\end{array}$ & $\begin{array}{c}0.034 \\
{[0.034,0.036]}\end{array}$ & $\begin{array}{c}-0.004 \\
{[-0.005,-0.004]}\end{array}$ \\
\hline Pepsi 500 & $\begin{array}{c}-2.67 \\
{[-2.70,-2.64]}\end{array}$ & $\begin{array}{c}0.091 \\
{[0.090,0.093]}\end{array}$ & $\begin{array}{c}0.051 \\
{[0.049,0.052]}\end{array}$ & $\begin{array}{c}0.079 \\
{[0.078,0.081]}\end{array}$ & $\begin{array}{c}0.061 \\
{[0.060,0.062]}\end{array}$ & $\begin{array}{c}-0.050 \\
{[-0.050,-0.049]}\end{array}$ \\
\hline Pepsi Diet 330 & $\begin{array}{c}-3.06 \\
{[-3.09,-3.04]}\end{array}$ & $\begin{array}{c}0.016 \\
{[0.016,0.016]}\end{array}$ & $\begin{array}{c}0.043 \\
{[0.042,0.044]}\end{array}$ & $\begin{array}{c}0.012 \\
{[0.012,0.013]}\end{array}$ & $\begin{array}{c}0.089 \\
{[0.087,0.091]}\end{array}$ & $\begin{array}{c}-0.001 \\
{[-0.002,-0.001]}\end{array}$ \\
\hline Pepsi Diet 500 & $\begin{array}{c}-2.86 \\
{[-2.89,-2.83]}\end{array}$ & $\begin{array}{c}0.042 \\
{[0.041,0.042]}\end{array}$ & $\begin{array}{c}0.100 \\
{[0.098,0.101]}\end{array}$ & $\begin{array}{c}0.038 \\
{[0.037,0.039]}\end{array}$ & $\begin{array}{c}0.119 \\
{[0.117,0.121]}\end{array}$ & $\begin{array}{c}-0.038 \\
{[-0.038,-0.037]}\end{array}$ \\
\hline Lucozade Energy 380 & $\begin{array}{c}-2.72 \\
{[-2.76,-2.69]}\end{array}$ & $\begin{array}{c}0.053 \\
{[0.052,0.055]}\end{array}$ & $\begin{array}{c}0.029 \\
{[0.028,0.030]}\end{array}$ & $\begin{array}{c}0.052 \\
{[0.051,0.054]}\end{array}$ & $\begin{array}{c}0.040 \\
{[0.039,0.041]}\end{array}$ & $\begin{array}{c}-0.012 \\
{[-0.012,-0.012]}\end{array}$ \\
\hline Lucozade Energy 500 & $\begin{array}{c}-2.58 \\
{[-2.60,-2.52]}\end{array}$ & $\begin{array}{c}0.043 \\
{[0.041,0.044]}\end{array}$ & $\begin{array}{c}0.024 \\
{[0.023,0.025]}\end{array}$ & $\begin{array}{c}0.040 \\
{[0.038,0.041]}\end{array}$ & $\begin{array}{c}0.024 \\
{[0.023,0.025]}\end{array}$ & $\begin{array}{c}-0.022 \\
{[-0.022,-0.021]}\end{array}$ \\
\hline Ribena 288 & $\begin{array}{c}-2.87 \\
{[-2.92,-2.85]}\end{array}$ & $\begin{array}{c}0.015 \\
{[0.015,0.016]}\end{array}$ & $\begin{array}{c}0.008 \\
{[0.007,0.008]}\end{array}$ & $\begin{array}{c}0.012 \\
{[0.012,0.013]}\end{array}$ & $\begin{array}{c}0.016 \\
{[0.015,0.016]}\end{array}$ & $\begin{array}{c}0.000 \\
{[0.000,0.000]}\end{array}$ \\
\hline Ribena 500 & $\begin{array}{c}-2.64 \\
{[-2.66,-2.59]}\end{array}$ & $\begin{array}{c}0.026 \\
{[0.025,0.026]}\end{array}$ & $\begin{array}{c}0.014 \\
{[0.014,0.014]}\end{array}$ & $\begin{array}{c}0.024 \\
{[0.023,0.025]}\end{array}$ & $\begin{array}{c}0.017 \\
{[0.016,0.017]}\end{array}$ & $\begin{array}{c}-0.013 \\
{[-0.014,-0.013]}\end{array}$ \\
\hline Ribena Diet 500 & $\begin{array}{c}-2.80 \\
{[-2.82,-2.76]}\end{array}$ & $\begin{array}{c}0.011 \\
{[0.011,0.012]}\end{array}$ & $\begin{array}{c}0.026 \\
{[0.025,0.026]}\end{array}$ & $\begin{array}{c}0.011 \\
{[0.011,0.012]}\end{array}$ & $\begin{array}{c}0.031 \\
{[0.030,0.032]}\end{array}$ & $\begin{array}{c}-0.010 \\
{[-0.010,-0.010]}\end{array}$ \\
\hline Sprite 330 & $\begin{array}{c}-3.25 \\
{[-3.30,-3.23]}\end{array}$ & $\begin{array}{c}0.012 \\
{[0.012,0.013]}\end{array}$ & $\begin{array}{c}0.007 \\
{[0.007,0.007]}\end{array}$ & $\begin{array}{c}0.008 \\
{[0.008,0.008]}\end{array}$ & $\begin{array}{c}0.009 \\
{[0.009,0.010]}\end{array}$ & $\begin{array}{c}-0.001 \\
{[-0.002,-0.001]}\end{array}$ \\
\hline Sprite 500 & $\begin{array}{c}-2.55 \\
{[-2.57,-2.49]}\end{array}$ & $\begin{array}{c}0.030 \\
{[0.029,0.031]}\end{array}$ & $\begin{array}{c}0.017 \\
{[0.017,0.018]}\end{array}$ & $\begin{array}{c}0.029 \\
{[0.028,0.030]}\end{array}$ & $\begin{array}{c}0.019 \\
{[0.018,0.020]}\end{array}$ & $\begin{array}{c}-0.016 \\
{[-0.016,-0.015]}\end{array}$ \\
\hline Irn Bru 330 & $\begin{array}{c}-2.94 \\
{[-2.99,-2.93]}\end{array}$ & $\begin{array}{c}0.009 \\
{[0.009,0.010]}\end{array}$ & $\begin{array}{c}0.004 \\
{[0.004,0.005]}\end{array}$ & $\begin{array}{c}0.007 \\
{[0.007,0.007]}\end{array}$ & $\begin{array}{c}0.008 \\
{[0.008,0.009]}\end{array}$ & $\begin{array}{c}-0.001 \\
{[-0.001,-0.001]}\end{array}$ \\
\hline Irn Bru 500 & $\begin{array}{c}-2.69 \\
{[-2.73,-2.65]}\end{array}$ & $\begin{array}{c}0.019 \\
{[0.019,0.020]}\end{array}$ & $\begin{array}{c}0.010 \\
{[0.010,0.011]}\end{array}$ & $\begin{array}{c}0.018 \\
{[0.017,0.018]}\end{array}$ & $\begin{array}{c}0.013 \\
{[0.013,0.014]}\end{array}$ & $\begin{array}{c}-0.010 \\
{[-0.010,-0.010]}\end{array}$ \\
\hline Irn Bru Diet 330 & $\begin{array}{c}-3.24 \\
{[-3.28,-3.22]}\end{array}$ & $\begin{array}{c}0.004 \\
{[0.004,0.004]}\end{array}$ & $\begin{array}{c}0.012 \\
{[0.012,0.013]}\end{array}$ & $\begin{array}{c}0.003 \\
{[0.003,0.003]}\end{array}$ & $\begin{array}{c}0.024 \\
{[0.023,0.025]}\end{array}$ & $\begin{array}{c}0.000 \\
{[0.000,0.000]}\end{array}$ \\
\hline Irn Bru Diet 500 & $\begin{array}{c}-2.91 \\
{[-2.94,-2.88]}\end{array}$ & $\begin{array}{c}0.009 \\
{[0.008,0.009]}\end{array}$ & $\begin{array}{c}0.019 \\
{[0.019,0.020]}\end{array}$ & $\begin{array}{c}0.008 \\
{[0.008,0.009]}\end{array}$ & $\begin{array}{c}0.025 \\
{[0.025,0.026]}\end{array}$ & $\begin{array}{c}-0.007 \\
{[-0.008,-0.007]}\end{array}$ \\
\hline
\end{tabular}

Notes: For each of the four products listed we compute the change in demand for that product, for alternative sugary and diet options and for total demand resulting from a $1 \%$ price increase. Numbers are means across time. $95 \%$ confidence intervals are shown in brackets. 
Table B.1 cont.

\begin{tabular}{|c|c|c|c|c|c|c|}
\hline & $\begin{array}{c}\text { Own } \\
\text { product } \\
\text { demand }\end{array}$ & $\begin{array}{c}\text { sugary } \\
\text { soft drinks }\end{array}$ & $\begin{array}{c}\text { Effect of } 1 \% \\
\text { cross de } \\
\text { diet } \\
\text { soft drinks }\end{array}$ & $\begin{array}{l}\text { ice increase } \\
\text { and for: } \\
\text { sugary } \\
\text { alternatives }\end{array}$ & $\begin{array}{l}\text { non-sugary } \\
\text { alternatives }\end{array}$ & $\begin{array}{c}\text { Total } \\
\text { drinks } \\
\text { demand }\end{array}$ \\
\hline Other Diet & $\begin{array}{c}-2.31 \\
{[-2.29,-2.17]}\end{array}$ & $\begin{array}{c}0.049 \\
{[0.047,0.049]}\end{array}$ & $\begin{array}{c}0.112 \\
{[0.108,0.114]}\end{array}$ & $\begin{array}{c}0.045 \\
{[0.043,0.045]}\end{array}$ & $\begin{array}{c}0.079 \\
{[0.077,0.080]}\end{array}$ & $\begin{array}{c}-0.034 \\
{[-0.034,-0.033]}\end{array}$ \\
\hline Fruit juice & $\begin{array}{c}-2.26 \\
{[-2.28,-2.22]}\end{array}$ & $\begin{array}{c}0.128 \\
{[0.125,0.130]}\end{array}$ & $\begin{array}{c}0.080 \\
{[0.078,0.081]}\end{array}$ & $\begin{array}{c}0.168 \\
{[0.164,0.171]}\end{array}$ & $\begin{array}{c}0.123 \\
{[0.121,0.125]}\end{array}$ & $\begin{array}{c}-0.012 \\
{[-0.012,-0.011]}\end{array}$ \\
\hline Flavoured milk & $\begin{array}{c}-2.66 \\
{[-2.69,-2.63]}\end{array}$ & $\begin{array}{c}0.035 \\
{[0.035,0.036]}\end{array}$ & $\begin{array}{c}0.018 \\
{[0.018,0.019]}\end{array}$ & $\begin{array}{c}0.035 \\
{[0.034,0.036]}\end{array}$ & $\begin{array}{c}0.029 \\
{[0.028,0.030]}\end{array}$ & $\begin{array}{c}-0.020 \\
{[-0.020,-0.019]}\end{array}$ \\
\hline Fruit water & $\begin{array}{c}-2.72 \\
{[-2.76,-2.69]}\end{array}$ & $\begin{array}{c}0.017 \\
{[0.017,0.018]}\end{array}$ & $\begin{array}{c}0.010 \\
{[0.009,0.010]}\end{array}$ & $\begin{array}{c}0.020 \\
{[0.019,0.020]}\end{array}$ & $\begin{array}{c}0.017 \\
{[0.017,0.018]}\end{array}$ & $\begin{array}{c}-0.011 \\
{[-0.011,-0.010]}\end{array}$ \\
\hline Water & $\begin{array}{c}-2.30 \\
{[-2.33,-2.28]}\end{array}$ & $\begin{array}{c}0.115 \\
{[0.114,0.118]}\end{array}$ & $\begin{array}{c}0.281 \\
{[0.277,0.284]}\end{array}$ & $\begin{array}{c}0.128 \\
{[0.127,0.131]}\end{array}$ & {$[.,]$.} & $\begin{array}{c}-0.141 \\
{[-0.144,-0.141]}\end{array}$ \\
\hline
\end{tabular}

Notes: For each of the four products listed we compute the change in demand for that product, for alternative sugary and diet options and for total demand resulting from a $1 \%$ price increase. Numbers are means across time. $95 \%$ confidence intervals are shown in brackets.

In Figures B.2 and B.3 we replicate Figures 3.2 and 3.3, splitting individuals out based on gender and in Figures B.4 and B.5 we split individuals out based on the socioeconomic status. The graphs show the patterns of how preferences vary with age and total dietary sugar broadly hold conditional on gender and socioeconomic status.

Figure B.2: Preferences variation with age and gender
(a) price preferences
(b) drink preferences
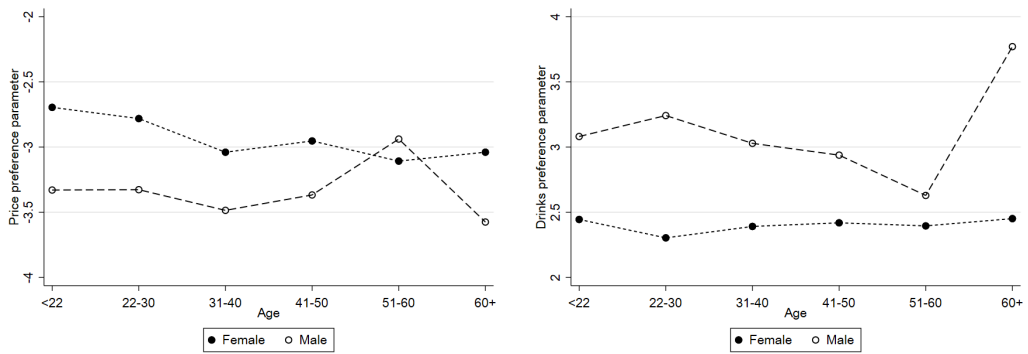

(c) infinite sugar preferences

(d) finite sugar preferences
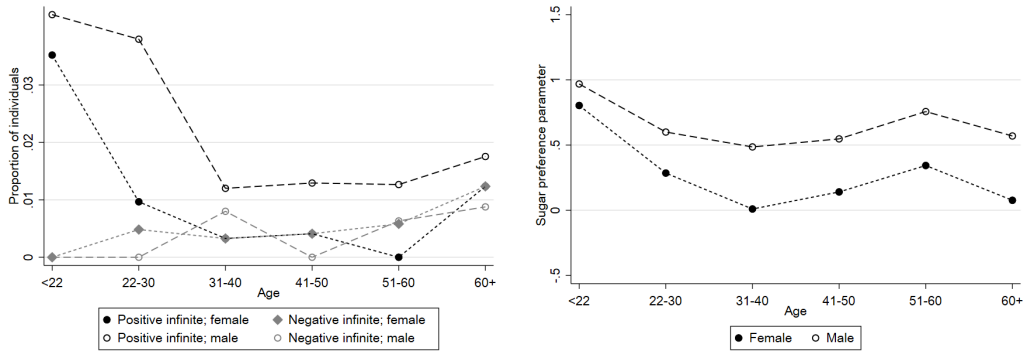

Notes: Figures show how the mean of price preferences, the mean of drinks preferences, the share of consumers with infinite sugar preferences and the mean of finite sugar preferences vary by age and gender. 
Figure B.3: Preferences variation with total dietary sugar and gender

(a) price preferences

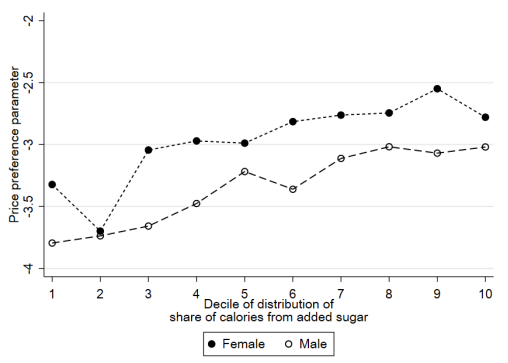

(c) infinite sugar preferences

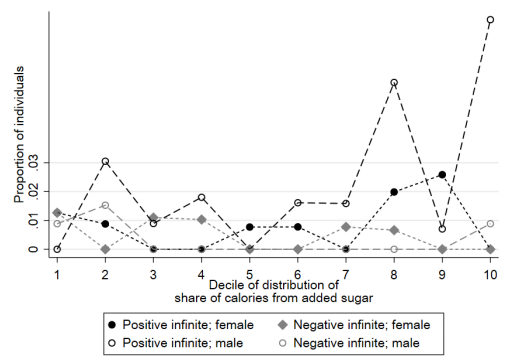

(b) drink preferences

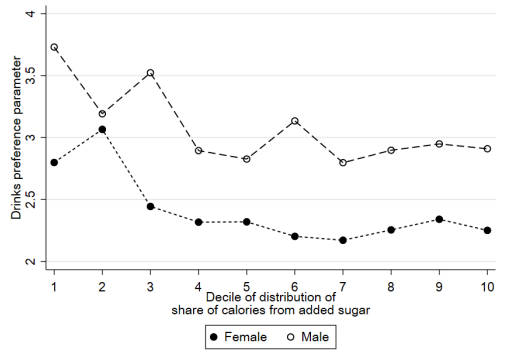

(d) finite sugar preferences

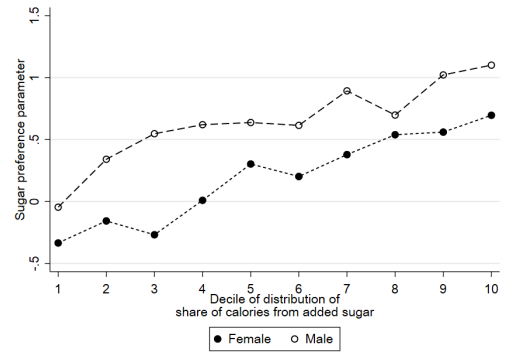

Notes: Figures show how the mean of price preferences, the mean of drinks preferences, the share of consumers with infinite sugar preferences and the mean of finite sugar preferences vary by deciles of the distribution of total annual dietary sugar and gender.

\section{Figure B.4: Preferences variation with age and socioeconomic status}

(a) price preferences

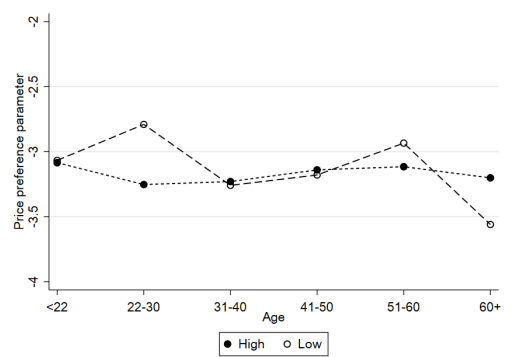

(c) infinite sugar preferences

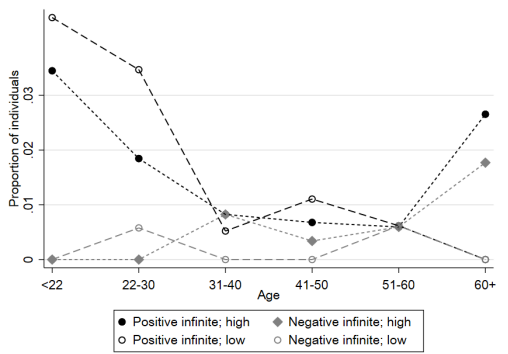

(b) drink preferences

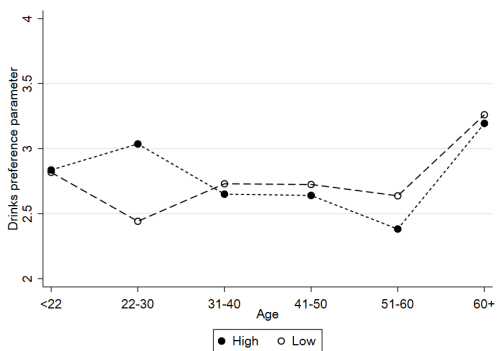

(d) finite sugar preferences

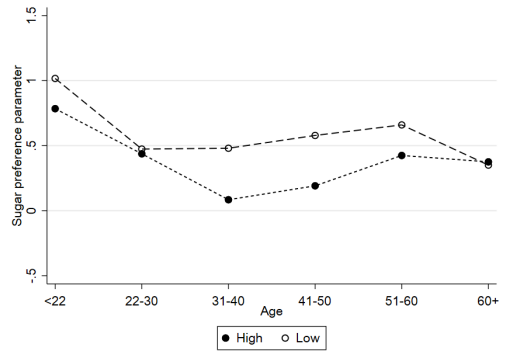

Notes: Figures show how the mean of price preferences, the mean of drinks preferences, the share of consumers with infinite sugar preferences and the mean of finite sugar preferences vary by age and socioeconomic status. "High" refers to those from a household whose head works in managerial or professional roles, "Low" refers to those from a household whose head works in manual work or relies on the state for their income. 
Figure B.5: Preferences variation with total dietary sugar and socioeconomic status

(a) price preferences

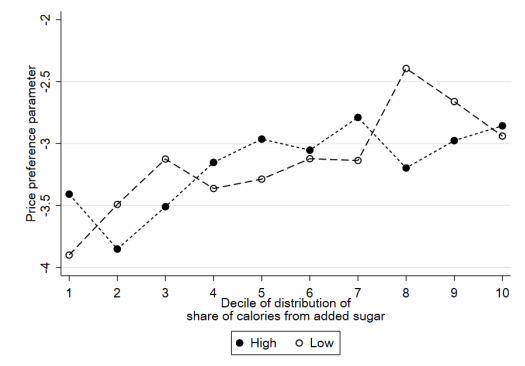

(c) infinite sugar preferences

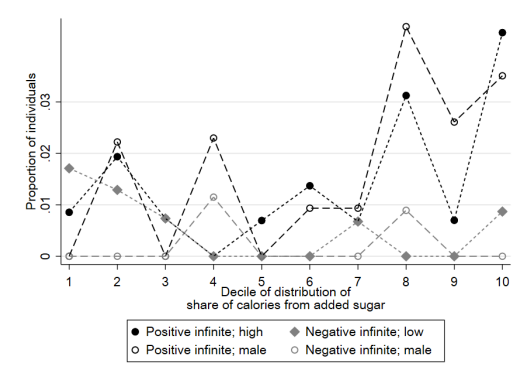

(b) drink preferences

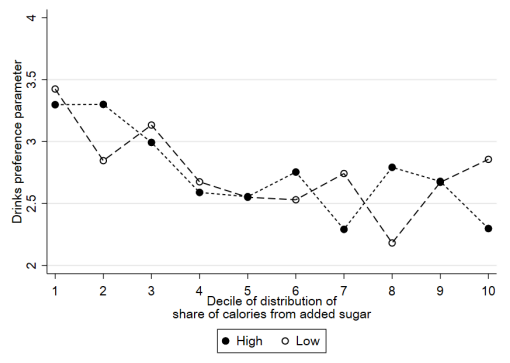

(d) finite sugar preferences

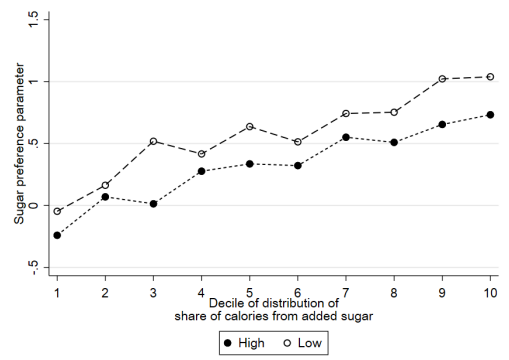

Notes: Figures show how the mean of price preferences, the mean of drinks preferences, the share of consumers with infinite sugar preferences and the mean of finite sugar preferences vary by deciles of the total dietary sugar and socioeconomic status. "High" refers to those from a household whose head works in managerial or professional roles, "Low" refers to those from a household whose head works in manual work or relies on the state for their income.

\section{B.1 Incidental parameters problem}

Figures B.6, B.7 and B.8 show, for the price, drinks and sugar preference parameters, how the jackknife $\left(\widetilde{\theta}_{\text {split }}\right)$ and the maximum likelihood estimates $(\widehat{\theta})$ relate to a) the number of choice occasions of individuals that are in the sample, b) age and c) total dietary sugar. They show no systematic relationship in the mean of $\left(\widetilde{\theta}_{\text {split }}-\widehat{\theta}\right)$ with any of these variables, with the dispersion of $\left(\widetilde{\theta}_{\text {split }}-\widehat{\theta}\right)$ falling in $T$.

Figures B.9 plot the distributions of price, drinks and sugar preference parameter estimates for both the estimators $\widehat{\theta}$ and $\widetilde{\theta}_{\text {split }}$, showing there is little difference in the distributions. 
Figure B.6: Relationship between bias and time in sample

(a) Price

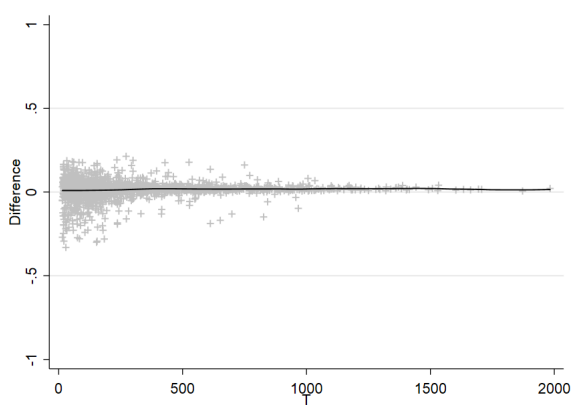

(b) Drinks

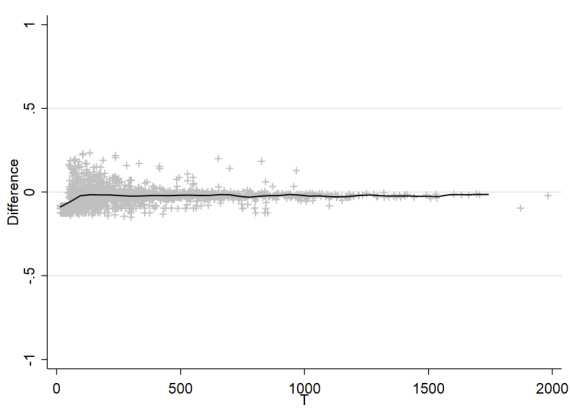

(c) Sugar

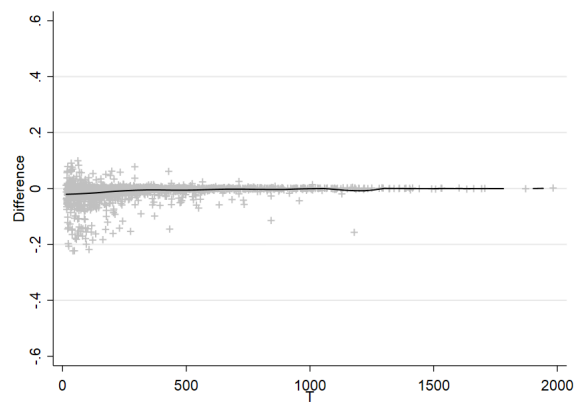

Notes: Marks represent consumer level differences. Lines are local polynomial regressions.

Figure B.7: Relationship between bias and age

(a) Price

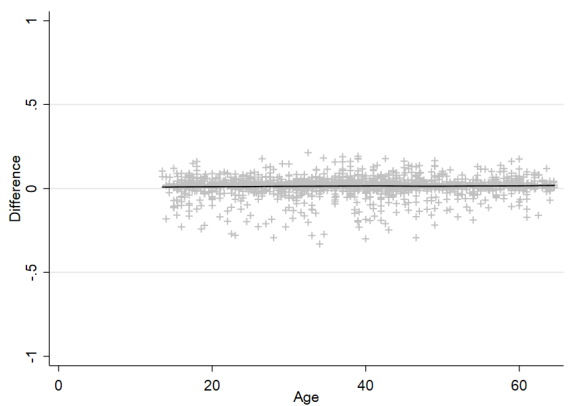

(b) Drinks

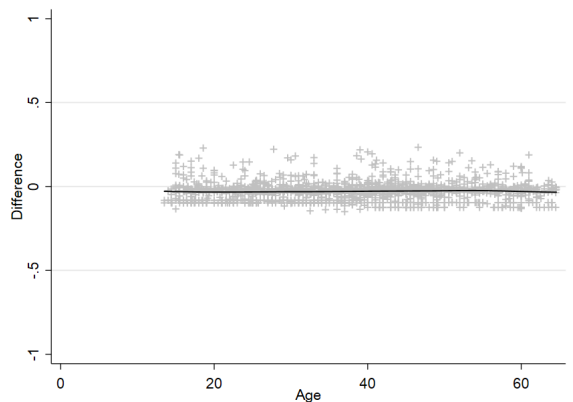

(c) Sugar

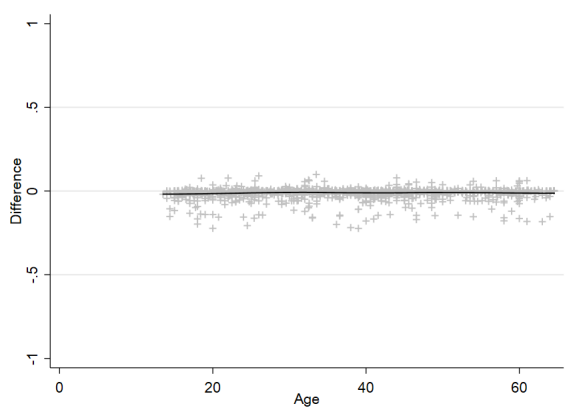

Notes: Marks represent consumer level differences. Lines are local polynomial regressions. 
Figure B.8: Relationship between bias and dietary sugar

(a) Price

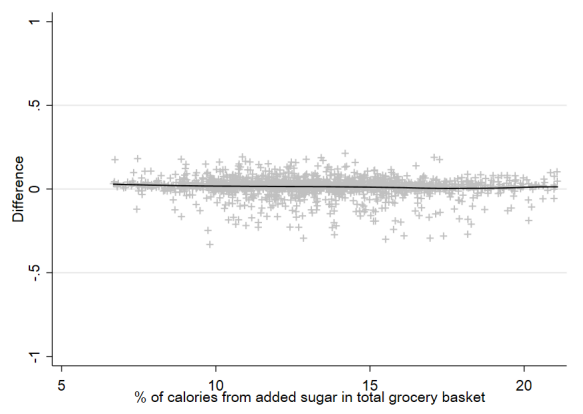

(b) Drinks

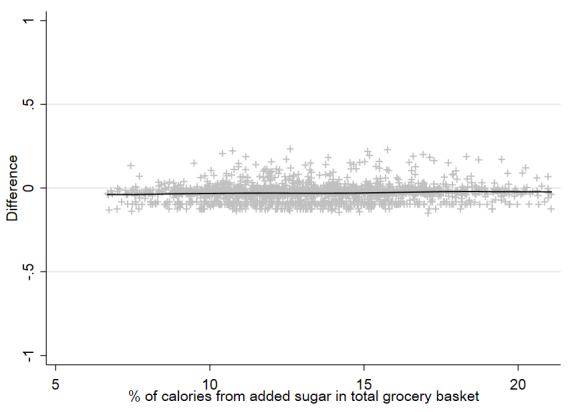

(c) Sugar

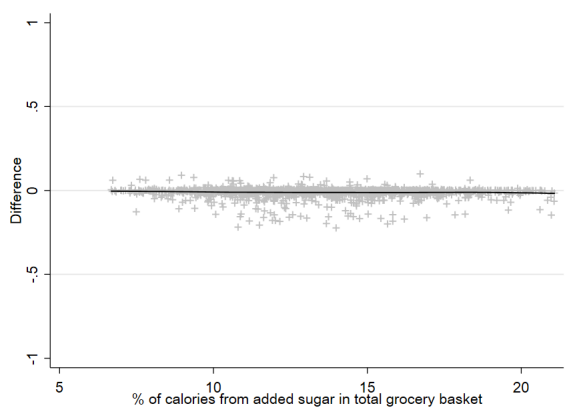

Notes: Marks represent consumer level differences. Lines are local polynomial regressions. (a) Price

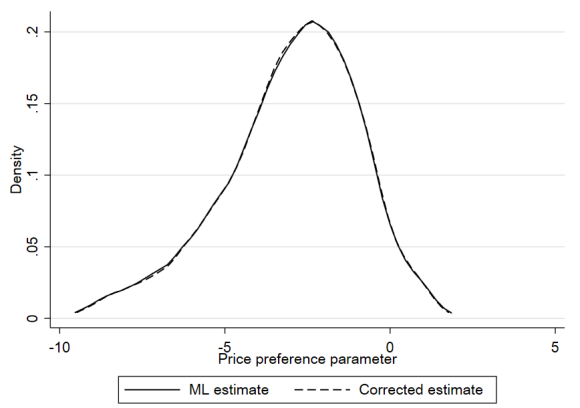

(b) Drinks

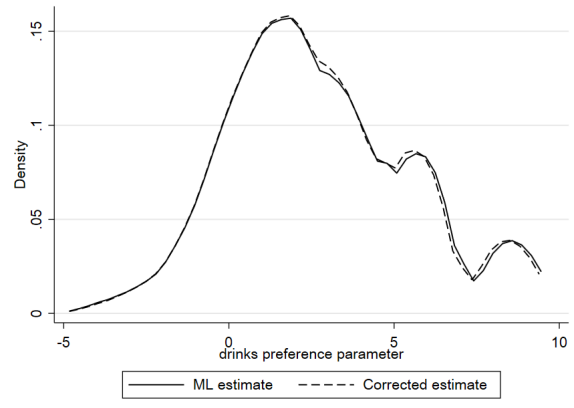

(c) Sugar

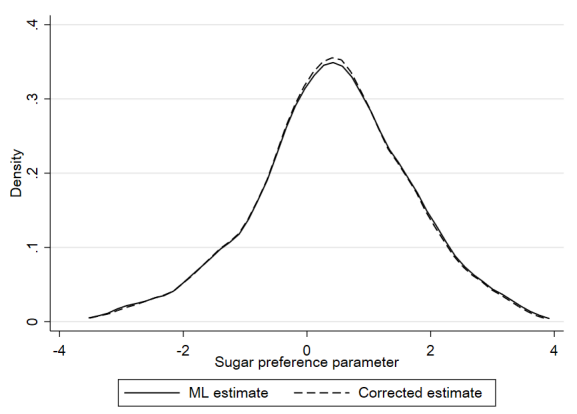

Notes: Lines are kernel density estimates. 


\section{Demand estimates in at-home segment}

\section{C.1 At-home data}

We use information on the at-home behavior of 4,205 households over June 2009December 2014. Of these 3,059 households are drinks purchasers. ${ }^{45}$ In Tables C.1, C.2 and C.3 shows the panel dimension of the data, the products we model choice over in the at-home segment and retailer types. This mirrors tables in Section 2.1 of the paper for the on-the-go segment. In the at-home demand model a choice occasion is defined as a week in which the household buys groceries and the outside option corresponds to not buying any non-alcoholic drinks (exclusive for non-flavored milk). In the estimation sample there are 653,063 choice occasions in total. Households choose the outside option on $59 \%$ of choice occasions.

Table C.1: Time series dimension of at-home estimation sample

\begin{tabular}{lcc}
\hline \multirow{2}{*}{$\begin{array}{l}\text { Number of choice } \\
\text { occasions observed }\end{array}$} & \multicolumn{2}{c}{ Individuals } \\
& on-the-go \\
& $\mathrm{N}$ & $\%$ \\
\hline$<25$ & 20 & 0.7 \\
$25-49$ & 59 & 1.9 \\
$50-74$ & 106 & 3.5 \\
$75-99$ & 151 & 4.9 \\
$100-249$ & 1573 & 51.4 \\
$250+$ & 1150 & 37.6 \\
\hline Total & 3059 & 100.0 \\
\hline
\end{tabular}

Notes: The table shows the number of choice occasions on which we observe household making at-home purchase choices based on the 3,059 households in the at-home estimation sample. A choice occasion is a week in which the household visits the grocery store.

\footnotetext{
${ }^{45}$ Defined as buying at 15 non-alcoholic drinks over the 5 and a half year period of our data.
} 
Table C.2: Products in at-home sample

\begin{tabular}{|c|c|c|c|c|}
\hline Firm & Brand & Product & $\%$ & price \\
\hline \multicolumn{5}{|c|}{ Soft drinks } \\
\hline \multirow[t]{41}{*}{ CocaCola } & & & 22.24 & \\
\hline & Coke & & 16.70 & \\
\hline & & Coca Cola Diet 330 & 0.15 & 0.57 \\
\hline & & Coca Cola 330 & 0.21 & 0.57 \\
\hline & & Coca Cola 500 & 0.74 & 1.01 \\
\hline & & Coca Cola Diet 500 & 1.18 & 1.01 \\
\hline & & Coca Cola multi can & 2.50 & 3.43 \\
\hline & & Coca Cola Diet multi can & 4.05 & 3.37 \\
\hline & & Coca Cola bottle & 3.37 & 1.40 \\
\hline & & Coca Cola Diet bottle & 4.27 & 1.37 \\
\hline & & Coca Cola multi bottle & 0.14 & 5.27 \\
\hline & & Coca Cola Diet multi bottle & 0.09 & 5.73 \\
\hline & Dr Pepper & & 1.60 & \\
\hline & & Dr Pepper 330 & 0.02 & 0.55 \\
\hline & & Dr Pepper 500 & 0.23 & 1.00 \\
\hline & & Dr Pepper multi can & 0.27 & 2.46 \\
\hline & & Dr Pepper Diet multi can & 0.11 & 2.41 \\
\hline & & Dr Pepper bottle & 0.72 & 1.36 \\
\hline & & Dr Pepper Diet bottle & 0.26 & 1.31 \\
\hline & Fanta & & 1.78 & \\
\hline & & Fanta 500 & 0.24 & 1.01 \\
\hline & & Fanta multi can & 0.23 & 2.33 \\
\hline & & Fanta Diet multi can & 0.25 & 2.53 \\
\hline & & Fanta bottle & 0.82 & 1.33 \\
\hline & & Fanta Diet bottle & 0.24 & 1.32 \\
\hline & Cherry Coke & & 0.86 & \\
\hline & & Cherry Coke 330 & 0.02 & 0.52 \\
\hline & & Cherry Coke Diet 500 & 0.10 & 1.03 \\
\hline & & Cherry Coke 500 & 0.14 & 1.03 \\
\hline & & Cherry Coke multi can & 0.13 & 2.90 \\
\hline & & Cherry Coke Diet multi can & 0.12 & 2.84 \\
\hline & & Cherry Coke bottle & 0.22 & 1.34 \\
\hline & & Cherry Coke Diet bottle & 0.12 & 1.32 \\
\hline & Oasis & & 0.38 & \\
\hline & & Oasis 500 & 0.38 & 1.01 \\
\hline & Sprite & & 0.93 & \\
\hline & & Sprite 500 & 0.12 & 1.00 \\
\hline & & Sprite multi can & 0.11 & 2.37 \\
\hline & & Sprite Diet multi can & 0.16 & 2.38 \\
\hline & & Sprite bottle & 0.35 & 1.33 \\
\hline & & Sprite Diet bottle & 0.20 & 1.34 \\
\hline \multirow[t]{9}{*}{ Pepsico } & & & 12.71 & \\
\hline & & Pepsi Diet 330 & 0.16 & 0.40 \\
\hline & & Pepsi 330 & 0.07 & 0.40 \\
\hline & & Pepsi 500 & 0.25 & 0.81 \\
\hline & & Pepsi Diet 500 & 0.71 & 0.81 \\
\hline & & Pepsi multi can & 1.04 & 2.14 \\
\hline & & Pepsi Diet multi can & 3.06 & 2.17 \\
\hline & & Pepsi bottle & 2.00 & 1.09 \\
\hline & & Pepsi Diet bottle & 5.43 & 1.10 \\
\hline \multirow[t]{17}{*}{ GSK } & & & 3.62 & \\
\hline & Lucozade Energy & & 3.04 & \\
\hline & & Lucozade Energy 380 & 0.21 & 0.76 \\
\hline & & Lucozade Energy 500 & 0.32 & 1.03 \\
\hline & & Lucozade Energy bottle & 1.41 & 1.14 \\
\hline & & Lucozade Energy multi bottle & 1.11 & 3.05 \\
\hline & Ribena & & 0.58 & \\
\hline & & Ribena 288 & 0.03 & 0.55 \\
\hline & & Ribena 500 & 0.08 & 1.05 \\
\hline & & Ribena multi & 0.47 & 1.98 \\
\hline & & & 1.09 & \\
\hline & & Irn Bru 500 & 0.04 & 0.94 \\
\hline & & Irn Bru Diet 500 & 0.04 & 0.94 \\
\hline & & Irn Bru multi can & 0.08 & 2.53 \\
\hline & & Irn Bru Diet multi can & 0.10 & 2.44 \\
\hline & & Irn Bru bottle & 0.44 & 1.19 \\
\hline & & Irn Bru Diet bottle & 0.39 & 1.19 \\
\hline
\end{tabular}


Table C.2 cont.

\begin{tabular}{|c|c|c|c|c|}
\hline Firm & Brand & Product & $\%$ & price \\
\hline \multicolumn{5}{|c|}{ Composite soft drinks } \\
\hline & & Other & 2.23 & 1.23 \\
\hline & & Other bg & 2.71 & 1.05 \\
\hline & & Other Diet bg & 1.11 & 1.03 \\
\hline & & Other multi & 1.02 & 2.08 \\
\hline & & Other Diet multi & 0.35 & 1.87 \\
\hline \multicolumn{5}{|c|}{ Alternative drinks } \\
\hline & Fruit juice & & 3.13 & 1.62 \\
\hline & Fruit juice & & 18.38 & 1.40 \\
\hline & Flavoured milk & & 3.32 & 0.79 \\
\hline & Flavoured milk & & 1.30 & 1.05 \\
\hline & Fruit water & & 0.04 & 0.76 \\
\hline & Fruit water & & 0.67 & 0.91 \\
\hline & Water & & 0.71 & 0.48 \\
\hline & Water & & 10.89 & 0.89 \\
\hline
\end{tabular}

Notes: Market shares are based on transactions made by the 3,059 households in the at-home estimation sample between June 2009 and December 2014. Prices are the means across all choice occasions.

Table C.3: Retailer types in at-home sample

\begin{tabular}{llrr}
\hline \multicolumn{2}{l}{} & $\mathrm{N}$ & $\%$ \\
\hline \multicolumn{2}{l}{ Retailer types } & & \\
\cline { 1 - 1 } Big four & Asda & 123,576 & 18.9 \\
& Morrisons & 86,949 & 13.3 \\
& Sainsbury's & 85,486 & 13.1 \\
Discounters & Tesco & 215,619 & 33.0 \\
Other & & 44,207 & 6.8 \\
\hline Total & 97,226 & 14.9 \\
\hline
\end{tabular}

Notes: The table shows the number and share of purchases made by 3,059 households in the at-home estimation sample in each retailer type between June 2009 and December 2014.

\section{C.2 At-home demand estimates}

In Table C.4 we summarize estimates of the household specific preference parameters governing at-home demand. In Figure C.1 we report estimates of the demographic specific preference parameters. 
Table C.4: Demand model estimates - at-home

\begin{tabular}{|c|c|c|c|}
\hline \multicolumn{4}{|c|}{ Moments of distribution of consumer specific preferences } \\
\hline \multicolumn{2}{|l|}{ Variable } & Estimate & $\begin{array}{c}\text { Standard } \\
\text { error }\end{array}$ \\
\hline \multirow[t]{4}{*}{ Price $\left(\alpha_{i}\right)$} & Mean & -2.2780 & 0.0146 \\
\hline & Standard deviation & 1.6388 & 0.0189 \\
\hline & Skewness & -2.2208 & 0.1187 \\
\hline & Kurtosis & 11.0800 & 1.2050 \\
\hline \multirow{4}{*}{ Drinks $\left(\gamma_{i}\right)$} & Mean & -4.4080 & 0.0655 \\
\hline & Standard deviation & 2.1179 & 0.0167 \\
\hline & Skewness & 0.1964 & 0.0362 \\
\hline & Kurtosis & 3.7723 & 0.1246 \\
\hline \multirow[t]{4}{*}{ Sugar $\left(\beta_{i}\right)$} & Mean & -0.2777 & 0.0092 \\
\hline & Standard deviation & 1.5127 & 0.0116 \\
\hline & Skewness & 0.0154 & 0.0404 \\
\hline & Kurtosis & 3.2652 & 0.0987 \\
\hline Price-Drinks & Covariance & -2.2546 & 0.0430 \\
\hline Price-Sugar & Covariance & 0.0166 & 0.0198 \\
\hline Drinks-Sugar & Covariance & 0.1907 & 0.0249 \\
\hline \multicolumn{4}{|l|}{ Demographic specific preferences } \\
\hline \multirow{5}{*}{ At-home inventory $\left(\delta_{d(i)}^{\kappa}\right)$} & No kids, high educ. & 0.4017 & 0.0033 \\
\hline & No kids, low educ. & 0.3899 & 0.0043 \\
\hline & Pensioners & 0.3884 & 0.0051 \\
\hline & Kids, high educ. & 0.6245 & 0.0051 \\
\hline & Kids, high educ. & 0.6482 & 0.0061 \\
\hline \multirow[t]{5}{*}{ Bottle } & No kids, high educ. & 0.9360 & 0.0917 \\
\hline & No kids, low educ. & 0.6614 & 0.1163 \\
\hline & Pensioners & -0.6708 & 0.1908 \\
\hline & Kids, high educ. & 0.2157 & 0.0873 \\
\hline & Kids, high educ. & 1.0181 & 0.1022 \\
\hline \multirow[t]{5}{*}{ Multi-pack } & No kids, high educ. & 1.5449 & 0.0687 \\
\hline & No kids, low educ. & 1.8543 & 0.0868 \\
\hline & Pensioners & 0.7329 & 0.1427 \\
\hline & Kids, high educ. & 0.6404 & 0.0679 \\
\hline & Kids, high educ. & 1.4604 & 0.0767 \\
\hline \multirow{5}{*}{ Advertising $\left(\delta_{d(i)}^{\mathfrak{a}}\right)$} & No kids, high educ. & 0.0033 & 0.0011 \\
\hline & No kids, low educ. & -0.0001 & 0.0015 \\
\hline & Pensioners & 0.0045 & 0.0021 \\
\hline & Kids, high educ. & 0.0062 & 0.0011 \\
\hline & Kids, high educ. & 0.0041 & 0.0013 \\
\hline \multirow[t]{5}{*}{ Temperature*Drinks $\left(\delta_{d(i)}^{h}\right)$} & No kids, high educ. & 0.0101 & 0.0022 \\
\hline & No kids, low educ. & 0.0138 & 0.0029 \\
\hline & Pensioners & 0.0136 & 0.0036 \\
\hline & Kids, high educ. & 0.0098 & 0.0022 \\
\hline & Kids, high educ. & 0.0136 & 0.0027 \\
\hline Demographic specific carton-size effects $\left(\delta_{d(i)}^{z}\right)$ & \multicolumn{3}{|c|}{ Yes } \\
\hline Time-demographic-brand effects $\left(\xi_{d(i) b(j) t}\right)$ & \multicolumn{3}{|c|}{ Yes } \\
\hline Retailer-demographic-brand effects $\left(\zeta_{d(i) b(j) r}\right)$ & \multicolumn{3}{|c|}{ Yes } \\
\hline
\end{tabular}

Notes: We estimate demand on a sample of 3,059 households who we observe on 653,063 at-home choice occasions. Estimates of the consumer specific preferences are summarized in the table. Moments of distribution are computed using estimates of consumer specific preference parameters. These moments are based on consumers with finite parameters and omit the top and bottom percentile of each distribution. Standard errors for moments are computed using the delta method.

Figure C.1 shows variation in preferences for sugar and price in the at-home segment and how they vary by deciles of the total dietary sugar and total equivalized 
grocery expenditure distributions. As expected, households that have higher added sugar in their total annual grocery basket also have stronger preferences for sugar when choosing what drinks to purchase, and households in lower deciles of the equivalized total grocery expenditure (income) are more price sensitive.

Figure C.1: Preferences variation - at-home

(a) sugar preferences by total dietary sugar (b) price preferences by total dietary sugar
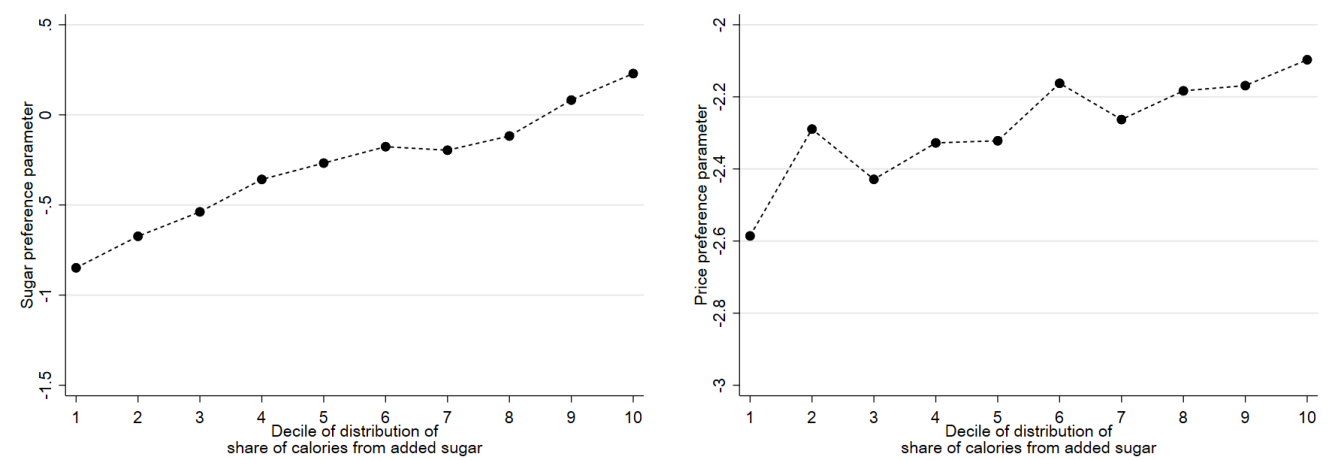

(c) sugar by total equivalized expenditure

(d) price by total equivalized expenditure
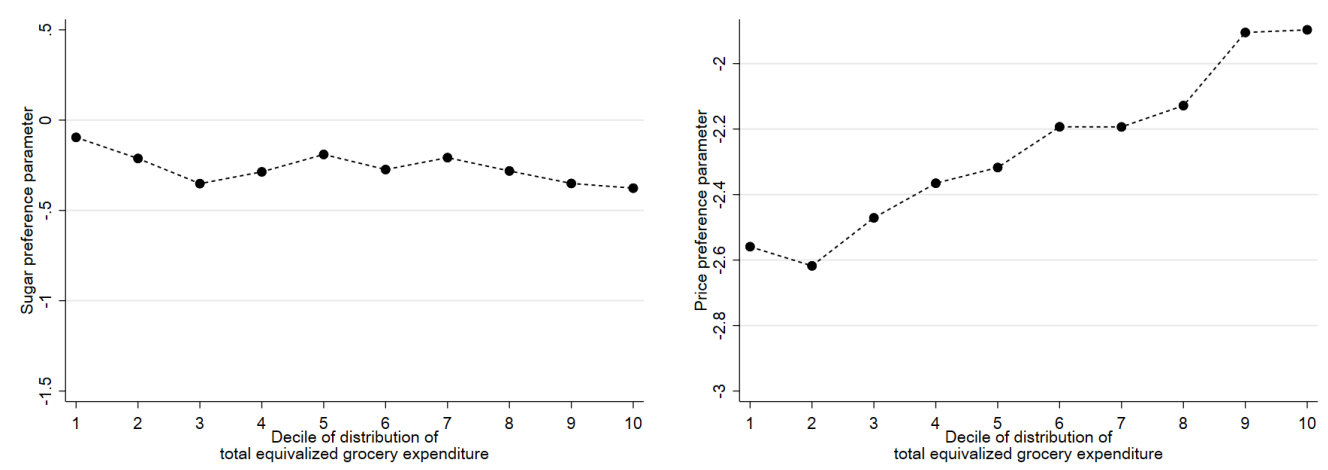

Notes: Figure shows how, the mean of finite sugar preferences and the mean of price preferences in the at-home segment vary by deciles of the distribution of total annual dietary sugar and by deciles of the distribution of total annual equivalized grocery expenditure. $95 \%$ confidence intervals are shown by bars.

\section{Compensating variation}

We use our demand estimates to compute compensating variation - the monetary amount an individual would require to be paid to be indifferent to the imposition of the tax based on their estimated preferences. Letting $p_{j r t}$ and $p_{j r t}^{\prime}$ denote the retailer type $r$ time $t$ price of product $j$ prior to and following the introduction of the tax, the expected compensating variation for individual $i$ on choice occasion $\tau$ 
is given by (Small and Rosen (1981)):

$$
\begin{aligned}
c v_{i \tau}=\frac{1}{\alpha_{i}} & {\left[\ln \left(\sum_{k \in \Omega_{i} \cap \Omega_{r(\tau)}} \exp \left(v_{i k r(\tau) t(\tau)}+\eta_{i k r(\tau) t(\tau)}-\alpha_{i}\left(p_{k r(\tau) t(\tau)}-p_{k r(\tau) t(\tau)}^{\prime}\right)\right)+1_{\overline{0} \in \Omega_{i}} \exp \left(\beta_{i}\right)\right)-\right.} \\
& \left.\ln \left(\sum_{k \in \Omega_{i} \cap \Omega_{r(\tau)}} \exp \left(v_{i k r(\tau) t(\tau)}+\eta_{i k r(\tau) t(\tau)}\right)+1_{\overline{0} \in \Omega_{i}} \exp \left(\beta_{i}\right)\right)\right]
\end{aligned}
$$

where $v_{i j r(\tau) t(\tau)}$ and $\eta_{i j r(\tau) t(\tau)}$ are defined in Section 3.1. ${ }^{46}$ Summing $c v_{i \tau}$ over an individual's choice occasions in the year gives their annual compensating variation.

\section{E Equilibrium tax pass-through}

In Section 5.3 we show that our results on the targeting of a soda tax are similar under the assumption of $100 \%$ pass-through and under estimates of equilibrium tax pass-through. Here we provide further details of our model of equilibrium tax pass-through.

We model tax pass-through by assuming that drinks manufacturers compete by simultaneously setting prices in a Nash-Bertrand game. We consider a mature market with a stable set of products, and we therefore abstract from entry and exit of firms and products from the market. We use our demand estimates for the onthe-go market, demand estimates for the at-home market (described in Appendix C) and an equilibrium pricing condition to infer firms' marginal costs (see Berry (1994) or Nevo (2001)) in order to then simulate the effect of a tax on consumer prices.

Let $f=\{1, \ldots, F\}$ index manufacturers and $F_{f}$ denote the set of products owned by firm $f$. We assume that prices are set by manufacturers and abstract from modeling manufacturer-retailer relationships. Such an outcome can be achieved by vertical contracting (Villas-boas (2007), Bonnet and Dubois (2010)). ${ }^{47}$ Bonnet and Dubois (2010) show that in the French grocery market price equilibria correspond to the case where manufacturers and retailers do use non-linear contracts in the form of two part tariffs. Testing for the form of vertical contracting in UK manufacturerretailer relations is an interesting question that we leave for future research.

We index markets by $m$. Markets vary over time and across retailer type. In particular a market is defined as a year-retailer pair. We denote the size of the

\footnotetext{
${ }^{46}$ Note, that $v_{i j r(\tau) t(\tau)}$ is defined such that it includes the effect of price prior to the introduction of the tax.

${ }^{47}$ Non-linear contracts with side transfers between manufacturers and retailers allow them to reallocate profits and avoid the double marginalization problem.
} 
on-the-go segment in market $m$ by $M_{m}^{\text {out }}$ and the size of the at-home segment by $M_{m}^{i n}$ and we denote the set of individual-choice occasions in the on-the-go and athome segments of market $m$ as $\mathcal{M}_{m}^{\text {out }}$ and $\mathcal{M}_{m}^{\text {in }}$. Aggregating across consumer level purchase probabilities we obtain the market level demand function for product $j$ :

$$
q_{j m}\left(\mathbf{p}_{m}\right)=\underbrace{M_{m}^{\text {out }} \sum_{(i, \tau) \in \mathcal{M}_{m}^{\text {out }}} P_{i \tau}(j)}_{\equiv q_{j m}^{\text {out }}\left(\mathbf{p}_{m}\right)}+\underbrace{M_{m}^{\text {in }} \sum_{(i, \tau) \in \mathcal{M}_{m}^{\text {in }}} P_{i \tau}(j)}_{\equiv q_{j m}^{\text {in }}\left(\mathbf{p}_{m}\right)}
$$

for each product $j$ and where $P_{i \tau}(j)$ follows equation (3.2).

If product $j$ is available only in the at-home segment (e.g. if it is a large multi portion product), then $P_{i \tau}(j)=0$ for all $(i, \tau) \in \mathcal{M}_{m}^{\text {out }}$, and if it is only available in the on-the-go segment then $P_{i \tau}(j)=0$ for all $(i, \tau) \in \mathcal{M}_{m}^{i n}$. However, for products available in both on-the-go and at-home segments the market demand curve depends on purchase probabilities (and hence preferences) in both segment.

Firm $f$ 's (variable) profits in market $m$ are given by:

$$
\Pi_{f m}=\sum_{j \in F_{f}}\left(p_{j m}-c_{j m}\right) q_{j m}\left(\mathbf{p}_{m}\right)
$$

and the firm's price first order conditions are:

$$
q_{j m}\left(\mathbf{p}_{m}\right)+\sum_{k \in F_{f}}\left(p_{k m}-c_{k m}\right) \frac{\partial q_{k m}\left(\mathbf{p}_{m}\right)}{\partial p_{j m}}=0 \quad \forall j \in F_{f}
$$

Under the assumption that observed market prices are an equilibrium outcome of the Nash-Bertrand game played by firms, and given our estimates of the demand function, we can invert the first order conditions to infer marginal costs $c_{j m}$. The introduction of a tax creates a wedge between post-tax prices, $\mathbf{p}$, and pre-tax prices, which we denote $\tilde{\mathbf{p}}$. The volumetric tax, $\pi$, on sugary soft drinks (denoted by the set $\left.\Omega_{w s}\right)$ implies pre-tax and post-tax prices are related by:

$$
p_{j m}= \begin{cases}\tilde{p}_{j m}+\pi l_{j} & \forall j \in \Omega_{w s} \\ \tilde{p}_{j m} & \forall j \notin \Omega_{w s}\end{cases}
$$

where $l_{j}$ is the volume of product $j$.

In the counterfactual equilibrium, prices satisfy the conditions:

$$
q_{j m}\left(\mathbf{p}_{m}\right)+\sum_{k \in F_{f}}\left(\tilde{p}_{k m}-c_{k m}\right) \frac{\partial q_{k m}\left(\mathbf{p}_{m}\right)}{\partial p_{j m}}=0 \quad \forall j \in F_{f}
$$


for all firms $f$. We solve for the new equilibrium prices as the vector that satisfies the set of first order conditions (equation (E.3)) when $\pi=0.25 .^{48}$ Tax pass-through describes how much of the tax is shifted through to post-tax prices, for products $j \in \Omega_{w s}$, we measure this as the difference in the post-tax and pre-tax equilibrium consumer price over the amount of tax levied, $\pi l_{j} .{ }^{49}$

\footnotetext{
${ }^{48}$ We solve for a new equilibrium price for each of the products belonging to the main soft drinks brands; we assume there is no change in the producer price (and therefore $100 \%$ pass-through) of the composite other soft drinks brand (which aggregates together many very small soft drinks brands). We also assume no pricing response for the set of outside products.

${ }^{49} \mathrm{We}$ solve for separate price equilibrium in each of the 11 retailers and for a representative month in each year, giving us 66 price equilibria.
} 